\title{
Patterns of migration/mobility and HIV risk among female sex workers: Tamil Nadu 2007-08
}

Niranjan Saggurti

Population Council

Ravi K. Verma

Suvakanta N. Swain

Population Council

Hanimi Reddy Modugu

Ajay Kumar Singh

See next page for additional authors

Follow this and additional works at: https://knowledgecommons.popcouncil.org/departments_sbsr-hiv

Part of the Demography, Population, and Ecology Commons, Family, Life Course, and Society Commons, International Public Health Commons, and the Migration Studies Commons How does access to this work benefit you? Let us know!

\section{Recommended Citation}

Saggurti, Niranjan, Ravi K. Verma, Suvakanta N. Reddy Swain, Hanimi Reddy Modugu, Ajay Kumar Singh, Saumya RamaRao, and Anrudh K. Jain. 2008. "Patterns of migration/mobility and HIV risk among female sex workers: Tamil Nadu 2007-08." New Delhi: Population Council. 


\section{Authors}

Niranjan Saggurti, Ravi K. Verma, Suvakanta N. Swain, Hanimi Reddy Modugu, Ajay Kumar Singh, Saumya RamaRao, and Anrudh K. Jain 
The migration/mobility of female sex workers in search of clients and income has been recognized as a challenge in HIV-prevention interventions in India. Little is known, however, about the patterns of migration/mobility of female sex workers in India, the facilitators and drivers of their mobility, and the implications of such mobility for the HIV pandemic. This lack of understanding has been an impediment in planning effective HIV-prevention programmes for these vulnerable populations.

A research study designed to increase understanding of the patterns and factors related to migration and mobility of at-risk populations of sex workers and male migrant workers and to examine the links of migration and mobility with HIV risk was conducted in four states of India experiencing high HIV prevalence, namely Andhra Pradesh, Karnataka, Tamil Nadu, and Maharashtra. This report presents the findings from the female sex workers study on volume and patterns of mobility and their linkages with HIV risk. The fieldwork among female sex workers in Tamil Nadu was implemented by TNS India Private Limited and the Population Council, New Delhi.

For additional information about the study, please contact:

Dr. Saggurti Niranjan HIV and AIDS Program

Population Council India Habitat Center Lodi Road

New Delhi 110003.

Telephone: 011- 24651314

Fax: 011 - 24645060

e-mail: nsaggurti@popcouncil.org website: www.popcouncil.org
For additional copies of this report, please contact:

South and East Asia Regional Office Zone 5A, India Habitat Centre

Lodi Road

New Delhi 110003

Tel: +91 11 24642901/02

Fax: +91 1124642903

Email: vthomas@popcouncil.org website: www.popcouncil.org 


\section{Population Council}

The Population Council is an international, nonprofit organization established in 1952, that seeks to improve the well-being and reproductive health of current and future generations around the world and to help achieve a humane, equitable, and sustainable balance between people and resources. The Council's biomedical, public health, and social scientists identify and evaluate responses to the most important population, health, and development issues. Work is focused on three programme areas: HIV and AIDS; Poverty, Gender, and Youth; and Reproductive Health.

\section{(C) 2008 The Population Council, Inc.}

This document may be reproduced in whole or part without permission of the Population Council, provided full source citation is given and reproduction is not for commercial purposes. 


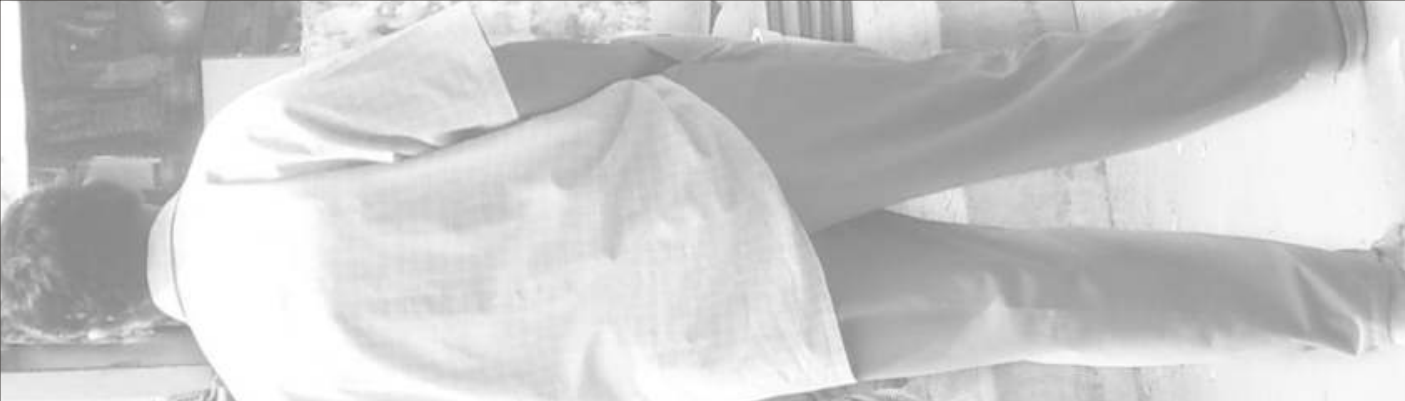

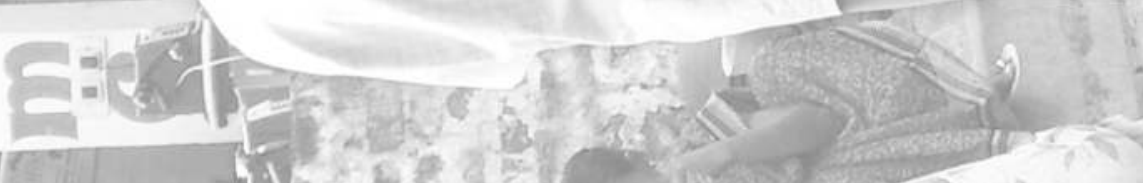

him: है

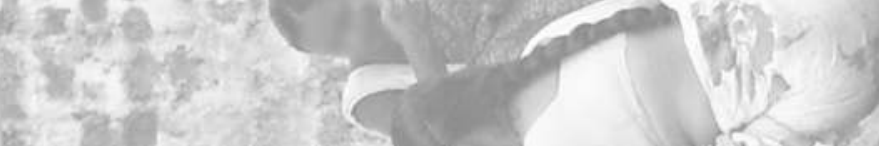

(2)

3

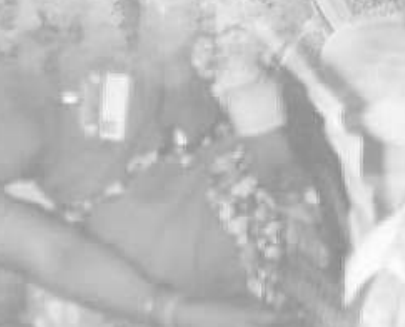

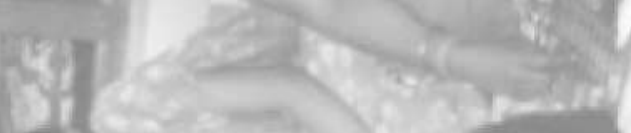

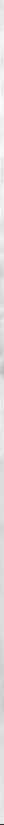




\section{CONTRIBUTORS}

Niranjan Saggurti ${ }^{1}$

Ravi K. Verma ${ }^{2}$

Suvakanta N.Swain ${ }^{1}$

Hanimi Reddy Modugu ${ }^{3}$

Ajay K. Singh ${ }^{2}$

Saumya RamaRao ${ }^{4}$

Anrudh Jain ${ }^{4}$

${ }^{1}$ Population Council, New Delhi, India

${ }^{2}$ International Center for Research on Women (ICRW), New Delhi, India

${ }^{3}$ TNS India Private Limited, New Delhi, India

${ }^{4}$ Population Council, New York, USA 


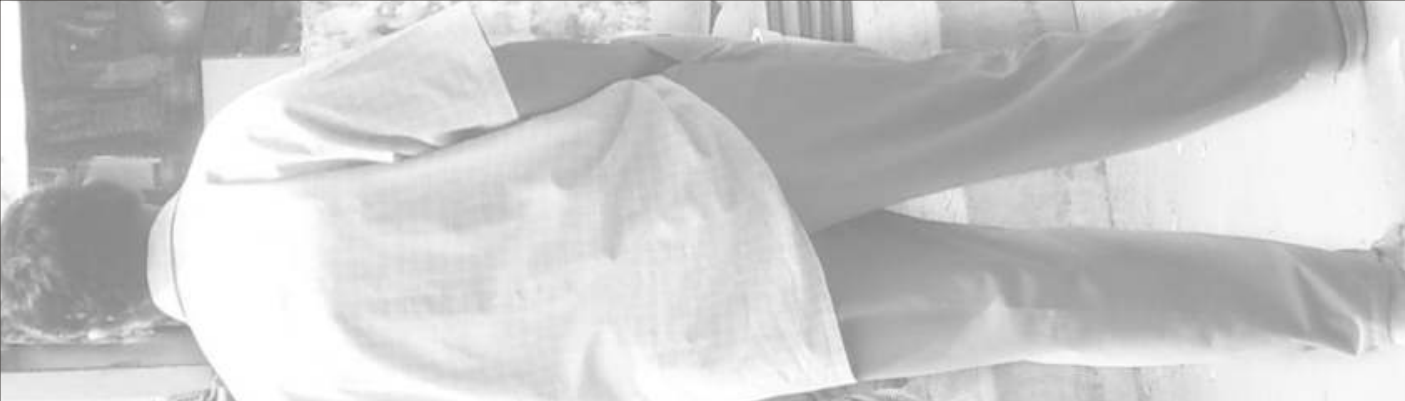

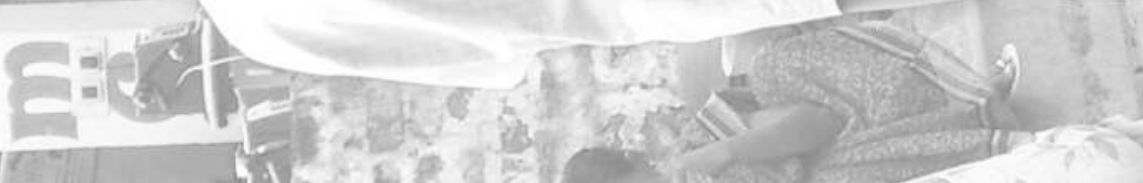

him: है

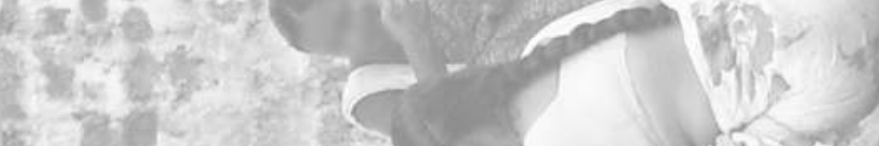

(2)

3

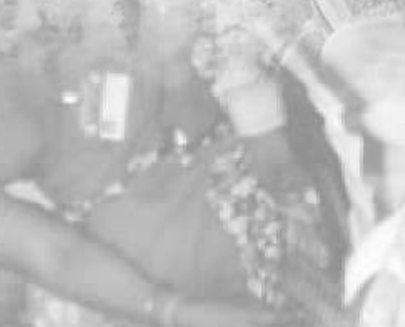

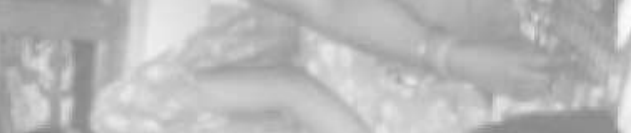

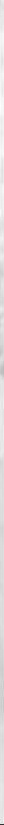




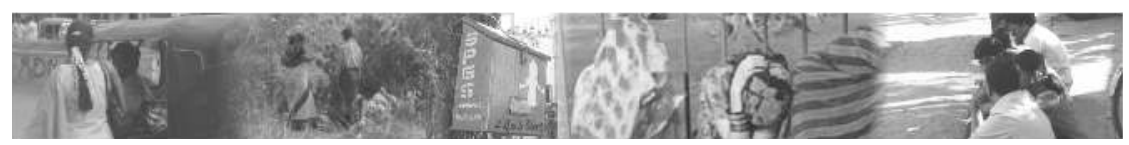

\section{FOREWORD}

In past years, considerable research has been undertaken on the role of female sex workers (FSWs) in the transmission of HIV infection. FSWs have been seen as a major 'source' of infection. Consequently, they have been extensively targeted to prevent its spread, There is, however, a gap in our understanding of the dynamics of sex work, sex workers' patterns of mobility and the relationship of such mobility with risk to HIV infection and gender-based violence.

During November, 2006 - November, 2007, the Population Council undertook a study to examine the patterns of mobility of FSWs and to study its links with HIV risk. The goal was to provide research-based evidence to inform the formulation of policies and to improve the implementation of programs. The study was conducted in 22 districts in four high HIV prevalence states namely Maharashtra, Karnataka, Tamil Nadu and Andhra Pradesh. It was undertaken in collaboration with the Karnataka Health Promotion Trust, the TNS India Private Limited and the GFK-MODE Private Limited.

Ethnographic and survey research methods were employed to collect data on FSWs' patterns and routes of mobility, and the condom use behaviors of over 5500 mobile female sex workers. Support provided by Avahan, Avahan's partner NGOs, the National AIDS Control Organisation, State AIDS Control Societies, other international and national organizations, and most importantly by the study participants themselves, was invaluable in undertaking this study.

The study shows that on average, mobile FSWs moved to four different locations for sex work in the two years prior to the survey. Sixty percent of the FSWs sampled for the survey reported that they had moved to atleast two different locations and that they had moved to atleast one location outside the district in the one in which they lived. There was greater mobility of sex workers in Andhra Pradesh and Karnataka than in Maharashtra and Tamil Nadu. In Andhra Pradesh and Maharashtra, greater mobility showed associations with a consistent decrease in condom use; increased exposure to sexually transmitted infections; and increased perceived risk of HIV. It is likely that since FSWs move to maximize trade opportunities, they use less discretion in using condoms when they are mobile. In Karnataka and Tamil Nadu, however, mobility was not associated with condom use. 


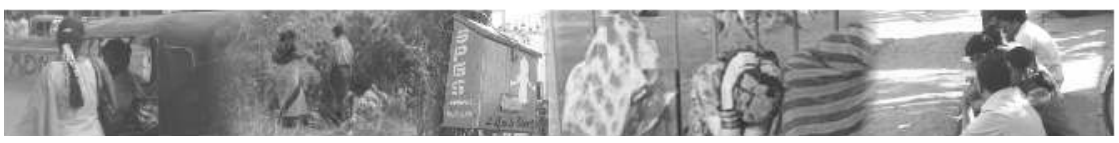

In places where FSWs had the opportunity to get more clients and where transaction time was short for example during Jataras (Pilgrimages), consistent condom use declined sharply in all for states where the study was conducted. About three-fourths of the mobile FSWs who visited places of jatara for sex work did not use condoms consistently. Thus, their vulnerability and risk to infection was enhanced in these situations. These findings indicate the need to design interventions that can be effectively implemented in places of Jatara and other such places.

Over three-fourths of the mobile FSWs, in the study were 19 to 34 years of age. Most were illiterate; many were in debt; and the majority belonged to lower castes such as Dommara, Madigra, Harijana, Devadasi, Kalavanthulu and Lambani. Most of these women were either vidowed, divorced or separated. More then two-fourths worked as domestic servants, vendors, agricultural laborers or construction laborers. The study showed that a large majority ofthe mobile FSWs suffered gender-based violence. Mobile FSWs who faced violence, were in debt, and/or were widowed, separated or divorced were less likely to use condoms. These results underscore the importance of designing program interventions for these specially disadvantaged, vulnerable subpopulations of FSWs.

The study mapped specific districts where mobile FSWs were conconcentrated. Clearly, those districts need special attention. Social support systems in these districts should be strengthened. Strategies should be designed to bring mobile FSWs within the ambit of the program. In addition, district-specific interventions should be designed and implemented to address the needs of these highly vulnerable sub-populations of FSWs.

FSWs have been traditionally categorized by place of work -- in brothels, roadsides, highways, dhabas, homes, railway stations and bus stands, and interventions are targeted to these pre-defined categories of sex workers. Our study, however, shows that mobile FSWs solicit clients in multiple places. And although hotels and lodges are most commonly used, they have sex with their clients, in a number of different places. These findings suggest the need to target interventions at places where significant numbers of FSWs can be reached. 


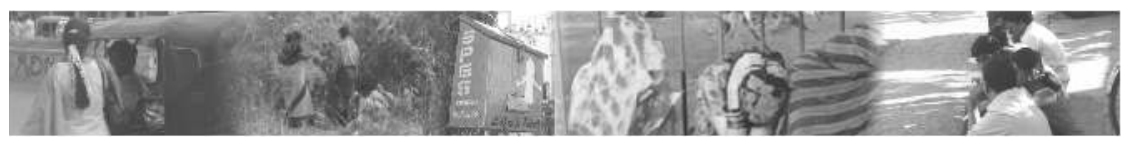

This pioneering research study provides important evidence that should be used at both the national and state levels for the design and implementation of program strategies for the prevention of HIV infection among FSWs and their clients. This information should be used by the national and state-level AIDS control organizations to inform the design of policies and the implementation of government programs. These research findings are also relevant for the large numbers of NGOs and others engaged in programs targeting FSWs and their clients. Thus, there are a number of stakeholders who could utilize the findings of this wide-scale research study for the prevention and control of HIV and AIDS.

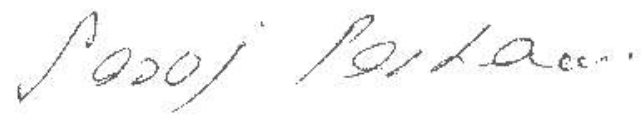

Dr. Saroj Pachauri MD, PhD.

Regional Director

South and East Asia

Population Council 




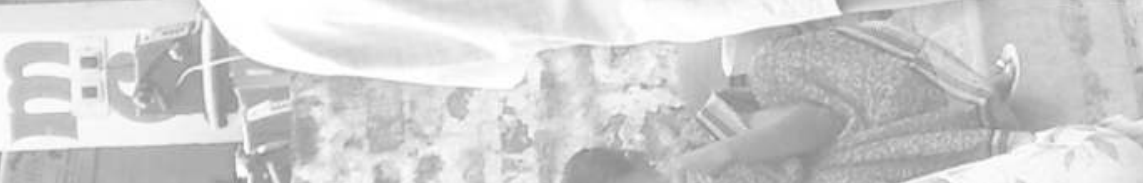

him: है

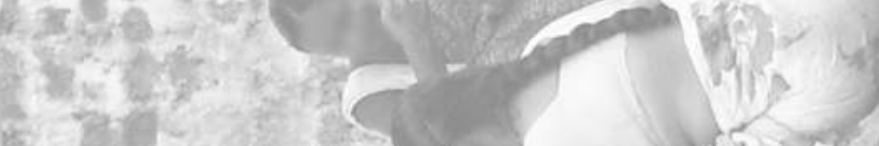

(2)

3



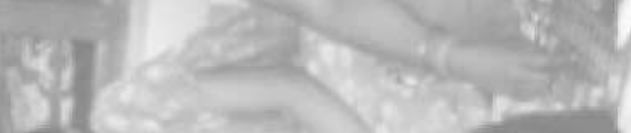

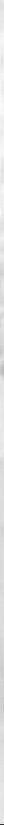




\section{Table of Contents}

Acknowledgements

Executive Summary 1

I. BACKGROUND AND OBJECTIVE 4

II. $\quad$ STUDY DESIGN AND METHODS 7

2.1 Identification of study areas

2.2 Characterization of study areas

2.3 The quantitative survey

2.4 Sample size and sampling design

2.5 Sex workers' degree of mobility

III. VOLUME AND PATTERNS OF MOBILITY

$3.1 \quad$ Volume of mobility

3.2 Patterns of mobility

IV. PROFILE OF MOBILE FEMALE SEX WORKERS

4.1 Socioeconomic and demographic profile

4.2 Sources of income

4.3 Debt

4.4 Reasons for entering into sex work

4.5 Lifestyle characteristics

4.6 Physical violence

4.7 Exposure to mass media and groups or associations

V. HIV RISK AMONG FEMALE SEX WORKERS

5.1 Condom use

5.2 Self-reported STI symptoms

5.3 Perception of HIV risk

5.4 Ability to use condoms and actual condom use

5.5 Socioeconomic insecurity and HIV risk

5.6 Degree of mobility and HIV risk

VI. IMPLICATIONS FOR THE HIV-PPREVENTION PROGRAMME ACCORDING TO LOCATIONS WHERE CLIENTS ARE SOLICTED AND SEX PERFORMED

6.1 Locations for sex work

6.2 HIV-prevention programme coverage of FSWs

VII. CONCLUSION AND RECOMMENDATIONS 46 


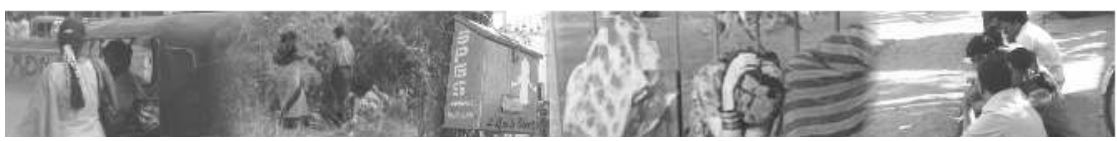

\section{List of Figures/Maps}

Figure 1: $\quad$ Percentage of mobile female sex workers surveyed who moved at least once across district for sex work, by district, Tamil Nadu State, India

Figure 2: $\quad$ Percentage of female sex workers surveyed, by their level of mobility, according to district, Tamil Nadu State, India Figure 3: Percentage of sex workers surveyed, by age and place of contact, Tamil Nadu State, India

Figure 4: Percentage of mobile female sex workers surveyed, by their marital status, according to district, Tamil Nadu State, India

Figure 5: Percentage distribution of mobile female sex workers surveyed, by their source of income, according to district, Tamil Nadu State, India

Figure 6: Percentage distribution of mobile female sex workers surveyed who have accrued debt, by district and amount of debt, Tamil Nadu State, India

Figure 7: Percentage of mobile female sex workers surveyed, by their reasons for entering into sex work, according to district, Tamil Nadu State, India

Figure 8: $\quad$ Percentage of mobile female sex workers surveyed who reported that they had drunk alcohol in the month prior to the survey, by district, Tamil Nadu State, India

Figure 9: $\quad$ Percentage of mobile female sex workers surveyed who reported having separate bank or post office accounts, by district, Tamil Nadu State, India

Figure 10: Percentage of mobile female sex workers surveyed who reported that they had experienced physical violence at least once in the past year, by district, Tamil Nadu State, India

Figure 11: Percentage of mobile female sex workers surveyed who reported that they had watched television in the month prior to the survey, by district, Tamil Nadu State, India

Figure12: $\quad$ Percentage of mobile female sex workers surveyed who reported using condoms consistently, by type of partner, according to district, Tamil Nadu State, India 


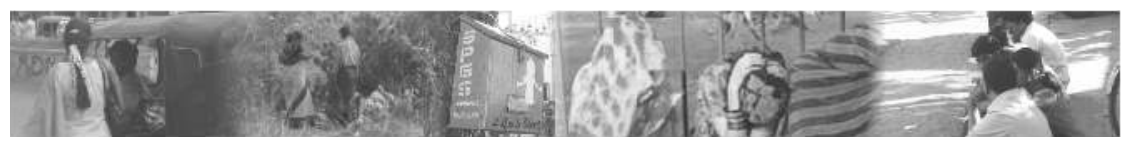

Figure 13: Percentage of mobile female sex workers surveyed who reported having had at least one STI symptom, by district, Tamil Nadu State, India

Figure 14: Percentage of mobile female sex workers surveyed who reported that they had experienced physical violence, used condoms consistently, had had STI symptoms, and perceived themselves to be at moderate risk of HIV infection, Tamil Nadu State, India

Figure 15: Percentage of mobile female sex workers surveyed who reported using condoms consistently with different types of partners, by marital status, Tamil Nadu State, India

Figure 16: Percentage of mobile female sex workers surveyed who reported using condoms consistently with different types of clients, by their degree of mobility, Tamil Nadu State, India

Figure 17: Percentage distribution of mobile female sex workers, by places where they solicit clients, Tamil Nadu State, India

Figure 18: Percentage distribution of mobile female sex workers surveyed, by places where they have sex with clients, Tamil Nadu State, India

Figure 19: Percentage of distribution of mobile female sex workers surveyed, by places where they solicit clients or have sex, Tamil Nadu State, India

Map 1. Avahan program areas in India

Map 2. Study districts in Tamil Nadu State, India

Map 3. Mobility routes of female sex workers currently located in Chennai urban district, Tamil Nadu State, India

Map 4. Mobility routes of female sex workers currently located in Kanyakumari urban district, Tamil Nadu State, India

Map 5. Mobility routes of female sex workers currently located in Madurai urban district, Tamil Nadu State, India

Map 6. Mobility routes of female sex workers currently located in Namakkal urban district, Tamil Nadu State, India

Map 7. Mobility routes of female sex workers currently located in Tiruchirapalli urban district, Tamil Nadu State, India 


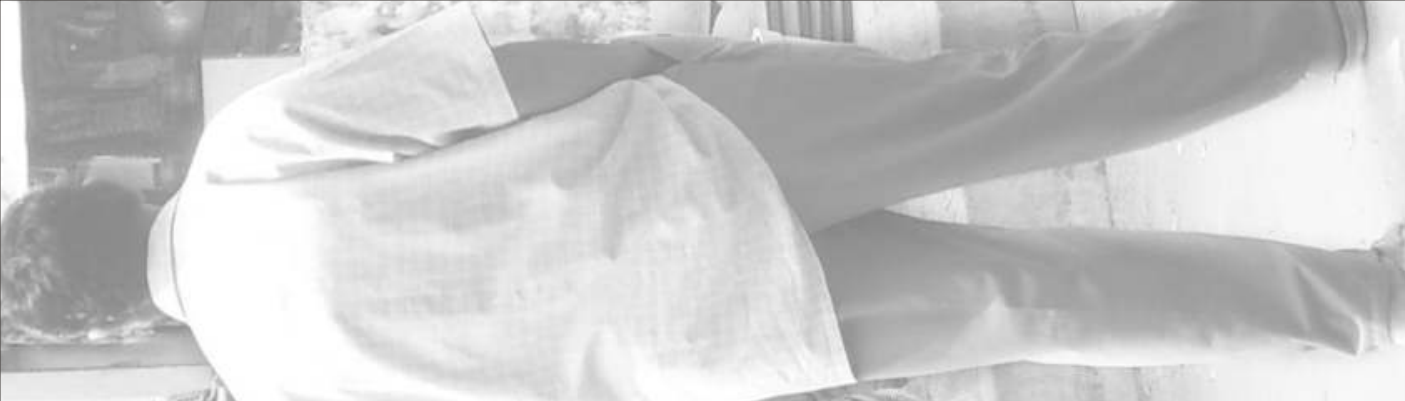

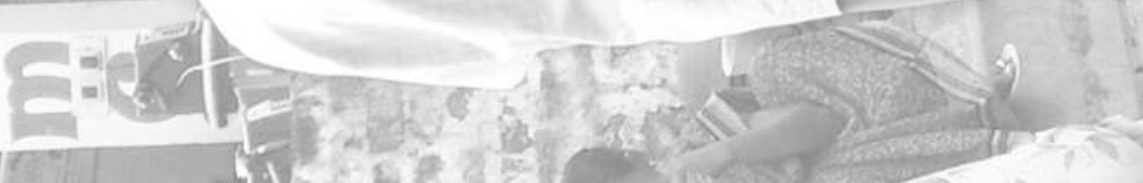

him: है

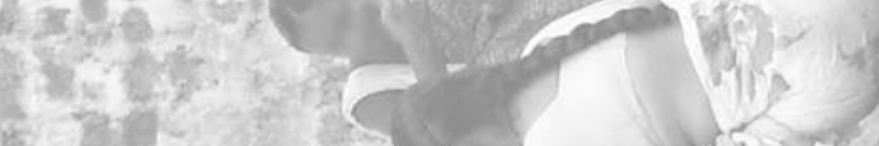

(2)

3

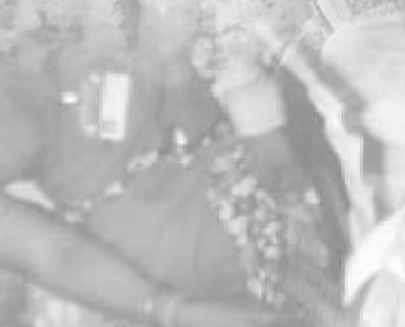

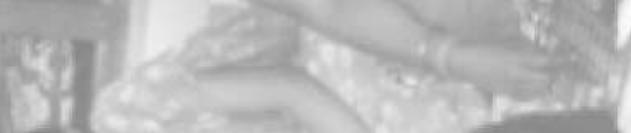

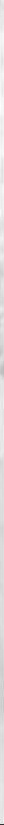




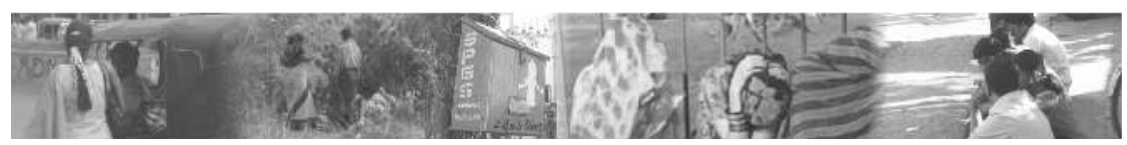

\section{ACKNOWLEDGEVIENIS}

The study on Migration/Mobility and HIV

Risk among Female Sex Workers was successfully completed during 2007-08. The efforts of a number of individuals who were involved in the study are acknowledged.

First of all, we are grateful to the Bill \& Melinda Gates Foundation for its support for the study through Avahan, its India AIDS Initiative. We are particularly thankful to Mr. Ashok Alexander, Ms. Padma Chandrasekaran, Dr. Gina Dallabetta, Dr. Aparajita Bhalla, Mr. Hari Menon, and Ms. Jayanti Rajagopalan, from Avahan, for their active support and involvement at all stages of the project. However, the views expressed herein are those of the authors and do not necessarily reflect the official policy or position of the Bill \& Melinda Gates Foundation and Avahan.

We would like to acknowledge the support of the members of the Technical Advisory Committee (TAC) for their overall guidance in the smooth conduct of the study. The contributions of the members: Dr. Prem Saxena, Dr. P. M. Kulkarni, Dr. Tarun K. Roy, Dr. R. R. Gangakhedkar, Dr. Rohini Pande, Dr. Gurumurthy Rangaiyan, Dr. Arvind Pandey, Dr. Rajatashuvra Adhikary, Dr. Shiva S. Halli, Dr. Tobi Saidel, and Dr. Shalini Bharat were helpful both through their direct involvement in TAC meetings and through interactions with individual members during the various stages of the project. Special thanks are due to Dr. Saroj Pachauri for chairing the Technical Advisory Committee and for guiding us at each stage of the project.

We acknowledge the contribution and support of the research team at the International Center for Research on Women (ICRW) for their review of and feedback on the study report.

We thank all of the experts who participated in a series of workshops that were organized to prepare qualitative research tools; undertake training of the research teams; plan qualitative data analysis; and prepare questionnaires, the sample design, and the tabulation plan for the report.

We are grateful to our consultants Dr. Pertti J. Pelto, Senior Anthropologist, Ms. Lakshmi Ramachandar, and Mr. Zaheer Ahmad Khan, for their assistance. Special thanks to Mr. V. L. Thomas, Executive Assistant at the Population 


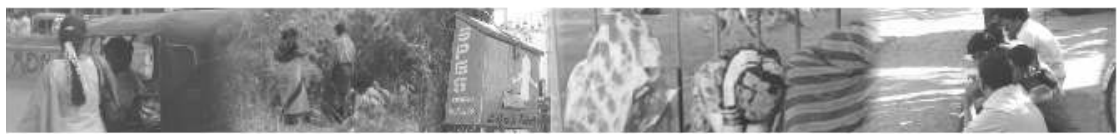

Council, for his administrative support throughout the study and his expert assistance in creating the tables and graphs and for formatting the report.

We convey our special thanks to Dr. Ajay K. Khera, Mr. Aslam Naved, and Ms. Lakshmi Murthy from the National AIDS Control Organization (NACO), and the authorities from the Tamil Nadu State AIDS Control Society (TNSACS), AIDS Prevention and Control (APAC), and the Tamil Nadu AIDS Initiative (TAI), for their help in facilitating data collection and interpretation.

We acknowledge the contribution of Dr. U.V. Somayajulu for his interest and hard work in implementation of the study. We also thank all the research investigators individually for their efforts in gathering data.

Most important, we are especially grateful to the participants in this study who have, without hesitation, given their time and narrated their experiences and views regarding their mobility and vulnerability to HIV risk.

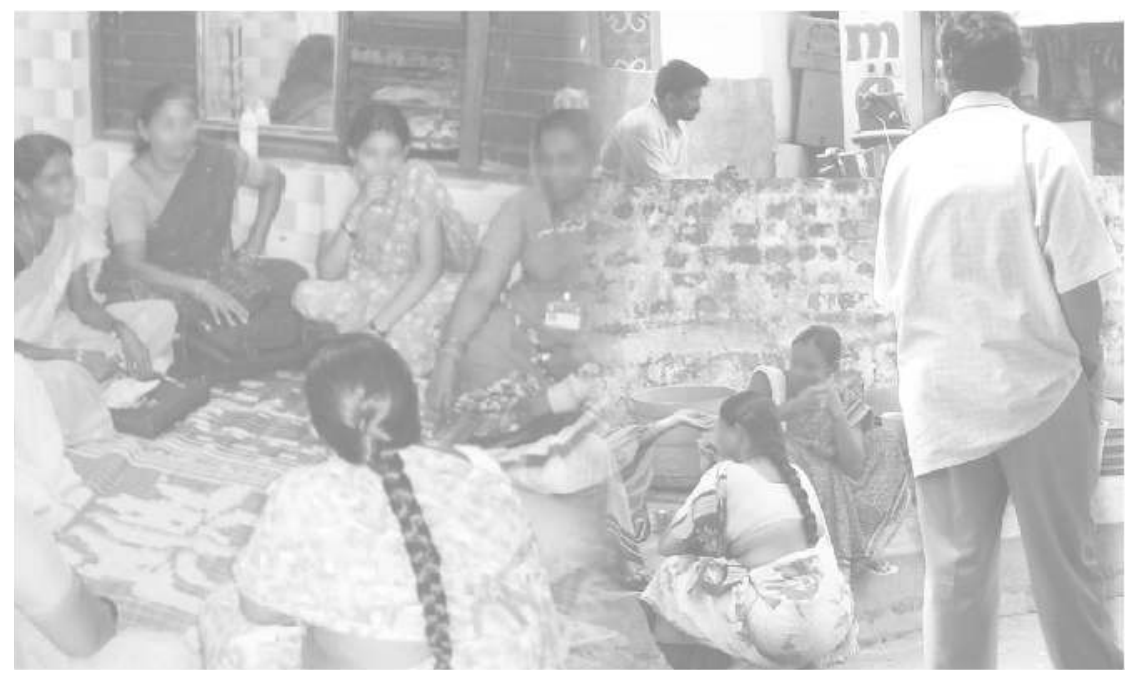




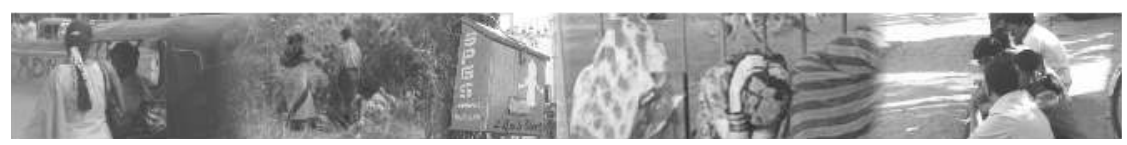

EXECUTIVE SUMMARY
Tamil Nadu, the state in which India's first case of HIV was detected in 1986, ranked third in 2006 for prevalence of HIV among the general population of India, according to the National Family Health Survey (NFHS3). The integrated Behavioural and Biological Assessment (IBBA) conducted in the year

2007 recorded HIV prevalence between 2 percent and 13 percent among female sex workers in selected districts of Tamil Nadu. Growing anecdotal information indicates that female sex workers move frequently in search of clients. At present, the programs in Tamil Nadu know little about the patterns of movement of various at-risk populations and the nature and extent of interaction among them. An understanding of why some forms of mobility are related to increased HIV transmission is necessary in order to design intervention programmes to reduce risky behaviour of mobile populations, particularly of those who are at a highest risk of infection, including sex workers.

The present study was undertaken to answer questions about the mobility and migration of female sex workers (FSWs) in Tamil Nadu as they relate to the HIV pandemic.

Specifically, the study was undertaken with the following objectives:

1. to assess the volume and patterns of mobility of female sex workers;

2. to describe the characteristics of mobile female sex workers; and

3. to examine the determinants of HIV risk among female sex workers, with particular emphasis on mobility-related characteristics.

The cross-sectional study involved collection of qualitative and quantitative data to identify and characterize destination points and interviews with sex workers to examine mobility patterns and associated vulnerabilities to HIV. The five major destination districts selected for the study were Chennai,

Kanyakumari, Madurai, Namakkal, and Tiruchirapalli. These districts were characterized using a variety of ethnographic methods, including key-informant interviews, in-depth interviews, and mobility maps drawn by the female sex workers. District-level descriptions helped to identify small and large sexworker sites, including brothels and places of solicitation such as roads, 


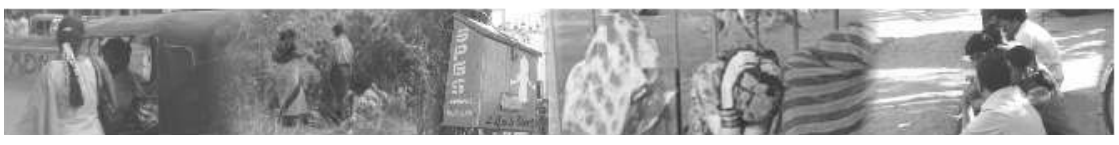

highways, bus stands, railway stations, and market areas. A total of 2,282 sex workers were screened for the survey, of which 1,310 met the eligibility criteria: they were aged 18 or older and had moved at least once in the past year. The sample was selected using these criteria and also that the sex workers had visited two or more places for the purpose of sex work.

The results indicate that 81 percent of the sex workers who were screened had moved at least once for sex work in the past two years, 79 percent had moved at least twice, and 59 percent had moved across the district. On average, FSWs had moved five times in the past two years and four of these moves were across the district. Around four-fifths of the FSWs from Madurai and Kanyakumari districts had moved at least once for sex work in the past two years; these two are the districts showing the highest mobility of FSWs.

About 80 percent of the mobile FSWs in Tamil Nadu are aged 25-39. More than 30 percent are divorced, widowed, or separated. Across all of the districts studied, however, the majority of sex workers are married. This proportion is highest in Madurai (77 percent) and lowest in Namakkal (60 percent). More than three-fourths of these women earn their living with a combination of sex work and other kinds of work such as daily-wage work, petty businesses, selling flowers or vegetables, and contract work. About one-third of them earn their living with a combination of sex work or sex-related work such as commissions from referring clients and renting rooms for sex. In Madurai and Namakkal, a different pattern is observed; more than four-fifths of the sex workers in their districts have earnings from sex work and from work that is unrelated to sex.

The FSWs were asked about their reasons for entering sex work. Economic conditions at home were the main reason that 70 percent gave for entering into sex work. About one-fifth reported that they began sex work because they were in debt. This proportion is consistent across all of the districts studied. In Chennai, however, a different pattern emerges: about one-third of the sex workers interviewed said that they entered into sex work because they were in debt at their place of origin.

Around half of the sex workers said they had consumed alcohol in the month prior to the survey, the largest proportion (57 percent) being in Chennai. Approximately 16 percent of the sex workers interviewed reported that they had been physically abused. The principal perpetrators of abuse across the district were policemen, and the next-largest proportion were clients. 


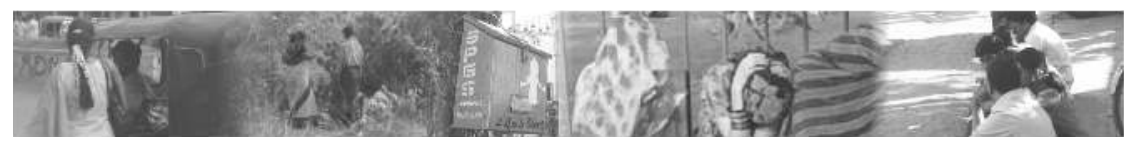

More than four-fifths of the mobile female sex workers reported using condoms consistently with various clients; this proportion is relatively consistent across all the study districts. Although there are district-level variations, about 87 percent of the sex workers reported consistent use of condoms. The proportion ranges from 67 percent in Madurai to 96 percent in Tiruchirapalli. In Tiruchirapalli, Namakkal, and Chennai districts, more than 90 percent of the FSWs reported using condoms with clients. In Kanyakumari and Madurai districts, consistent condom use with nonpaying partners was reported by only 50 and 42 percent of women surveyed, respectively, posing a risk to the workers and their clients of HIV infection transmission.

The association between the FSWs' degree of mobility and the indicators of their HIV risk was also examined. Degree of mobility was defined as visiting two places, three to four places, and five or more places. About 90 percent of the FSWs reported consistent use of condoms with different clients when they visited or stayed in three to four and five or more places. Consistency in condom use is slightly lower among those who visited or stayed in only two places. A significant association exists between FSWs' mobility and their HIV risk perception and STI symptoms. More than half of the sex workers who visited more than three places reported that they have a high-to-moderate HIV risk, and more than two-thirds reported having at least one symptom of a sexually transmitted infection (STI).

To target such a highly mobile population of female sex workers who appear to be vulnerable to HIV requires a comprehensive understanding of where they go to solicit clients and have sex. In Tamil Nadu, mobile female sex workers solicit customers for sex in various places; the most commonly mentioned places are railway stations (71 percent), bus stands (65 percent), and marketplaces (32 percent). Sex workers also reported a variety of sites where they have sex with their customers, including hotels/lodges ( 69 percent), rented rooms (49 percent), and their own homes (34 percent). The responses are similar across the study districts. The association between place of contact and places of solicitation reveals that hotels/lodges, railway stations/bus stands, marketplaces, and the women's own homes are places where targeted interventions could cover the maximum number of women and that existing efforts to reach female sex workers and their clients in hotels. could be increased and expanded. 

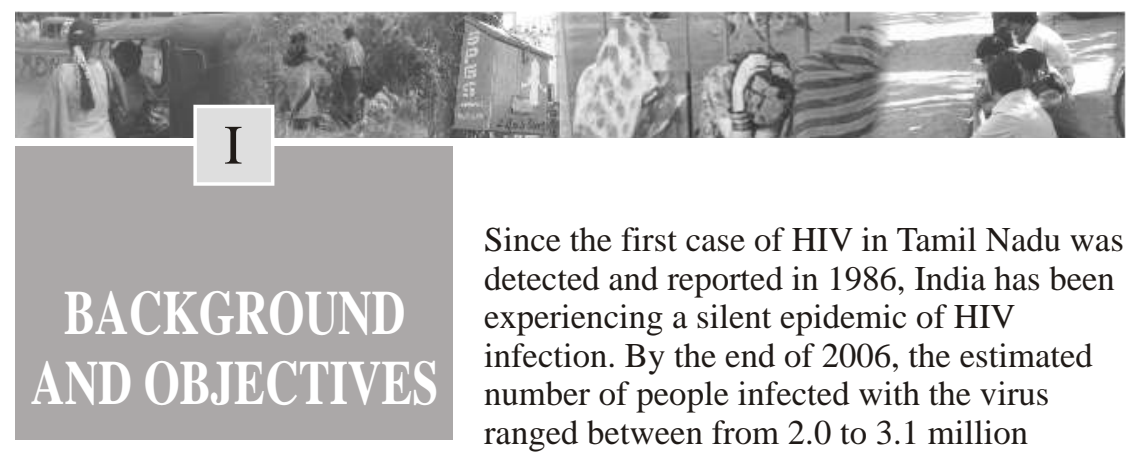

Since the first case of HIV in Tamil Nadu was detected and reported in 1986, India has been experiencing a silent epidemic of HIV infection. By the end of 2006, the estimated number of people infected with the virus ranged between from 2.0 to 3.1 million (based on Sentinel surveillance reports). The third National Family Health Survey (NFHS-3) was designed to provide a national estimate of the incidence of HIV in the household population of women aged 15-49 and men aged 15-54 and separate estimates for each of the six-highest states in terms of HIV prevalence (Manipur, Andhra Pradesh, Karnataka, Maharashtra, Tamil Nadu, and Nagaland). Results of the NFHS-3 survey indicate that 0.28 percent of adults aged 15-49 are infected with HIV. This figure translates into 1.7 million HIV-positive individuals in this age group as of April 2006. The HIV-prevalence rate is 0.22 percent for women and 0.36 percent for men aged 15-49.

According to NFHS-3, the prevalence of HIV in men and women was highest in Manipur (1.13 percent), followed by Andhra Pradesh ( 0.97 percent), Karnataka (0.69 percent), Maharashtra (0.62 percent), and Tamil Nadu (0.34 percent). Irrespective of prevalence according to state, in India, HIV/AIDS is concentrated mainly in the high-risk groups including FSWs and their clients, men who have sex with men (MSMs) and injecting drug users (IDUs). A majority of the clients of FSWs in India are male migrant workers (MMWs) who are separated from their families when they migrate to find work. To reduce the prevalence of HIV/AIDS in India, the infection must first be controlled or managed in these high-risk groups. These groups are mostly mobile, spreading the infection to multiple locations. The current study aims to determine the migration/mobility patterns of such high-risk groups as FSWs, hijras (eunuchs who sometimes engage in prostitution), and MMWs in the four states with the highest HIV prevalence. The current report, however, describes the patterns and drivers of migration/mobility of FSWs in Tamil Nadu and may generate discussion by associating the groups' mobility with the risk of acquiring HIV. The findings of this research provide empirically validated evidence for designing interventions to prevent the spread of HIV among FSWs and their clients in Tamil Nadu. 


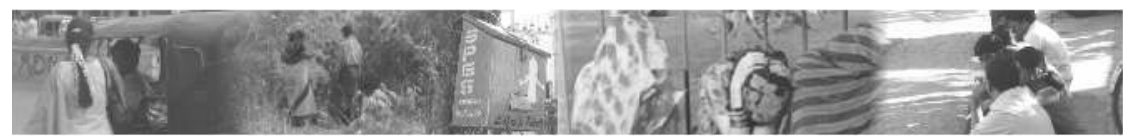

The Bill \& Melinda Gates Foundation's India AIDS Initiative, Avahan, was started in 2003 with the aim of slowing down the HIV epidemic through focused, integrated, large-scale prevention programmes complementing other providers of HIV-prevention services to achieve saturated coverage (greater than 90 percent) of high-risk populations. The focus of Avahan is on FSWs and their clients, MSM, hijras, and IDUs in 83 districts in six states with high HIV prevalence and in 17 sites along the national highways (NH-19).

The NFHS-3 estimates the prevalence rate in Tamil Nadu as 0.34 percent, much lower than the National AIDS Control Organization standard to qualify as a high-prevalence state (that is, with more than 1 percent infected with HIV among antenatal women). This standard removes Tamil Nadu from its longheld position as one of the six states with the highest HIV prevalence.

Simultaneously, it also indicates Map 1.1 Avahan program areas in India that greater awareness exists concerning HIV/AIDS among the 15-49 age group. While the figure for awareness is 98 percent for men, the corresponding figure for women is 94 percent, a far cry from the abysmal 23 percent recorded during the first NFHS conducted in 1992-93. Unsurprisingly, urban areas show greater levels of awareness than do rural areas.

Recognizing the need for evidence to inform HIVprevention programmes, Avahan is placing special emphasis on FSWs to check

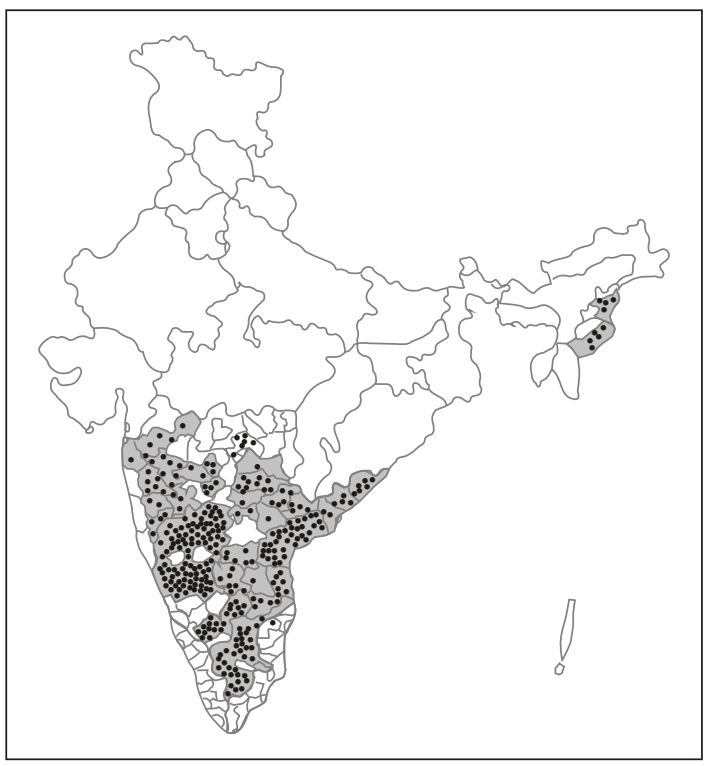
the spread of the epidemic. Little is known about the patterns of migration and mobility of at-risk populations or about the nature and extent of interaction 


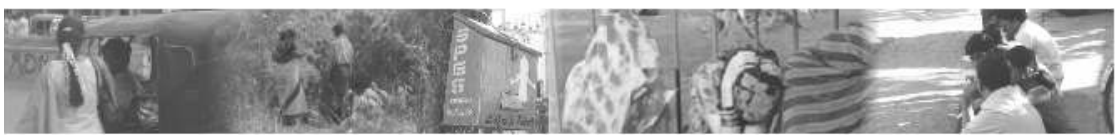

among them. For an effective intervention model to benefit the mobile population, it is important to determine why mobility at certain times and under certain conditions is related to increased HIV transmission, particularly for sex workers, who are clearly at high risk of infection. The present study was undertaken by the Population Council to study the patterns and drivers of sex workers' migration at their destination points, intermediate points, and points of origin, and their connection to high-risk activities in Tamil Nadu. The Population Council collaborated with its local partner, TNS, to carry out this study in Tamil Nadu.

Specifically the study sought to explore the following objectives:

1. to assess the volume and patterns of mobility of female sex workers;

2. to describe the characteristics of mobile female sex workers; and

3. to examine the determinants of HIV risk among female sex workers, with particular emphasis on mobility-related characteristics.






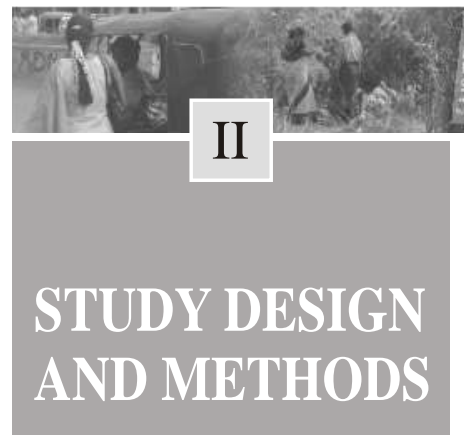

The cross-sectional study design involved the following steps and engaged both qualitative and quantitative methods as outlined below:

1. identification of major destination points, including intermediate destination points where female sex workers (FSWs) are concentrated;

2. characterization of destination points, including intermediate destination points, using qualitative research methods; and

3. gathering of quantitative data at the destination, including intermediate destination points.

The fieldwork was carried out from July to October 2007. In the first phase, destination points (also referred to here as "study areas") were identified and characterized using primarily qualitative data, followed by a quantitative survey.

\subsection{Identification of study areas}

Major destination and intermediate destination points were identified using FSWs' mapping data and were later verified through discussions with organizations working in the areas. The five districts with the highest concentration of FSWs and high prevalence of HIV were selected. Data from the mapping of the FSWs' population in Tamil Nadu and Sentinel surveillance sites were listed in descending order according to the concentration of the FSW population and HIV prevalence. The districts selected were Namakkal, Kanyakumari, Madurai, Chennai, and Tiruchirapalli.

\subsection{Characterization of study areas}

Study areas were characterized from qualitative data gathered by ethnographic methods, including key-informant interviews, in-depth interviews, and mobility 


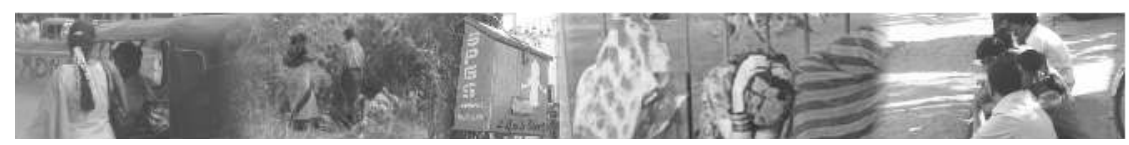

\section{Map 2 : Study districts in Tamil Nadu State, India.}

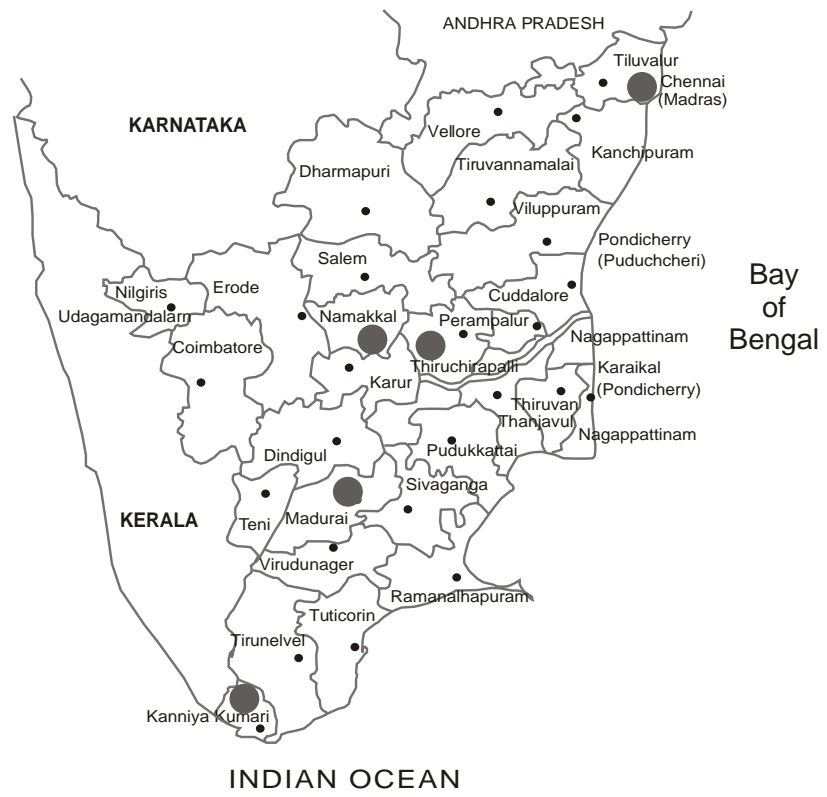

maps drawn by female sex workers. The purpose of the characterization was twofold: to identify individual, community, and structural factors that determine the mobility of female sex workers and also influence their risk and vulnerabilities, and to inform the selection of primary sampling units (PSUs) for the quantitative survey.

A total of 104 interviews (40 key-informant interviews and 64 in-depth interviews) were carried out in the selected study areas. All interviews were conducted with a purposive selection of respondents following informedconsent procedures.

The qualitative interviews were carried out in three stages. In the first stage, interviews were held with local key informants, including female sex workers, to map the physical locations used for solicitation of clients and to develop a 


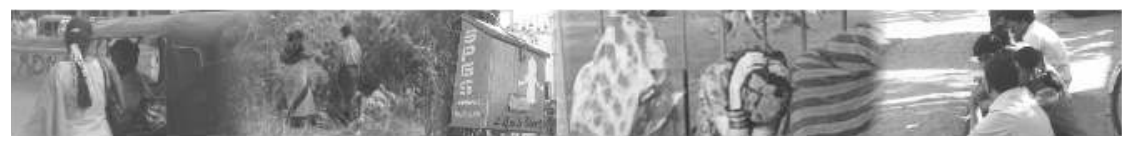

profile of mobile female sex workers and their mobility patterns. In the second stage, in-depth interviews were conducted with selected female sex workers to generate individual mobility maps, and interviews were held with groups of sex workers to describe group dynamics and group mobility.

The qualitative data were gathered by a team of 12 experienced and specially trained investigators (seven women and five men). The information was collected in Tamil (the state language of Tamil Nadu). The interviews were translated into English and analysed with the help of Atlas.ti, a computer-based text-search programme.

\subsection{The quantitative survey}

The purpose of the quantitative survey was to provide an estimate of the extend of mobility among female sex workers and to identify the relationship between mobility-related factors and HIV-risk behaviour. For the purposes of the survey, a female sex worker was defined as "mobile" and included in the study if she had:

1. engaged in sex work for at least one year;

2. had visited two or more places for the purpose of obtaining sex work (excluding the current location) in the past two years; and

3. one of those moves/visits was made across the district.

The study was confined to female sex workers aged 18 and older.

\subsection{Sample size and sampling design}

Power calculations based on 30 percent nonuse of condoms among female sex workers indicated that a sample of 200 mobile sex workers was sufficiently powerful for determining consistent nonuse and associated risk factors, including degree of mobility. Assuming half of the randomly selected FSWs were mobile, between 300 and 400 FSWs were sampled for the survey in each district.

A total of 2,282 sex workers were screened for the survey, of which 1,310 were eligible for interview, satisfying the inclusion criteria described above. Thus, 57 percent of all the female sex workers screened were surveyed. 


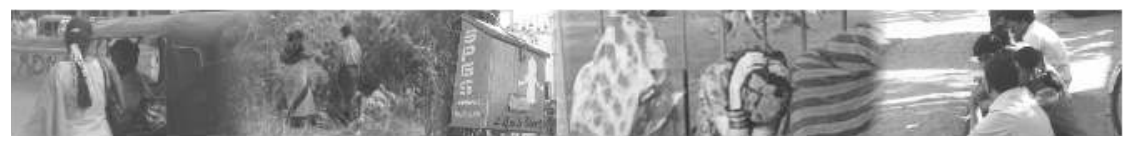

In each primary sampling unit (PSU) within each district, the study adopted two types of sampling procedures, two-stage systematic sampling and timelocation sampling, for selecting brothel-based and non-brothel-based sex workers, because of the differences in the way sex work is practiced.

To select sex workers in brothel-based areas, a two-stage systematic procedure was used. First, the lanes/small pockets/areas within each larger brothel site were listed. Using the probability-proportionate-to-size procedure, the number of brothels to be selected in each large area was predetermined. The sub-lanes or small areas were selected systematically from the lists in the first stage. In the second stage, brothels were systematically selected, with the first house being randomly selected and subsequent houses selected according to a calculated interval. One sex worker from each selected brothel was interviewed using a screening tool.

For the selection of sex workers in non-brothel-based areas, a timelocation sampling procedure was used. The social maps prepared during the qualitative research formed the basis for this sample. From the maps, locations of smaller sites were listed. Then, key informants and the nongovernmental organization (NGO) staff were contacted again to determine the timing of the sex workers' visits to the sites. Thus, for each area, a detailed schedule was prepared listing when sex workers would be available. Time slots were fixed for the interviewers to visit the sites and wait for the sex workers. Those who came to the site at the specified time were selected for the interview using a screening tool.

Screening interviews collected information on the sex worker's age, place of contact, the district where the interview was conducted, the number of places she had ever visited for sex work, the number of places she had visited in the past two years for sex work, and the number of districts she had visited in the past two years. This information helped to identify those sex workers who were mobile, according to the study criteria, and to estimate the proportion who were mobile among representative sex workers at the district level.

The survey questionnaire administered to eligible sex workers included questions about their socioeconomic and demographic status, living conditions, exposure to the media, life style, support services they use, migration/mobility pattern, and sex-work history, jatara/event-related mobility for sex work, 


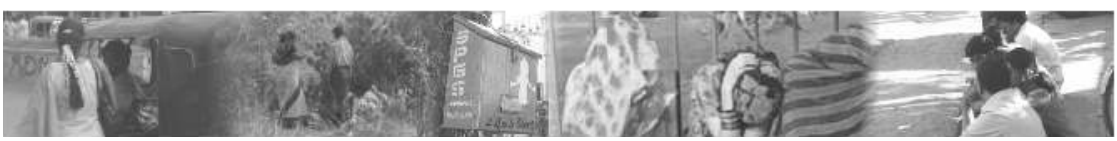

seasonal mobility, connection with their place of origin; clients' profiles, experience of physical violence, availability and access to condoms and ability to use them, condom use in their current and previous locations, their sexually transmitted infections (STIs), and their knowledge and risk perception concerning HIV/AIDS.

For collecting the specified qualitative data, interviewers and supervisors with previous experience in collecting such data for social science projects were selected. Population Council and TNS researchers trained the selected interviewers and supervisors in Chennai from 27 February to 2 March 2007.

The quantitative data was collected using personal digital assistants (PDAs) by eight trained and experienced female researchers. Interviewers were specially trained to adhere to ethical conduct concerning issues that are sensitive for the marginalized population that they would be surveying. Informed consent was obtained from all the participants prior to the interviews, and they were assured that the information they provided would remain confidential. Data quality was ensured through a supervisory structure that provided regular feedback in the field and data cleaning in the office and, if necessary, a revisit to the field. The data were downloaded from the PDAs on a daily basis to a laptop and sent each week to the Population Council. Researchers at the Council verified the quality of the data by running consistency checks for key variables on a regular basis. Teams were given regular feedback concerning data quality. The Statistical Package for Social Sciences (SPSS) software was used for data analysis.

\subsection{Sex workers' degree of mobility}

An index was constructed for classifying female sex workers on a continuum of mobility ranging from least to most mobile. The indicators of mobility used in the study are: total number of locations the sex worker visited or stayed in the past two years $(1,2,3,4$, or 5+ locations); the number of districts they visited or stayed at the past two years (1,2 or 3+ districts); and whether they visited jatara (festival) areas (no, yes went alone; yes went with a group). 


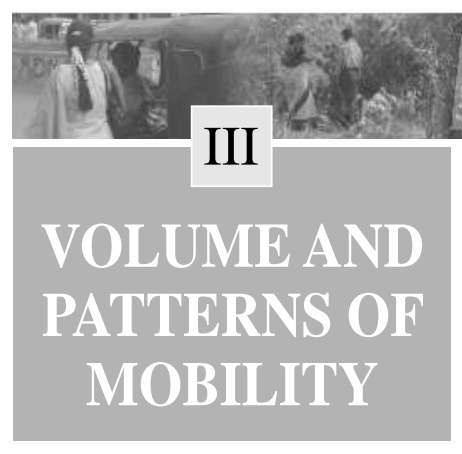

3.1

Volume of mobility

As shown in Figure 1, the data indicate that 81percent of sex workers interviewed moved at least once for sex work in the past two years, 79 percent moved at least twice, and 59 percent moved across the district. On

average, FSWs moved five times in the past two years, and four of these moves were across the district (see Table 1). More than four-fifths across the district of the FSWs from Madurai and Kanyakumari districts moved at least once across district for sex work in the past two years.

Figure 1 : Percentage of mobile female sex workers surveyed who moved at least once across district for sex work, by district, Tamil Nadu State, India

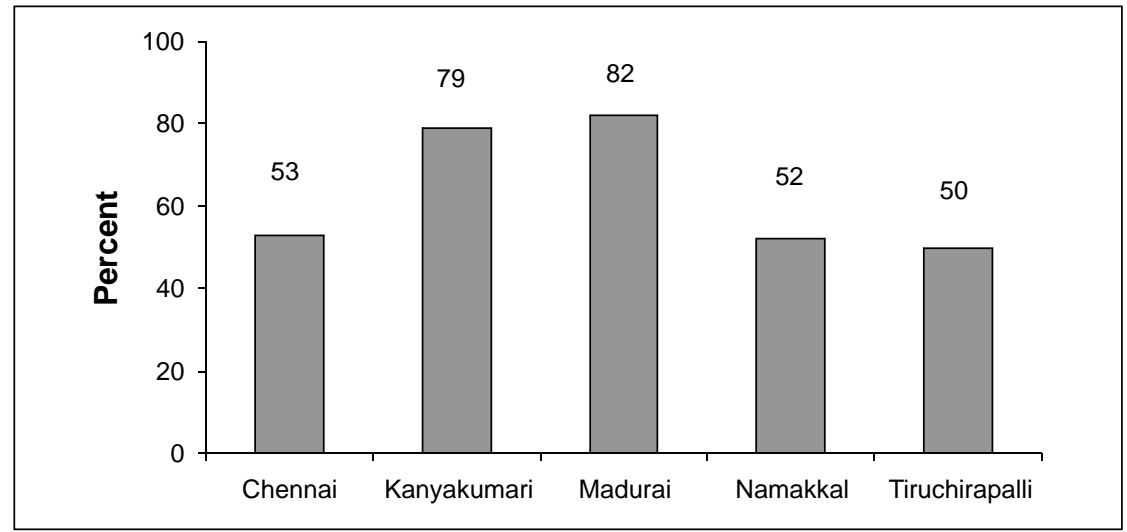

As the table shows, female sex workers in Tamil Nadu are highly mobile. On average, they moved five times in the past two years for sex work, and on average, four of these moves were made across the districts. 


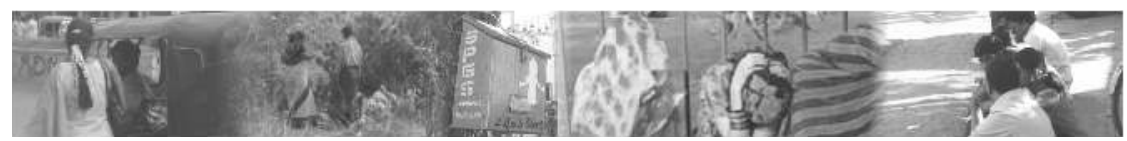

Figure 2 : Percentage of female sex workers surveyed, by their level of mobility, according to district

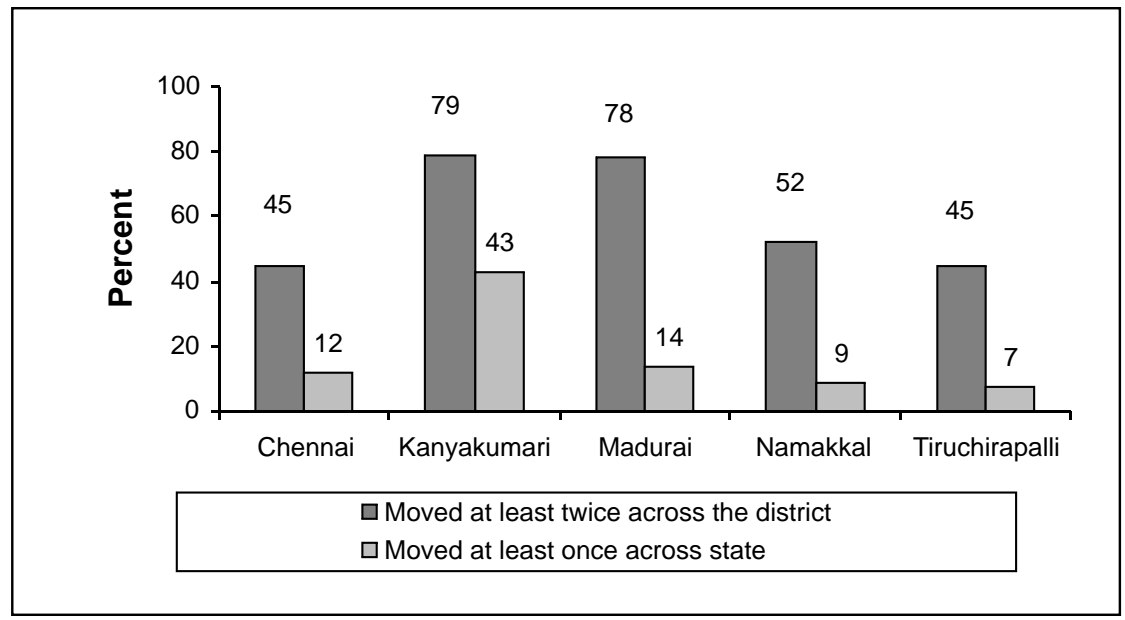

Interdistrict variation occurred in the sex workers' mobility. More than half of the sex workers in all of the districts, however, reported at least one move across the district (see Figure 2). Seventy-nine percent of sex workers from Kanyakumari and 82 percent from Madurai moved at least once across the district in the past two years.

An in-depth look at the mobility patterns of FSWs who moved at least twice during the past two years and at least outside the district by age group and place of contact indicates that FSWs aged 30-34 from Kanyakumari and Madurai districts are more mobile than their counterparts from other study districts (see Table 2).

Table 2 also indicates that FSWs who were contacted at brothel sites, homes, highways, and lodges were more mobile than those who worked in the streets, especially in the districts of Kanyakumari and Madurai. Due to lack of any designated brothel site in Tamil Nadu, most sex workers contacted were from the streets, and of them, 58 percent reported that they were mobile. 


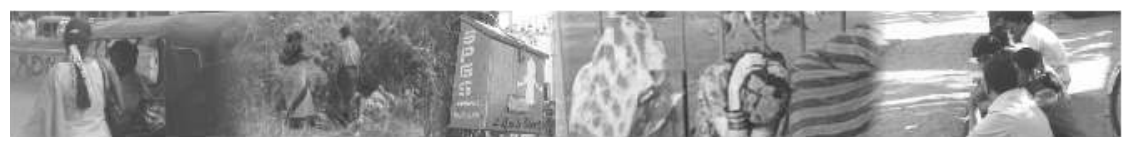

Mobility is greater among those aged 30 and older regardless of their place of contact (see Figure 3).

Figure 3 : Percentage of sex workers surveyed, by age and place of contact, Tamil Nadu State, India

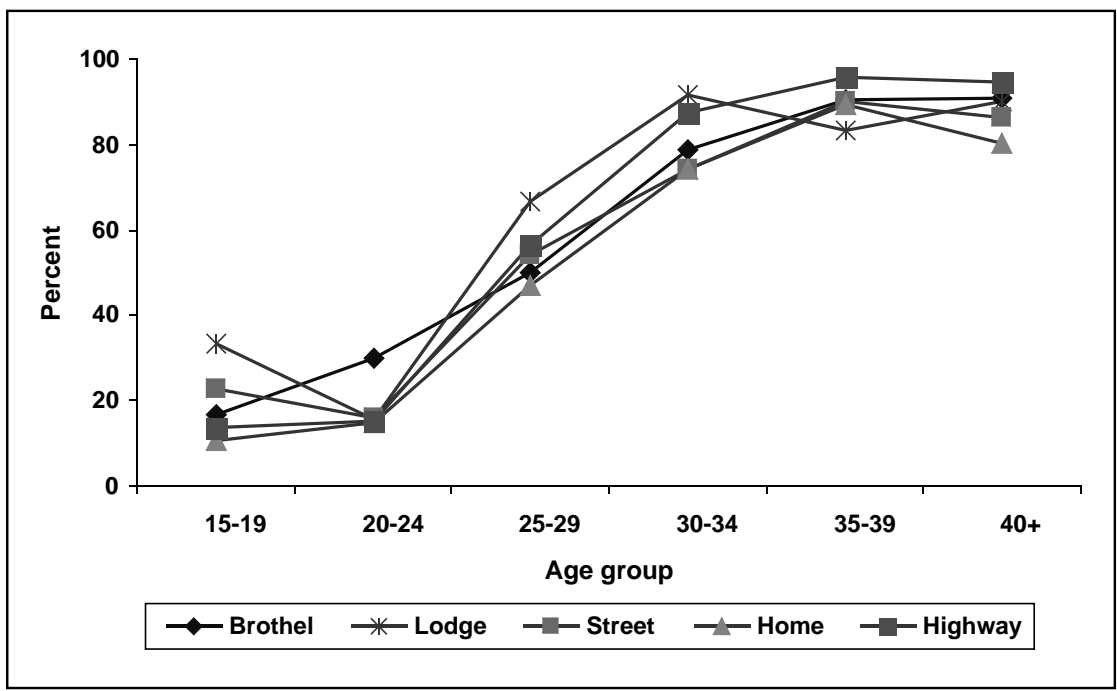

\subsection{Patterns of mobility}

The responses of the mobile sex workers who participated in the survey provided data that describe the patterns of their mobility. Data concerning their current locations and their previous two locations are presented visually in the maps. The thickness of the line represents the volume of sex workers' mobility, and the arrows indicate the direction of their mobility. The four thicknesses of line weight indicate (from heaviest to lightest) that more than 40 percent, between 30-39 percent, between 20-29 percent, and between 10-19 percent of the sex workers travel the routes shown. Routes travelled by fewer than 10 percent are not presented on the map because they do not constitute a major route of mobility. Dotted lines indicate interstate mobility; solid gray lines indicate interdistrict movement within the state. 


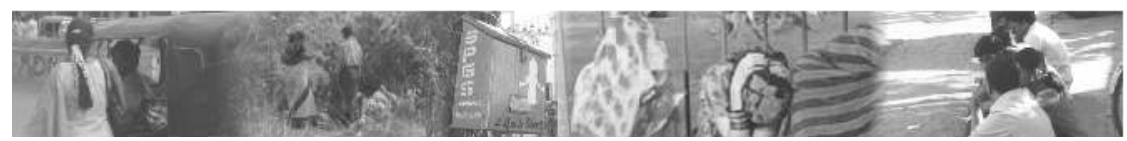

Map 3 shows the pattern of movement of mobile FSWs in Chennai urban district. Clearly, the sex workers in Chennai tend to move across the districts that are at a distance, such as Kancheepuram, Pondichery, Salem, Dindigul, Madurai and Nilgiris.

Map 3 : Mobility routes of female sex workers currently located in Chennai urban district, Tamil Nadu State, India

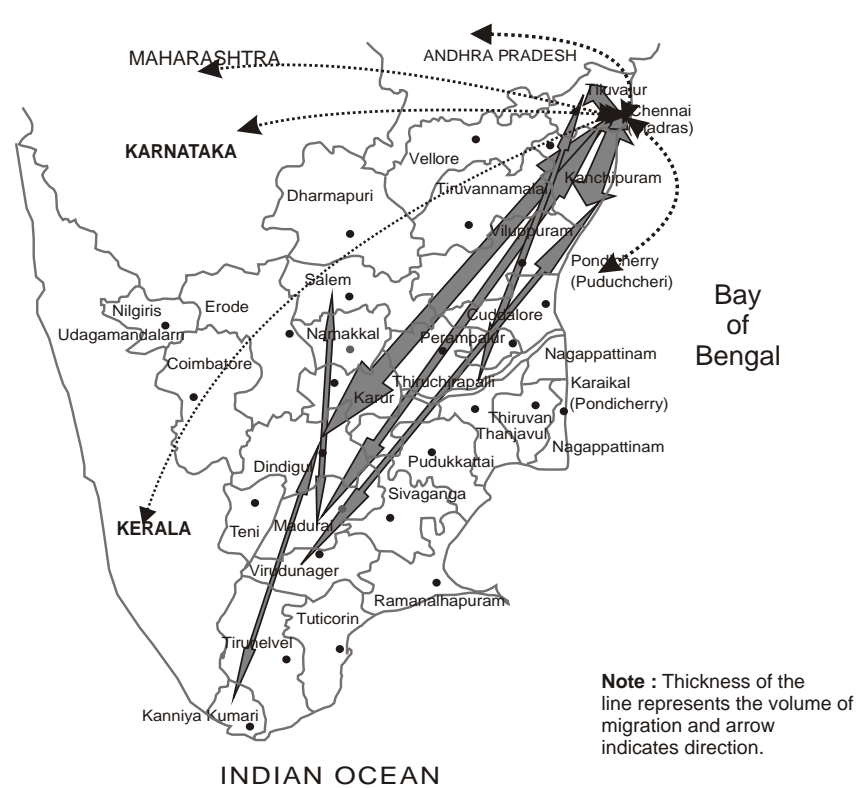




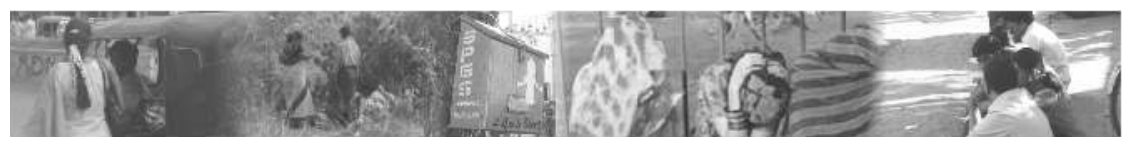

Map 4 shows the pattern of movement of the mobile FSWs in Kanyakumari. Kanyakumari is the only district from which the mobile FSWs move across states, and most of them moved towards the neighbouring state of Kerala. Interdistrict migration, however, was mostly concentrated across the neighbouring districts such as Tirunelveli, Tuticorin, Virudunagar, and Madurai.

Map 4 : Mobility routes of female sex workers currently located in Kanyakumari urban district, Tamil Nadu State, India

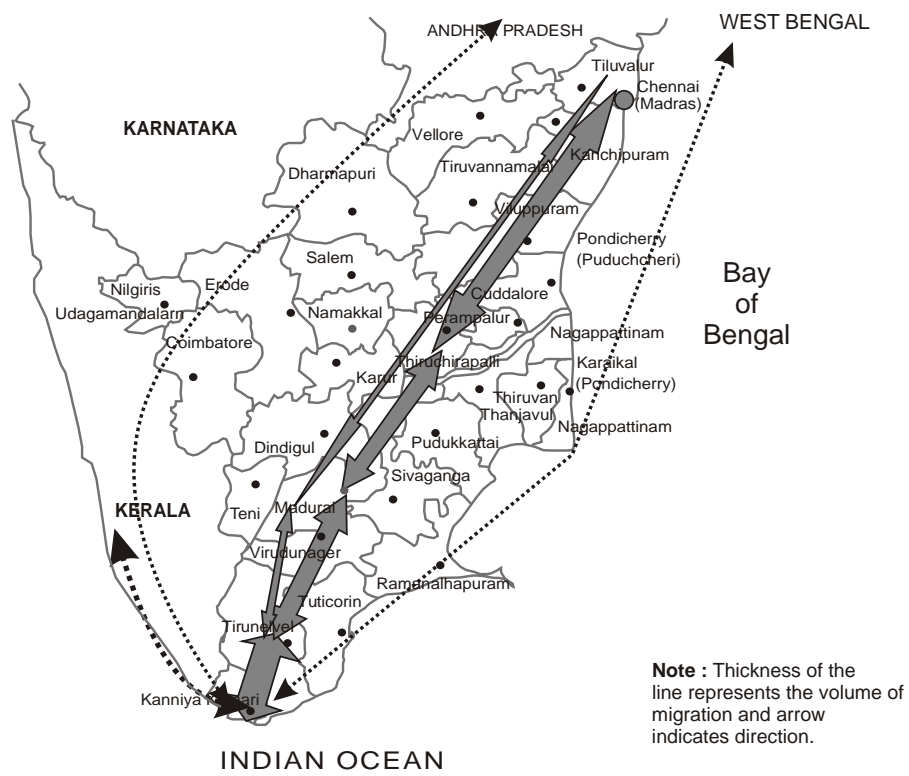




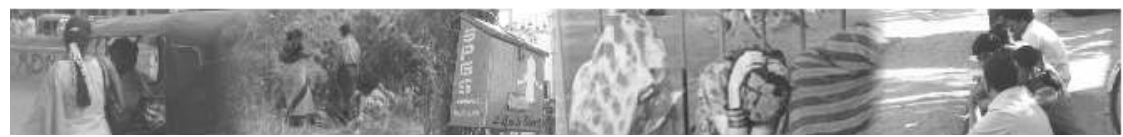

Mobile FSWs of Madurai have shown a tendency to move to neighbouring districts, however, greater mobility was found towards the districts that shared state boundaries with Kerala such as Virudunagar, Teni, Dindugal, Tirunelveli, Thanjavur, Coimbatore, and Nilgiris. A considerable number of sex workers also move to the coastal district of Nagapattinam (see Map 5).

Map 5 : Mobility routes of female sex workers currently located in Madurai urban district, Tamil Nadu State, India

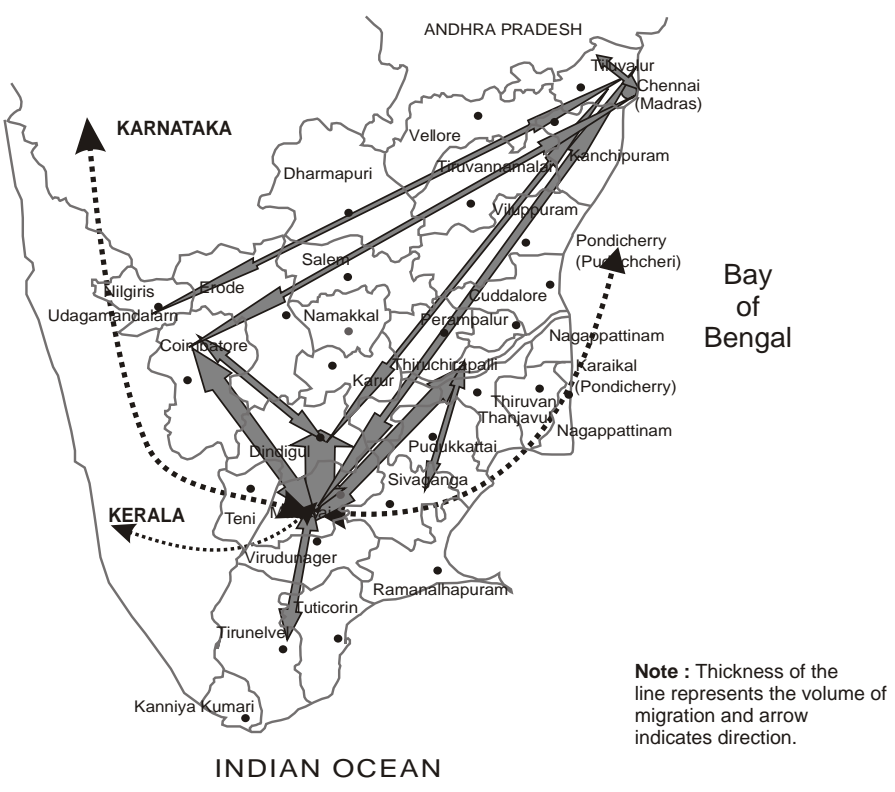




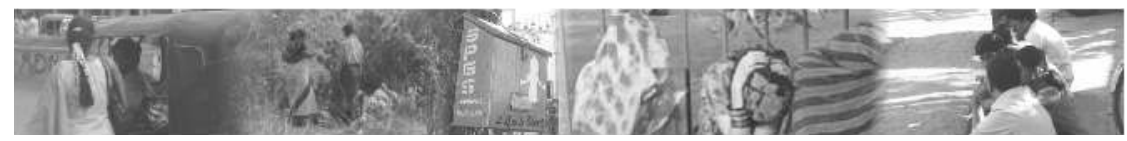

Namakkal is a district with a very high prevalence of HIV and fewer destinations for mobile FSWs (see Map 6). Most the FSWs in this district have shown a tendency to move towards the distant coastal districts of Erode, Nagapattinam, and Chennai.

\section{Map 6 : Mobility routes of female sex workers currently located in Namakkal urban district, Tamil Nadu State, India}

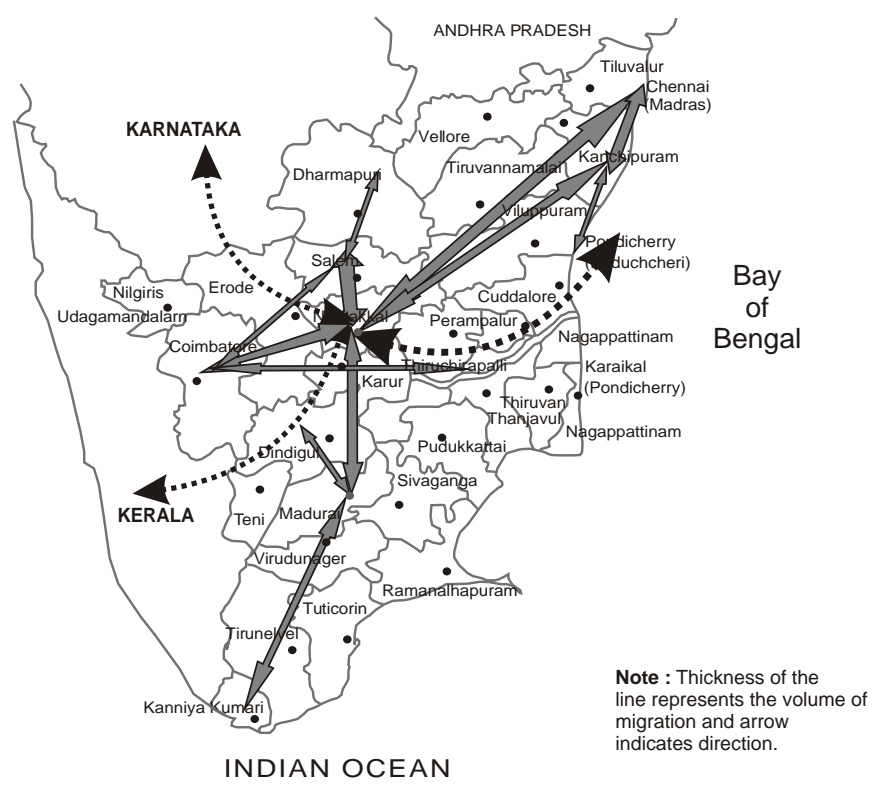




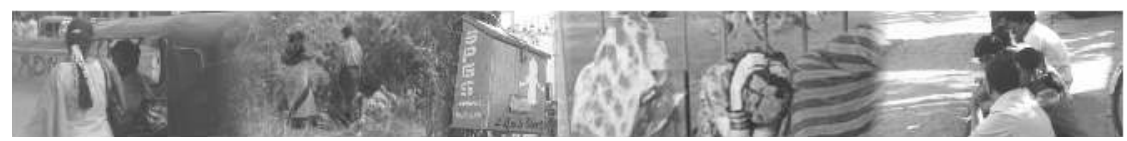

Mobility patterns of FSWs in Tiruchirapalli are mostly directed to the neighbouring districts, such as Karur, Namakkal, Thiruvanamalai, Nagapattinam, and Madurai. The FSWs initially come from Chennai to Tiruchirapalli and then more farther afield (see Map 7).

\section{Map 7 : Mobility routes of female sex workers currently located in Tiruchirapalli urban district, Tamil Nadu State, India}

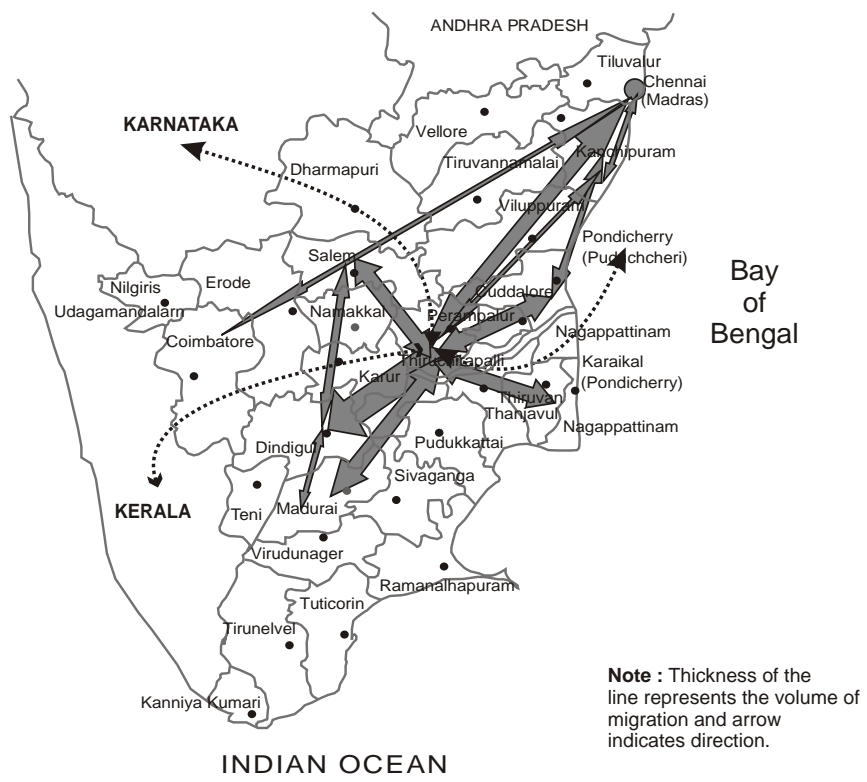

Other factors that influence the mobility patterns of FSWs relate to religious festival (popularly known as jataras) and harvest seasons, during which single migrant men work in groups in the fields. In Tamil Nadu, jataras or thiruvilzhas as they are called, mostly occur around the times of the temple festivals or annual festivals in the native towns of the home deity. In rural areas, people attach great importance to these festivals, and each district holds numerous such festivals throughout the year. During these festivals, thousands of people, 


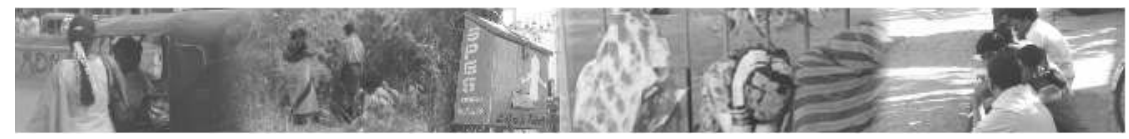

sometimes hundreds of thousands, throng places of religious importance to celebrate for three to five days of festivities. FSWs visit such festivals to obtain work from the large number of men who attend them. Only about one in ten FSWs visited jataras in Tamil Nadu during the 12 months preceding the survey; the proportion is larger in Namakkal (23 percent) and in Chennai (18 percent). Usually, sex workers travel to jataras in groups, the data show that around half of the FSWs who visited such jataras in Tamil Nadu did so in groups (see Table 3).

At these jataras, two-fifths of the sex workers' clients are migrants from different places, and 35 percent are migrants from the same district. The sex workers report consistent condom use at about 90 percent across the state among those visiting jataras. A larger proportion of FSWs inNamakkal and Tiruchirapalli are able to negotiate condom use with clients, compared with those in other districts.

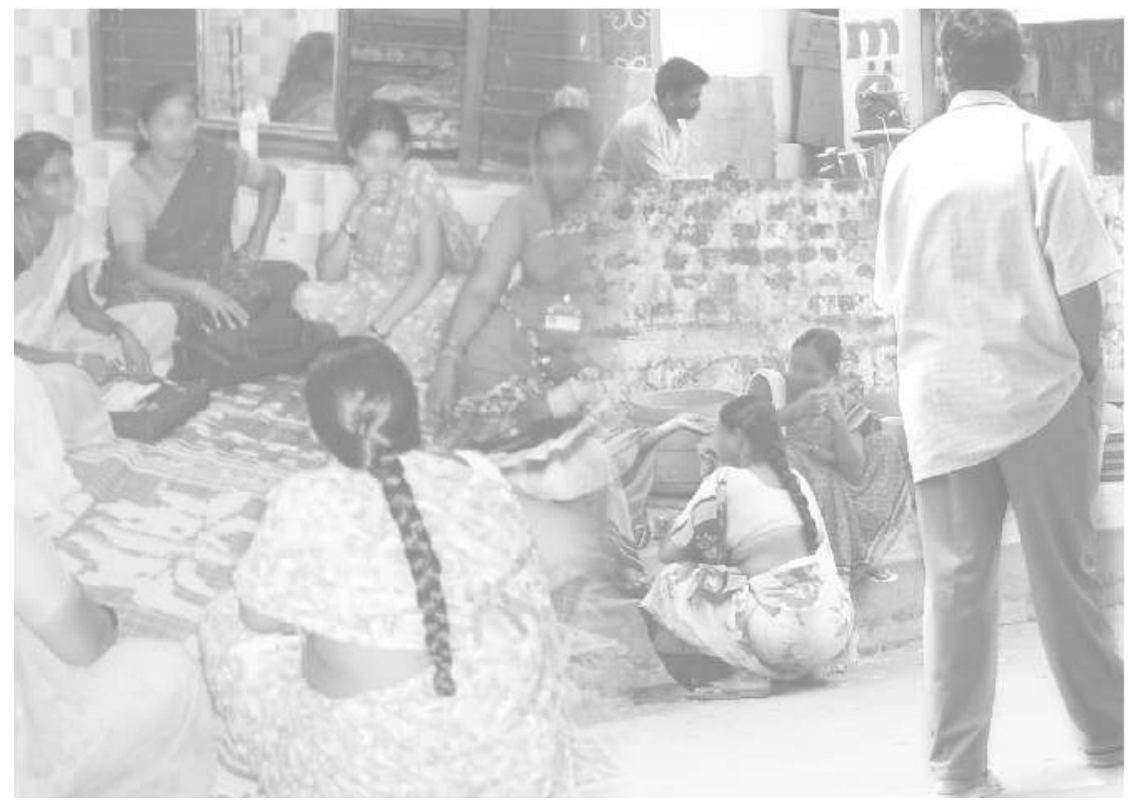




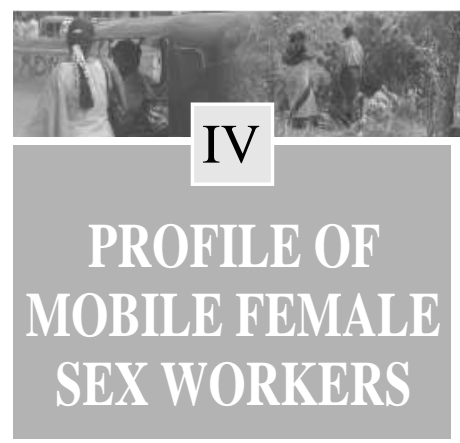

\subsection{Socioeconomic and demographic profile}

The socioeconomic and demographic profile of the FSWs surveyed is shown by district in terms of age, education, marital status, main source of income, and the amounts these FSWs owed to others (see Table 4).

Around 75 percent of the mobile FSWs in Tamil Nadu are aged 25-39 and 15.2 percent are illiterate. More than 30 percent are divorced, widowed, or separated. In all the districts, however, the majority of sex workers are married. This proportion is highest in Madurai (77 percent) and lowest in Namakkal (60 percent) (see Figure 4).

Figure 4 : Percentage of mobile female sex workers surveyed, by their marital status, according to district, Tamil Nadu State, India

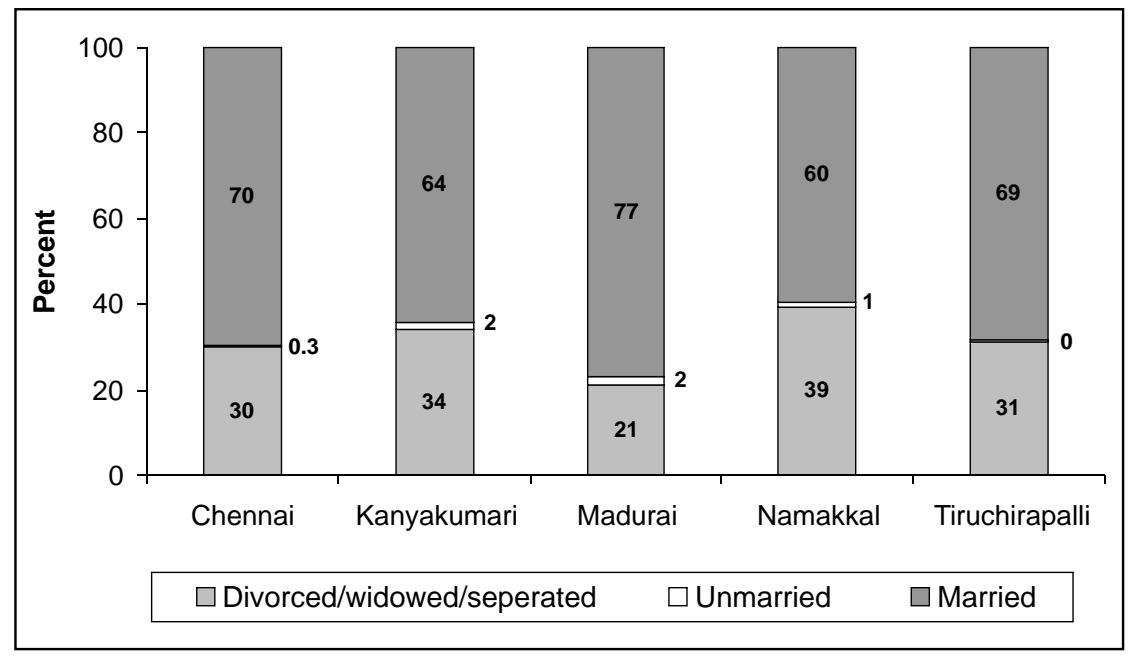

The in-depth interviews corroborate that a considerable number of FSWs in Tamil Nadu were married. In most cases, the husband's alcohol addiction and low income were the reasons that the woman became a sex worker. 


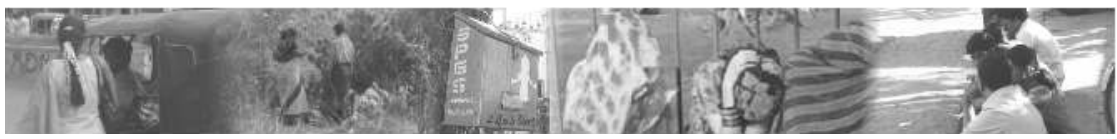

"My husband is the one responsible for my entry into sex work because he is a heavy drinker and does not care for me or my child." (26 years old, married, home-based sex worker, Tiruchirapalli)

"I divorced my first husband for not trusting me, and I left my second husband for some problem after four years. Now I am married for the third time and have been living with my husband in Poonamalle for the past five years. He knows about my sex work and has no problem with it because he earns very little and is also old." (45 years old, married, street-based sex worker, Chennai)

Some women had left their husbands mainly because of the men's suspicious attitude, violent behavior, and relationship with other women.

"My husband used to abuse me physically to the extent that once I was admitted to a hospital. There was no one to look after me and my mother. I started living with my neighbour who bought medicines, gave me money and took care of me and my mother. After some time, he started quarrelling with me so we were separated. Now I am married to a van driver. Neither my husband nor my in-laws know that I am a sex worker." (33 years old, married, homebased sex worker, Chennai)

"My husband drinks a lot. He was suspicious if I talked to anybody and used to beat me for that. He married my sister also. Due to his difficult nature and second marriage, I started living separately in the same village." (35 years old, separated, home-based sex worker, Namakkal)

"I was a nurse and I used to have sex with doctors in various hospitals where I worked. My husband used to suspect me and physically tortured me. So one day, I packed my bags and left with my children to the place where my sister's family stays. I started sex work in the lodges, mostly with regular clients." (46 years old, separated, lodge-based sex worker, Madurai)

\subsection{Sources of income}

More than three-fourths of the sex workers earn money through a combination of sex and other work such as daily-wage work, petty businesses, selling flowers or vegetables, and contract work. About one-third earn money through a combination of sex work and sex-related work such as taking commissions from referring clients and renting rooms for sex. In Madurai and in Namakkal, a different pattern is observed, and more than four-fifths of the sex workers earn from both sex work and from work that is unrelated to sex (see Figure 5). 


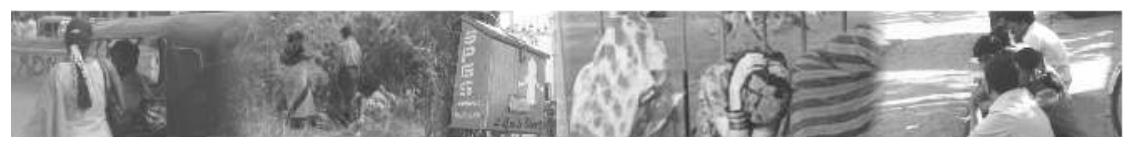

Figure 5 : Percentage distribution of mobile female sex workers surveyed, by their source of income, according to district, Tamil Nadu State, India

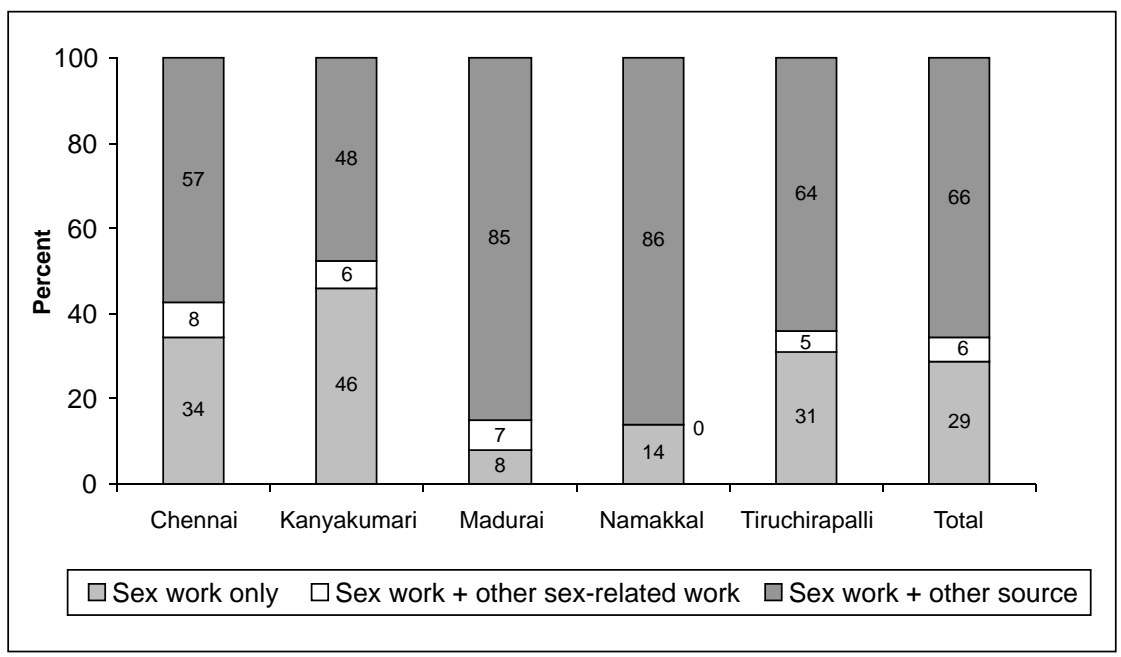

In the qualitative study, too, FSWs mentioned that they had sources of income other than sex work.

"I am doing camphor-packaging work besides this sex work. I earn Rs.200-300 per month. Also, I am working as a housemaid in two houses which gets me Rs.500 (US\$ 10) per month." (29 years old, separated, street-based sex worker, Tiruchirapalli)

"Nobody knows about my sex work. I am working in an export company. When I used to go out of station, I told my neighbours that I was going for some office work." (27 years old, married, lodge-based sex worker, Chennai)

"I have studied up to the third standard and am operating a fruit business, although I can earn only Rs.60-70 per day out of it. My husband works in a cinema theatre and earns Rs.3,000 a month." (40 years old, married, homebased sex worker, Madurai) 


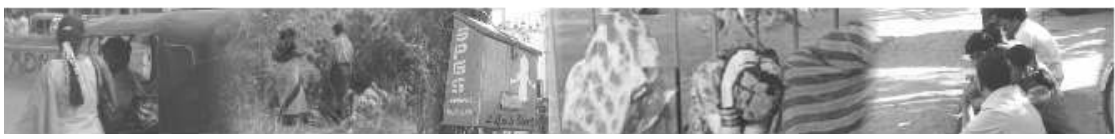

\subsection{Debt}

All of the sex workers surveyed in Tamil Nadu owed money to other people. About half owed more than Rs.50,000 to others. The amount owed varied by district. The districts where sex workers owed more than Rs. 10,000 to others are Tiruchirapalli (85 percent), Namakkal (83 percent), and Kanyakumari (82 percent) (see Figure 6).

Figure 6 : Percentage distribution of mobile female sex workers surveyed who have accrued debt, by district and amount of debt, Tamil Nadu State, India

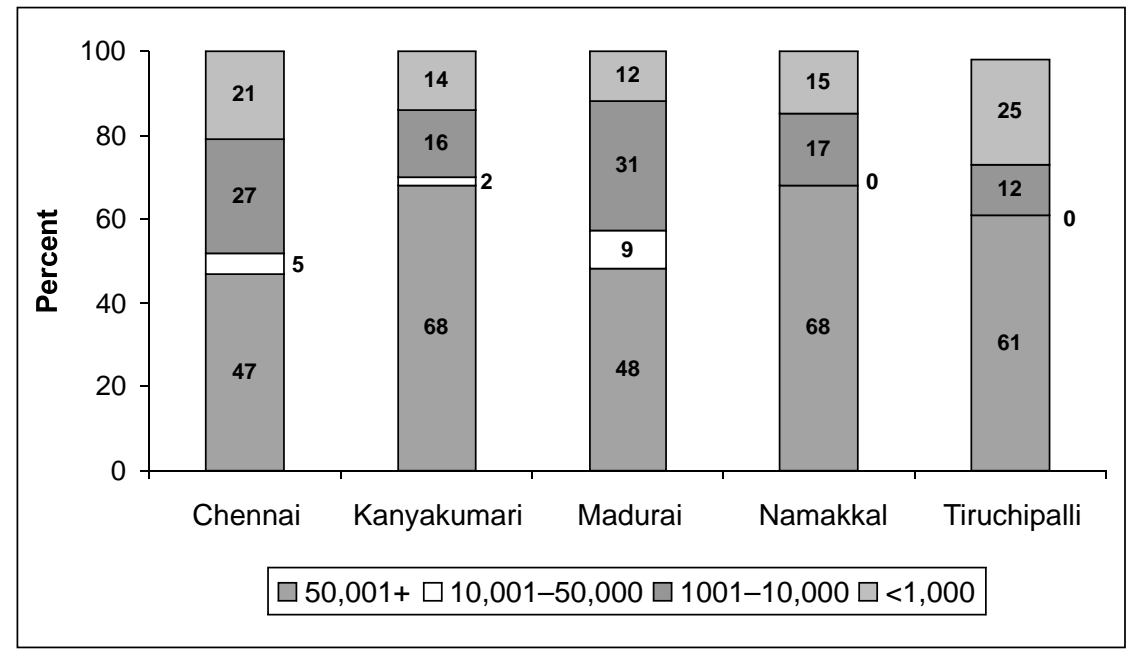

\subsection{Reasons for entering into sex work}

The FSWs were asked about their reasons for entering sex work, and their responses indicate that their financial situation at home was their main reason (70 percent) (see Figure 7). About one-fifth of the sex workers reported that they entered sex work because they were in debt. This proportion is consistent across almost all the districts of Tamil Nadu (see Table 5). Chennai, however, shows a different pattern: about one-third of the sex workers there said that they began sex work because they had debt at their place of origin. 


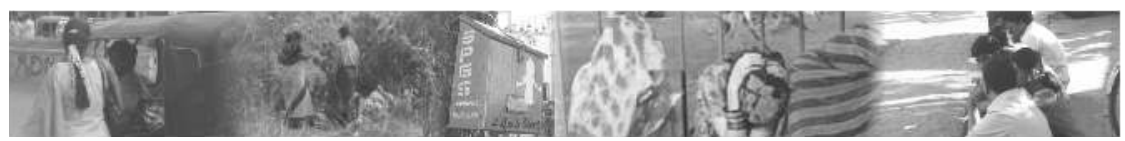

Figure 7 : Percentage of mobile female sex workers surveyed, by their reasons for entering into sex work, according to district, Tamil Nadu State, India

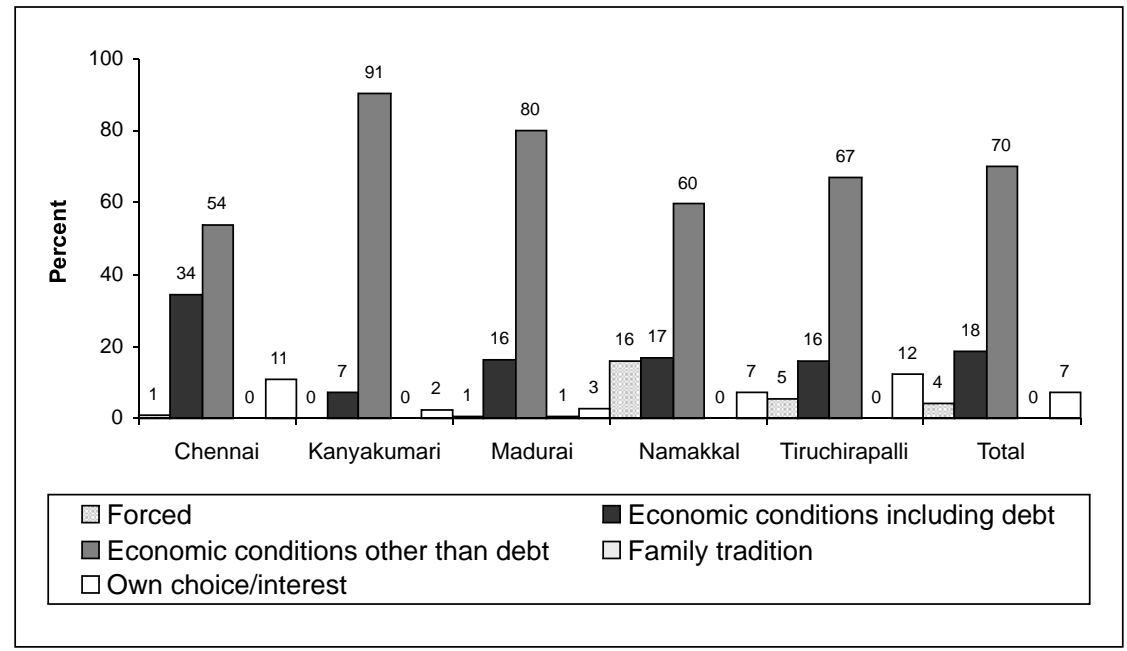

Apart from economic reasons for entering into sex work, 16 percent in Namakkal reported that they were forced to take up sex work. Family tradition and own choice or interest are negligible reasons these women gave for entering into sex work.

The qualitative interviews also reveal that the women's family's poor financial situation was the principal reason that they became sex workers. A few reported poor economic conditions and coercion as their reasons.

"My husband was selling arrack (an alcoholic beverage) prior to our marriage. He started selling phenol after our marriage. He took good care of our family for four years, but after some time, he stopped working for no reason. I was getting only Rs.40 per day. My husband met with an accident on the roadside and was severely injured. Now he can't walk or get work anymore." (32 years old, married, street-based sex worker, Kanyakumari)

"My husband is a typist in the court and earns Rs.10,000 per month. However, he gives me only Rs.2,000 for household expenses and the rest he spends on 


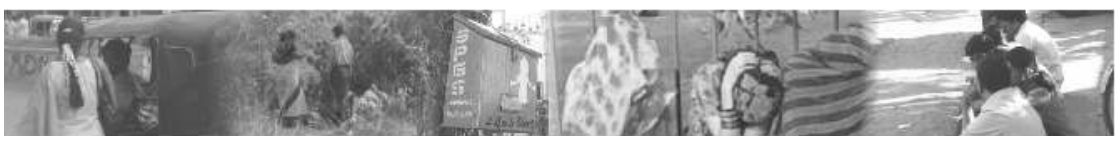

liquor. He is always in a drunken state. I was not sure that he would ever change. So in this condition, I entered into sex work for money." (31 years old, married, home-based sex worker, Madurai)

"I could not have brought up my daughter to this level ( she is studying to be a nurse) unless I did this work (sex work). My husband's salary was insufficient for running the household." (33 years old, separated, street-based sex worker, Kanyakumari)

One of the sex workers spoke of how she was forced into sex work by her husband.

"My husband got into heavy financial debt. He said he would bring customers (clients) for me so that I can earn money and support him financially. He also said that once the debts were cleared, I could stop the sex work. My mother could not help me, nor was my mother-in-law against my husband's idea." (29 years old, married, home-based sex worker, Madurai)

Most of the sex workers who reported that their poor financial situation was the reason they had entered sex work mentioned that their entry was facilitated by a friend, acquaintance, neighbour, or employers.

"An "akka" (older sister but not one's own) who lived in the neighbourhood used to talk to me kindly and was friendly. ... I came to know that she runs this business (sex work).

... I had serious financial problems. . . The akka told me that she would give me Rs.200 if I spent time with a man once in her house and also that she would keep it confidential." (31 years old, married, home-based sex worker, Tiruchirapalli)

\subsection{Lifestyle characteristics}

About half of the sex workers surveyed reported that they had consumed alcohol in the month prior to the survey. The proportion of those who reported drinking was highest in Chennai (57 percent), followed by 45 percent in Tiruchirapalli, and 44 percent in Kanyakumari and Namakkal (see Figure 8). Around 43 percent of the sex workers in Tamil Nadu also reported using tobacco in the month prior to the survey; again, this proportion is highest in Chennai (58 percent), followed by Namakkal (53 percent) and Tiruchirapalli (50 percent). Tobacco consumption is relatively low among sex workers in Kanyakumari (24 percent) and in Madurai (26 percent) (see Table 6). 
Figure 8 : Percentage of mobile female sex workers surveyed who reported that they had drunk alcohol in the month prior to the survey, by district, Tamil Nadu State, India

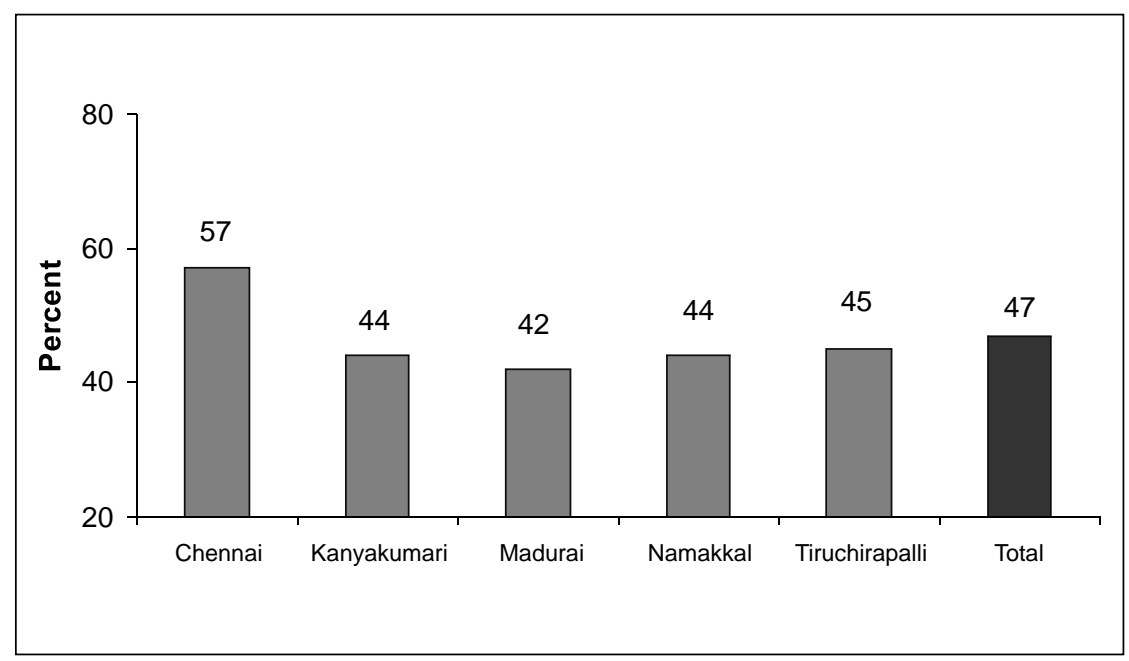

Only 24 percent of the sex workers reported that they owned a cellular phone, although the figure varied across the districts . The proportion was the highest in Namakkal (36 percent), followed by Chennai (30 percent), and Tiruchirapalli (27 percent). Cellular phone use among sex workers in Kanyakumari and Madurai is low (14 percent) (see Table 7). 


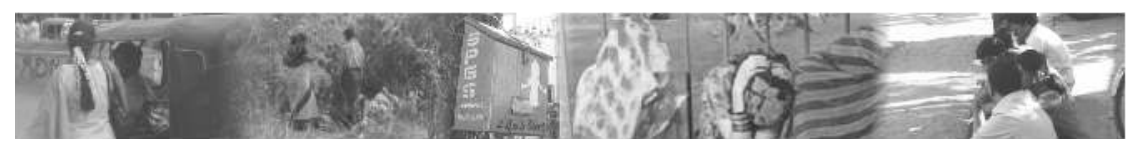

Figure 9 : Percentage of mobile female sex workers surveyed who reported having separate bank or post office accounts, by district, Tamil Nadu State, India

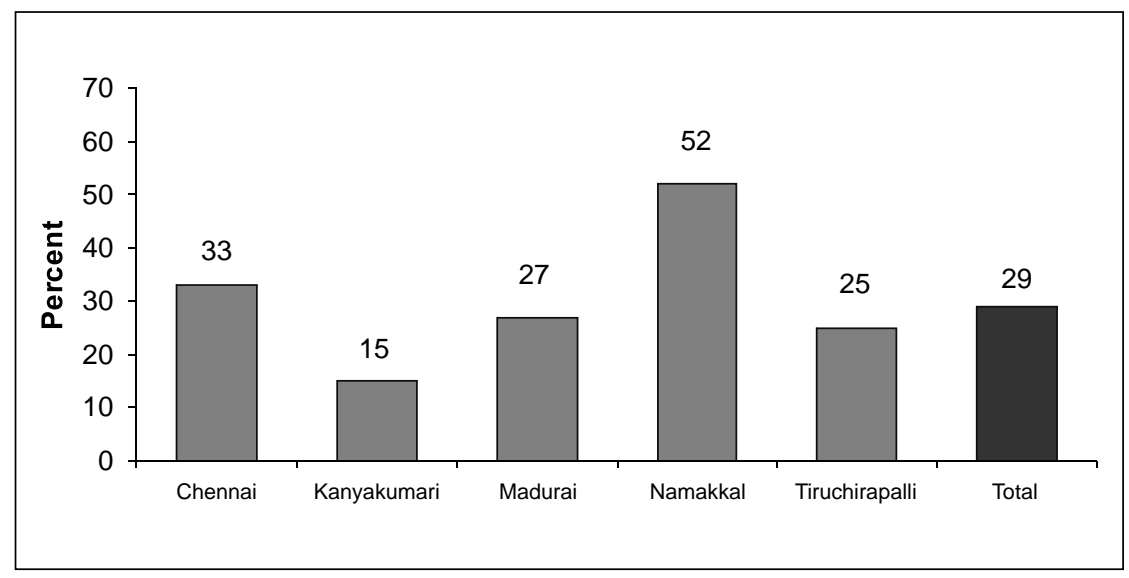

The data reveal that a vast majority (77 percent) of sex workers in Tamil Nadu are able to set aside money for themselves. This proportion is consistent across all the districts (see Figure 9 and Table 7).

\subsection{Physical violence}

Around 16 percent of sex workers in Tamil Nadu reported having been physically abused (beaten/hit/thrown out of the house) during the year prior to the survey. District-level variations were found in the prevalence of physical violence reported. The proportion was highest in Chennai (26 percent) (see Figure 10). The most frequently mentioned perpetrators of physical violence overall were the police (66 percent); police were mentioned most often in Kanyakumari (92 percent) followed by Tiruchirapalli ( 87 percent) and Namakkal (84 percent) (see Table 8$)$. 


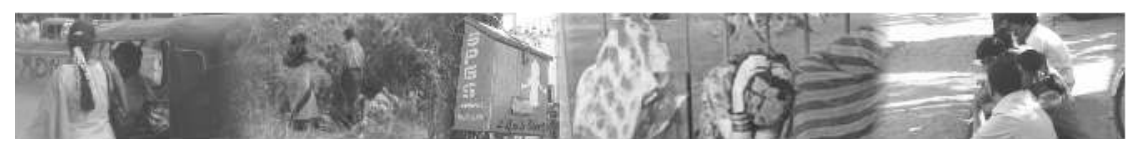

Figure 10 : Percentage of mobile female sex workers surveyed who reported that they had experienced physical violence at least once in the past year, by district, Tamil Nadu State, India

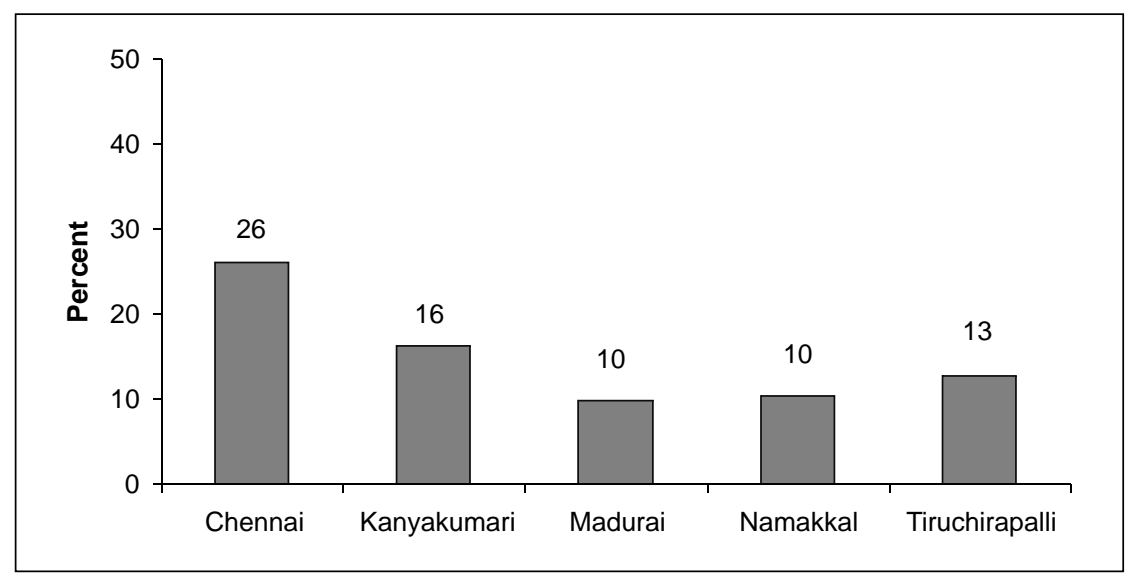

Findings from the qualitative survey also include FSWs' accounts of physical violence that they experienced at the hands of people associated with their profession, including rowdies, clients, brokers, and pimps.

"One day, one of the clients who was drunk had sex with me. For a long time he didn't withdraw from me. I told him that I am having pain in my vagina and to leave me. But he continued to have sex. I tried to pull away from him; he bit my hands very hard and they started bleeding. I pushed him and went to see a doctor near that lodge. I didn't even receive any money from the client." (35 years old, separated, lodge-based sex worker, Namakkal)

"I have no police problem, but I had a problem with rowdies. One enquired about my rates and asked me to have sex with him for less money. But later, he my purse, which was inside my blouse. Some clients have also cheated me. They had sex with me and did not pay." (27 years old, divorced, lodge-based sex worker, Chennai)

"Once, I had a sex in a broker's house at Kodaikanal with a drunken client. His activities gave me severe pain. When I resisted, he slapped me and told me to lie down. I asked him to leave me. He said that he would continue until ejaculation. I shouted and called the broker who scolded him and asked him to get out. He quarreled even with them." 


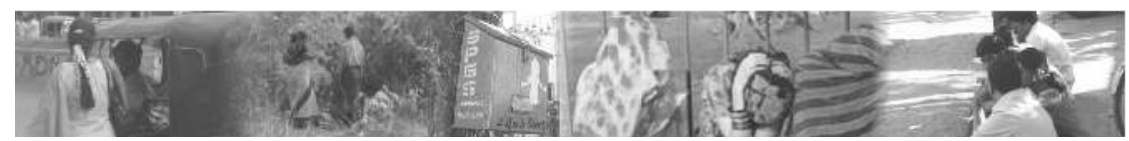

The same woman described another encounter pertaining to her vulnerability to HIV/AIDS.

"In Palani, when I had intercourse with a client, the condom was torn. I was so scared about HIV after that... . The TAI clinic teaches us about STIs, and they gave me treatment for that." (27 years old, married, lodge-based sex worker, Madurai).

\subsection{Exposure to the mass media and groups or associations}

The sex workers were asked questions about their exposure to the mass media including newspapers, magazines, radio, television, and cinema. Their responses indicate that nearly all of them watch movies and television (96 percent) (see Figure 11). This proportion is consistent across the study districts. Variations are found, however, across districts for exposure to radio. The proportion of respondents who listen to the radio range between 31 percent in Kanyakumari and 72 percent in Namakkal. A similar pattern is observed in all the districts with regard to reading newspapers and magazines and ranges from 30 to 41 percent among the FSWs (see Table 9).

Figure 11 : Percentage of mobile female sex workers surveyed who reported that they had watched television in the month prior to the survey, by district, Tamil Nadu State, India

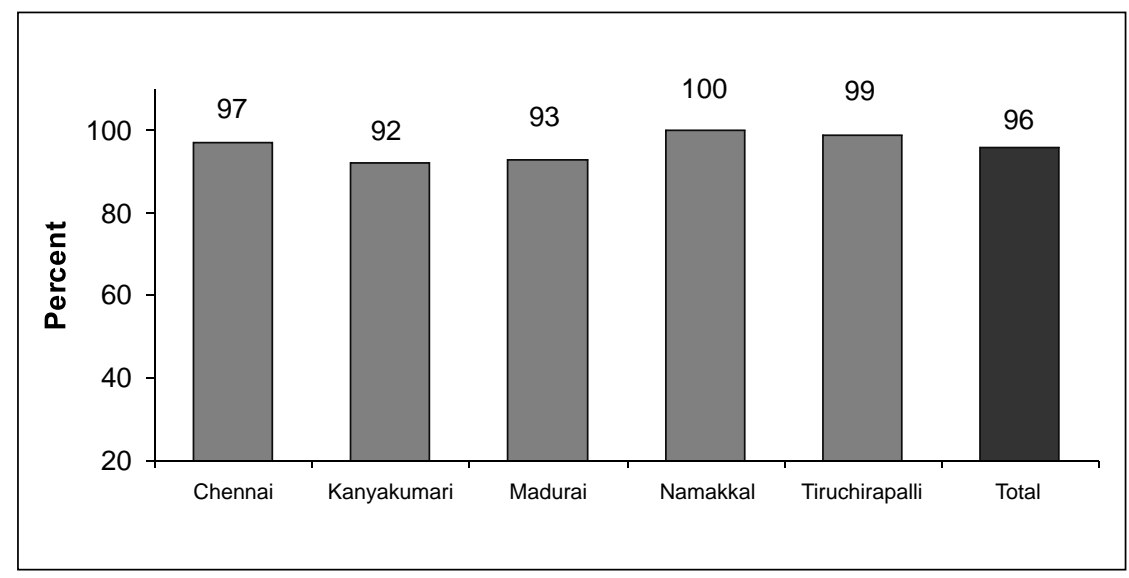




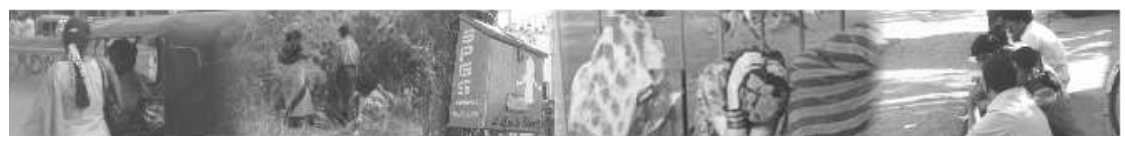

Only three-fourths of the FSWs are members of or exposed to self-help groups, NGOs, community-based organizations and/or collectives. Whereas more than 90 percent are associated with social organizations in Madurai and Namakkal, only around two-thirds in Chennai and Kanyakumari reported such memberships (see Table 10).

Because three-fourths of the FSWs are associated with an organization of some sort, their exposure related to intervention programme related to the issues is moderate. Seventy percent reported having received program benefits such as condoms (more than 90 percent in Madurai and Namakkal), 60 percent have gained knowledge of STDs, and about 40 percent have availed themselves of referral services to health centers. The benefits received by FSWs in Kanyakumari District are comparatively poor. The NGO programme's outreach is high; more than 70 percent of respondents received support, and half have been approached by government outreach workers. Female sex workers in Madurai reported maximum contact from outreach workers from Avahan (92 percent; such contact was low in Kanyakumari (32 percent) and only 11 percent in Tiruchirapalli. Most of the FSWs availed themselves of the services of STI clinics run by NGOs or private doctors (61 percent).

The findings of the qualitative survey reveal that FSWs benefit from NGOs in many ways and that NGOs play a key role in educating them and supplying them with condoms. The NGOs outreach staff also educate the FSWs about STIs including HIV and provide referrals or treatment to symptomatic women.

"I am going to NGOs to have regular checkups. Condoms are available free here. ... I am aware of HIV/AIDS and STIs through NGOs." (38 years old, separated, street-based sex worker, Madurai)

"When I was selling flowers in Kaylipalayam, a field officer from NGO enquired about my flower business and then invited me to the NGO office and said they would help me. I have been in touch with the NGO for the past four years. Some of the benefits I receive through the NGO are the access to a clinic, to regular medical check-ups, and to a variety of programmes and training in work such as basketweaving, tailoring, mat weaving, and making incense sticks and cigarettes." (35 years old, separated, sex worker, Madurai) 


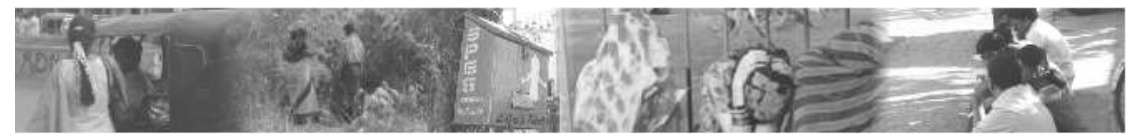

"My friend introduced me to DESH NGO. I learned more about condoms, STIs, and HIV/AIDS. . . . These days, I use condoms regularly." (35 years old, separated, street-based sex worker, Chennai)

"After I came to know the Anbalayam NGO, I learned more about HIV. I have been taking ART tablets for the past four years. Once every three months I go for a test at the NGO or at the general hospital." (36 years old, deserted, homebased sex worker, Tiruchirapalli)

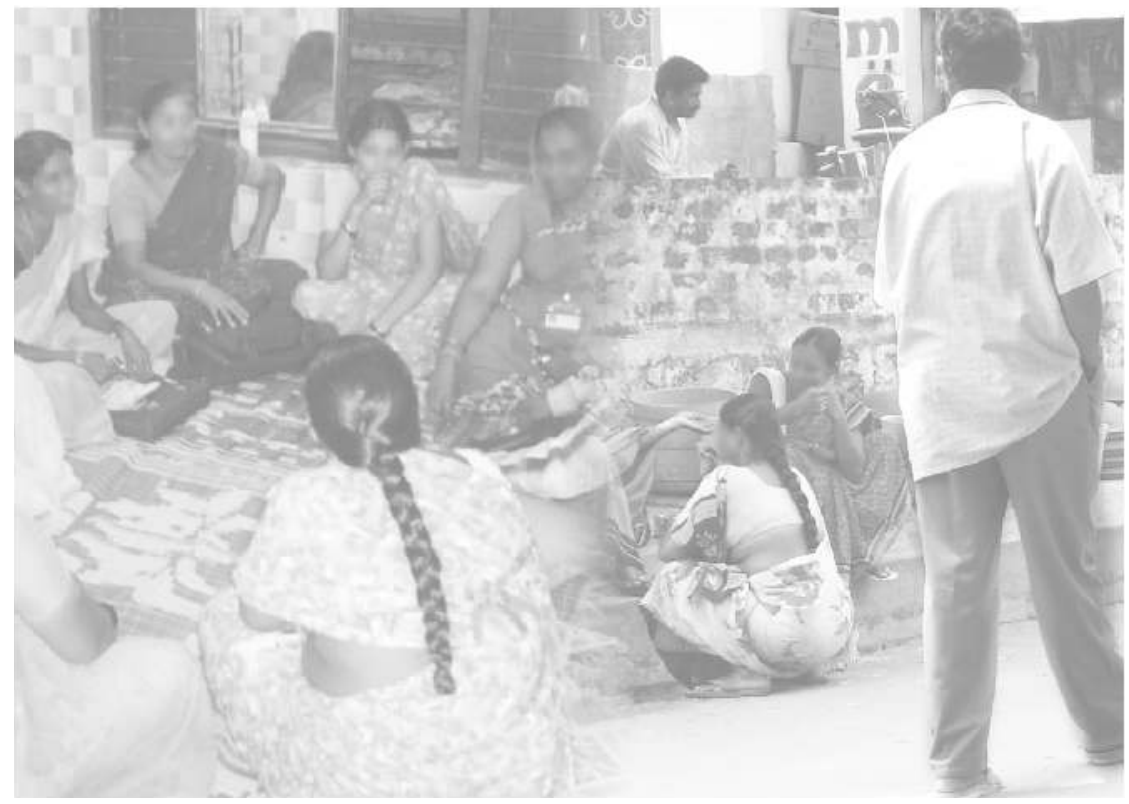




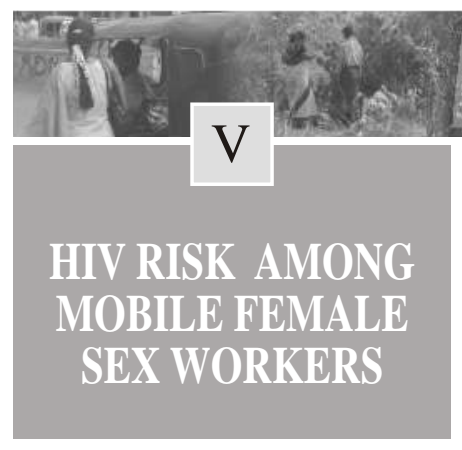

The risk to FSWs of acquiring STIs/HIV has been assessed in terms of the availability, accessibility, and ability to use condoms with their clients. Specifically, it is assessed in terms of such indicators as consistent condom use with occasional clients, regular clients and nonpaying partners; experience of STI symptoms; continuing to have sex while experiencing STI symptoms; experience of sexual violence and condom use during an incident of violence; and self-perception of the risk of HIV. In this study, these indicators are crosstabulated with condom-negotiation variables, sociodemographic and economic characteristics, alcohol use, experience of violence, and mobility. The association between FSWs' degree of mobility and the indicators of their HIV risk are examined below.

\subsection{Condom use}

More than four-fifths of the sex workers surveyed reported using condoms consistently with various types of clients; the reported level of such use is found to be consistent across all study districts. Although district-level variations were found, about 87 percent of the sex workers interviewed reported consistent use of condoms with any client, with proportions ranging from 67 percent in Madurai to 96 percent in Tiruchirapalli (see Table 11). In Tiruchirapalli, Namakkal and Chennai districts, more than 90 percent of FSWs reported condom use with different types of clients (see Figure 12). In Kanyakumari and Madurai districts, consistent condom use with nonpaying partners is reduced to only 50 and 42 percent, respectively, which poses a risk of vulnerability to HIV for these sex workers.

The qualitative findings also indicate that the majority of the FSWs use condoms with their partners; some have reported not using condoms as a result of resistance or threats from their clients or because they are offered more money for having sex without a condom.

"Earlier, I did not know about condoms. One of my FSW friends told me about them; she is like a god to me. I understood the advantage of Nirodh, that you cannot suffer your whole life long for five minutes of happiness. I don't have sex without condoms with anybody now." (29 years old, widowed, street-based street worker, Namakkal) 


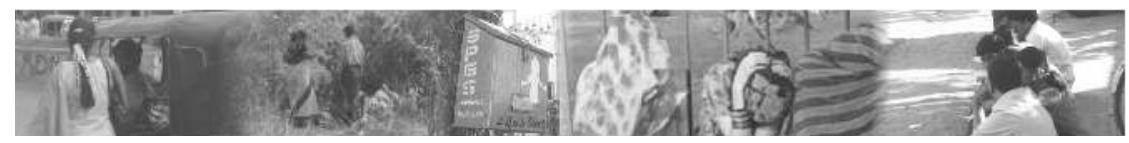

Figure12 : Percentage of mobile female sex workers surveyed who reported using condoms consistently, by type of partner, according to district, Tamil Nadu State, India

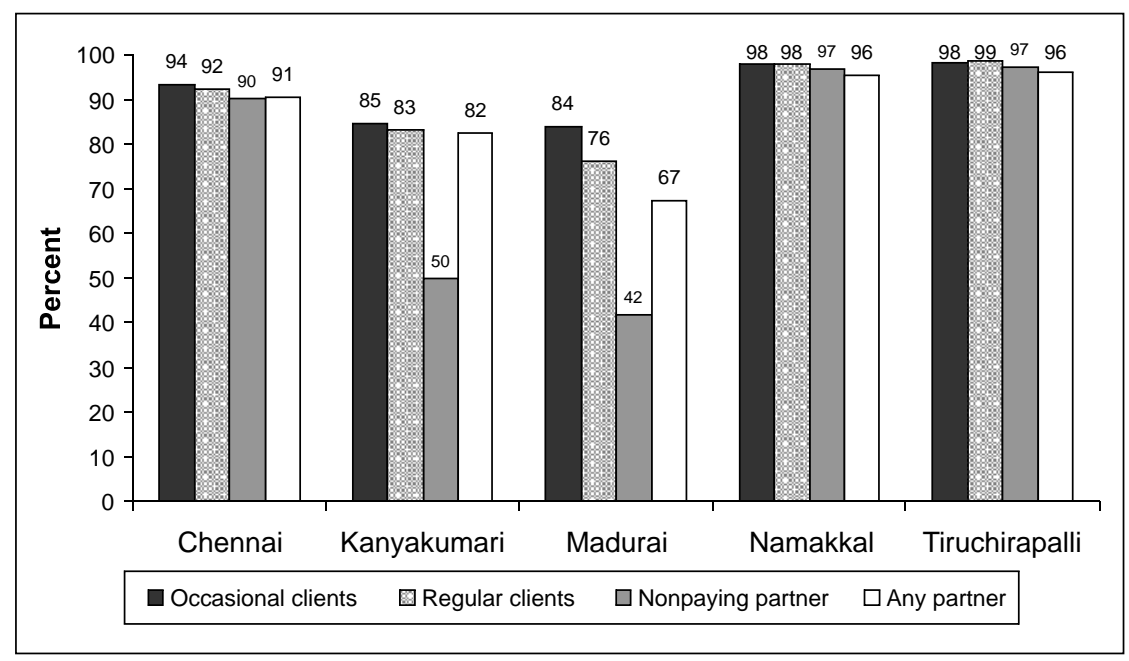

"Once a client was both drunk and had taken ganja. He threatened me with a knife to make me have sex without a condom. I agreed to it because I didn't want to lose a client. This has happened three times in the past three months. It is easy to make the clients who are older than 35 understand the need to use a condom." (35 years old, separated, home-based sex worker, Madurai)

"I did not know about condoms at that time. I asked my client, and he clarified that men or women who have more than one sex partner should use condoms to escape from AIDS. I started using condoms after getting in touch with the $N G O$. . . I stayed at a lodge in Koyambedu, Chennai, with my client four months ago. ... Two more of his friends joined us there, and I used condoms with all of them." (25 years old, married, home-based sex worker, Chennai) 5.2 Self-reported STI symptoms 


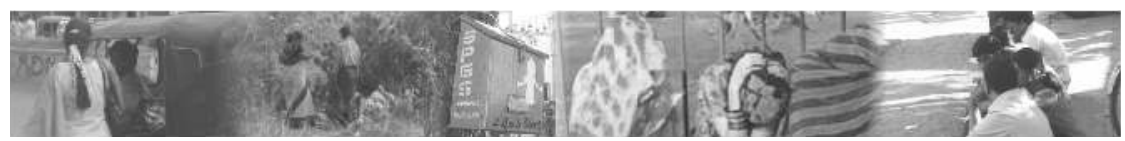

Around three-fifths of the mobile FSWs reported having had one or more of eight STI symptoms, and only 4 percent continued to have sex while they had the STI symptom(s) (see Table 11). A significant district-level variation was found in the prevalence of STI symptoms among the FSWs. The highest proportion was observed in Namakkal (82percent) followed by Tiruchirapalli (61percent) and Chennai (59 percent) (see Figure 13).

Figure 13 : Percentage of mobile female sex workers surveyed who reported having had at least one STI symptom, by district, Tamil Nadu State, India

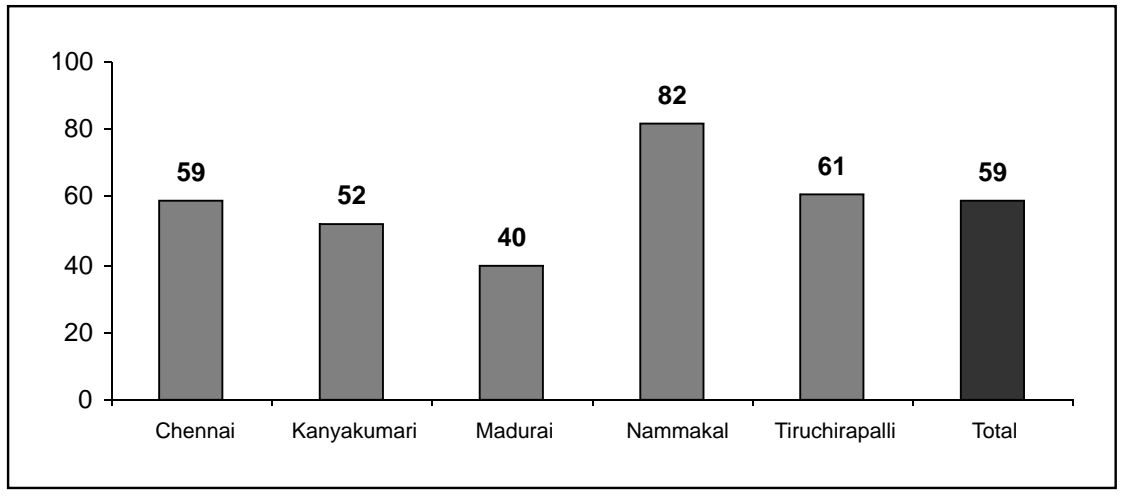

\subsection{Perception of HIV risk}

More than two-thirds of the sex workers said that they had a low perception of their own HIV risk; 31 percent, however, perceived themselves to be at moderate risk for the infection. In Kanyakumari and Namakkal, slightly less than half of the sex workers perceived themselves to be at moderate risk (see Table 11).

\subsection{Ability to use condoms and actual condom use}

More than one-fourth of the sex workers surveyed reported that they did not use condoms because they were unavailable. This proportion was consistent across all the districts studied except Namakkal, where 43 percent of the sex workers reported that condoms were unavailable. One-fifth of the sex workers reported 


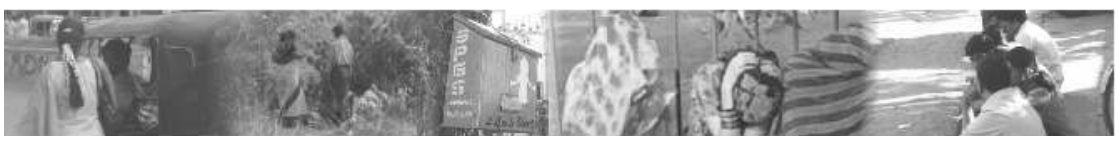

nonuse of condoms because clients refused to use them. The highest proportion of nonuse for this reason was reported in Namakkal (43 percent). Only 45 percent of the respondents said they were able to convince their clients to use condoms after the clients had refused to use them. This proportion was higher in Namakkal (78 percent, and 57 percent in Chennai) (see Table 12).

As noted above, 59 percent of the sex workers surveyed across Tamil Nadu reported consistent condom use with any sexual partner. At the same time, more than four-fifths of respondents admitted that they had had sex with various partners without using condoms because they were unavailable (see Table 13). Among the sex workers who said that they did not use condoms because of their unavailability, 81 percent reported having STI symptoms in the six months prior to the survey, and 56 percent reported a moderate perception of their own risk of acquiring HIV infection.

Nearly four-fifths of all the sex workers interviewed reported that sometimes they agreed to the customer's demand to have sex without a condom. Ninetyone percent of these sex workers reported at least one symptom of an STI, and 11 percent continued to have sex despite having a symptom. About two-thirds of these women had a moderate perception of their own risk of acquiring HIV infection.

About 90 percent of the sex workers in Tamil Nadu were not able to convince their clients to use condoms, and this proportion is consistent across all the study districts (not shown). However, 68 percent of these sex workers reported at least one STI symptom, and 38 percent had only a moderate perception of their own risk of acquiring HIV.

From the qualitative findings it is evident that the FSWs refuse to have sex without condoms. In a few cases, however, the FSWs do not use condoms because they would lose clients if they insisted.

"I use condoms with everybody that I have sex with; 50 percent of my clients are not interested in using condoms, but I insist on it. I explain to them about STIs and HIV/AIDS when they refuse to use a condom." (38 years old, married, home-based sex worker, Chennai)

"Out of 100, 50 men prefer to have sex without using a condom. If the customer refuses, then I refuse to have sex with him. I have not had sex without a condom in the past five years." (35 years old, deserted, home-based sex worker, Madurai) 


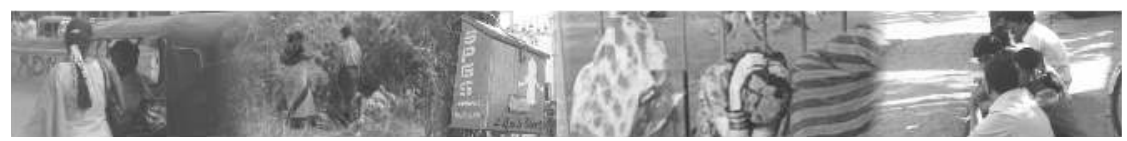

"Sometimes I carry condoms with me. Some of the clients are not interested in using condoms. I insist that they use them, but they refuse. If I force them to use one, they just leave, and my income is affected. That is why I agree to have sex without condom use. I insist with most of my clients, but a few won't agree." (34 old, separated, lodge-based sex worker, Namakkal).

\subsection{Socioeconomic insecurity and HIV Risk}

Eighty percent of those sex workers who reported experiencing physical violence during the year prior to the survey also reported having at least one STI symptom during the past six months, and about half of them had perceived themselves to be at moderate risk of acquiring HIV (see Figure 14).

Figure 14 : Percentage of mobile female sex workers surveyed who reported that they had experienced physical violence, used condoms consistently, had STI symptoms, and perceived themselves to be at moderate risk of HIV infection, Tamil Nadu State, India

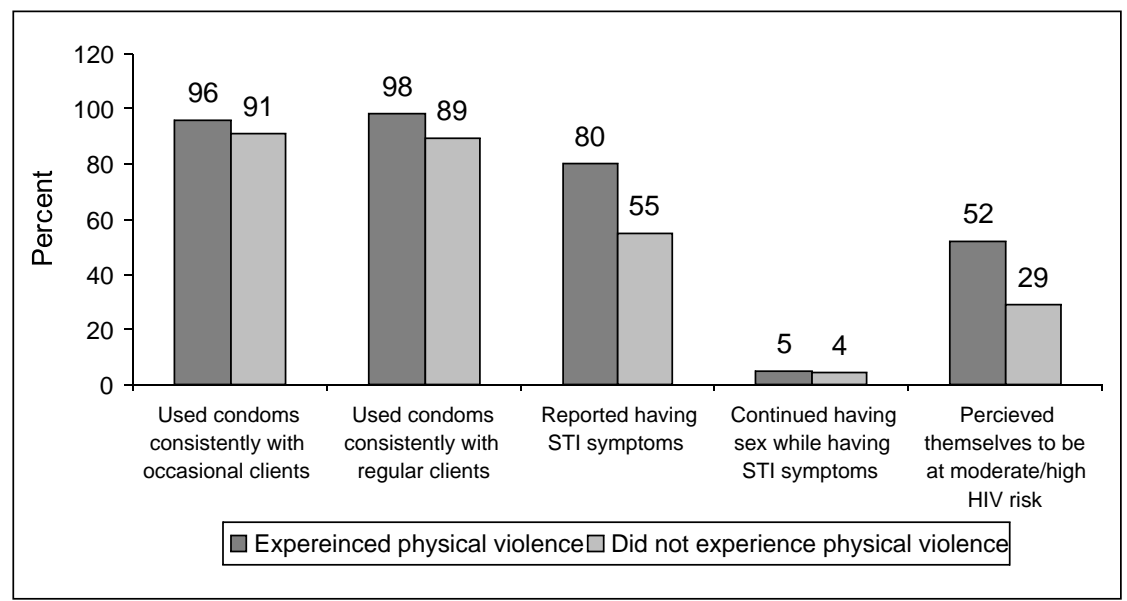

The survey findings also suggest that sex workers' vulnerability to HIV increased with alcohol use, dependence on sex work for a living, indebtedness, and destitution (see Table 14). Consistent condom use was higher, however, among those sex workers who reported sex work as their sole source of income (91 percent). 


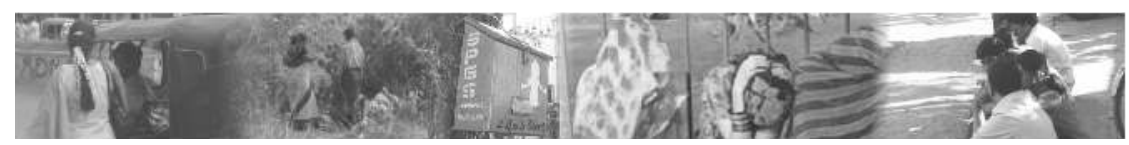

Figure 15 : Percentage of mobile female sex workers surveyed who reported using condoms consistently with different types of partners, by marital status, Tamil Nadu State, India

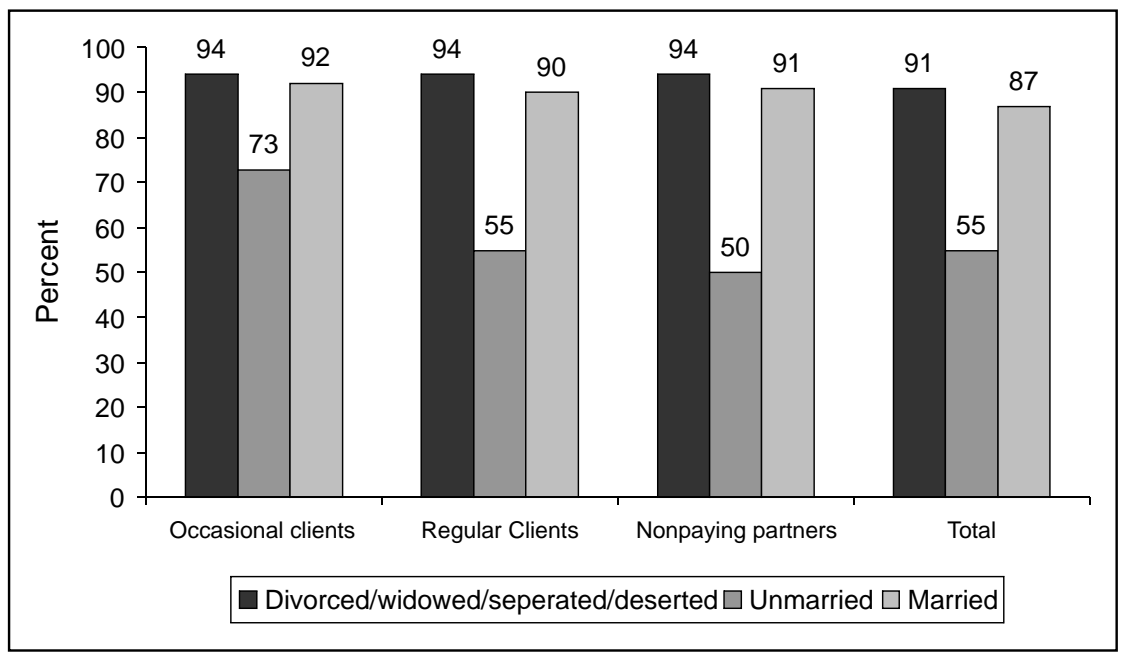

Although the survey's qualitative findings indicate that FSWs are usually able to negotiate condom use with their clients, thereby reducing their vulnerability to HIV/AIDS. Constant threats to their social and economic security increase that vulnerability to infection.

"My husband died in a road accident. Because of my poor financial situation, I borrowed money from my landlord for the treatment of my son who was suffering from severe fever. . . My landlord forced me to have sex. He closed the door and told me that he won't ask me for the money back if I have sex with him. I had no option. The arrangement continued for two to three months.... I am HIV-positive." (30 years old, widowed, lodgebased sex worker, Namakkal)

"Six men were plucking coconut from the trees near the spot where I was having sex with a client..... they threatened me with a knife and said that they will kill and bury me if I shout. In the meantime, the taxi driver and the client with whom I came left the place. None of the men used condoms while having sex with me." (40 years old, married, street-based sex worker, Kanyakumari) 


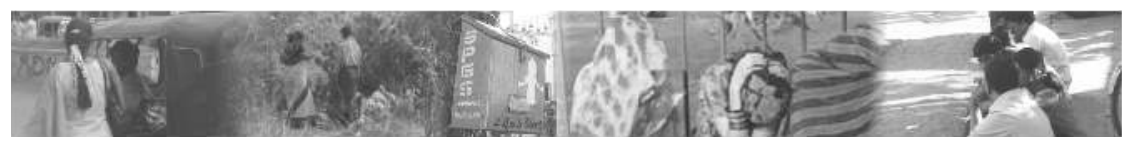

"Initially I felt bad, but then I agreed to have sex with a man because I needed money. We had sex in my neighbour's house. He paid me Rs.500, and we did not use condoms." (28 years old, married, home-based sex worker, Kanyakumari)

Some of the FSWs have reported not using condoms when they began to do commercial sex work.

"During the first sex I ever had with an outside man, I did not use a condom with him." (32 years old, deserted, lodge-based sex worker, Kanyakumari)

"In my first commercial sexual contact outside, I went to Bangalore with a local client, and I stayed in a lodge for three days. He and his three friends came who were nearly 40 years old, and I attended everybody. They gave Rs.3,000, and I didn't use condoms." (27 years old, separated, street-based sex worker, Chennai)

\subsection{Degree of mobility and HIV risk}

The measure of sex workers' mobility was constructed as (1) those who visited only two locations; (2) those who visited three to four locations and (3) those who visited five or more locations. About 90 percent of the FSWs surveyed reported using condoms consistently with different types of clients when they visited or stayed at three to four and five or more locations. Consistency of condom use is slightly lower among those who visited or stayed in two places (see Figure 16). However, a greater proportion of sex workers who visited more than three places as compared to those moved to only two places, perceived that they have a high-to-moderate risk of acquiring HIV, and more than twothirds of this group reported having at least one STI symptom (see Table 15).

FSWs' reporting of consistent condom use with regular and nonpaying clients is lower compared with condom use with occasional clients when the sex workers visit jataras. The risk increases if they visit jataras alone rather than in a group. Reporting of STI symptoms is higher among those FSWs who visit jataras and is also higher among those who visit them alone (see Table 15). 


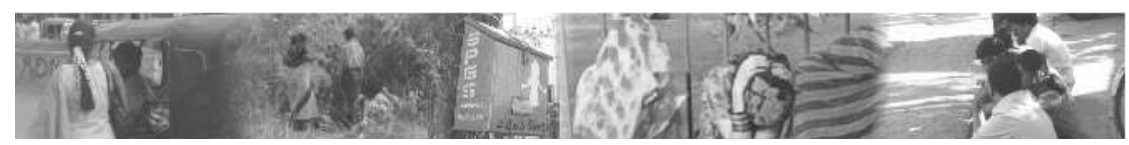

Figure 16 : Percentage of mobile female sex workers surveyed who reported using condoms consistently with different types of clients, by their degree of mobility, Tamil Nadu State, India

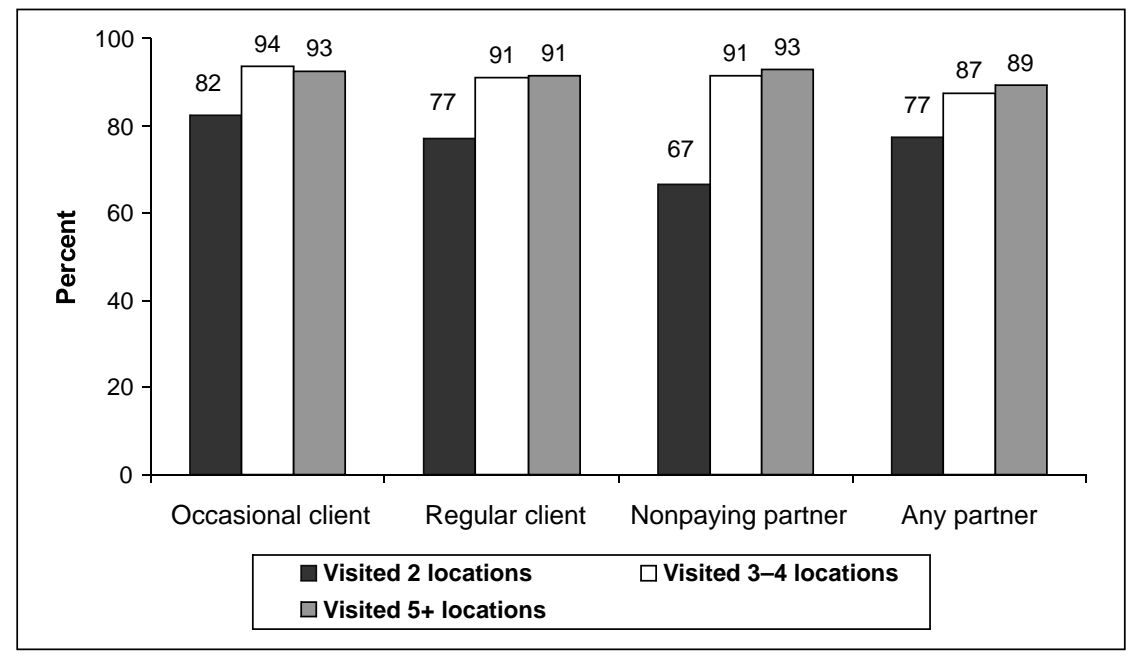

The condom use among mobile female sex workers in Tamil Nadu is already high and it does not show any major differences in the consistent condom use by mobility or the duration of migration. Experience of STI symptoms during the past six months did not show any pattern according to the levels of migration duration. Responses to questions about HIV risk perception are mixed and follow no pattern. Sex workers who migrated for more than two years had a higher perception of their vulnerability to HIV risk than did those who migrated for less than two years.

Consistent condom use seems to be affected by the number of locations visited and by type of sex-work practice. Among the separate categories of sex workers, consistent condom use is almost same across all the number of locations visited. A relatively larger number (more than 90 percent) of sex workers situated in brothels reported consistent condom use with different 


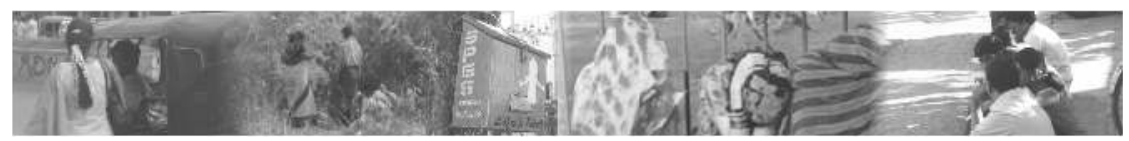

types of clients, although the sample is not large enough to draw any conclusions. Tamil Nadu has more street-based sex workers than other kinds, and the data suggest that with the increase in their mobility, consistent condom use with clients has also increased. On average, more than four-fifths of the sex workers reported consistent condom use with clients (see Table 17). Little variation is found in condom use among sex workers who have had experienced STI symptoms during the past six months. Less than 10 percent reported experiencing physical violence across all levels of migration duration and all types of sex workers.

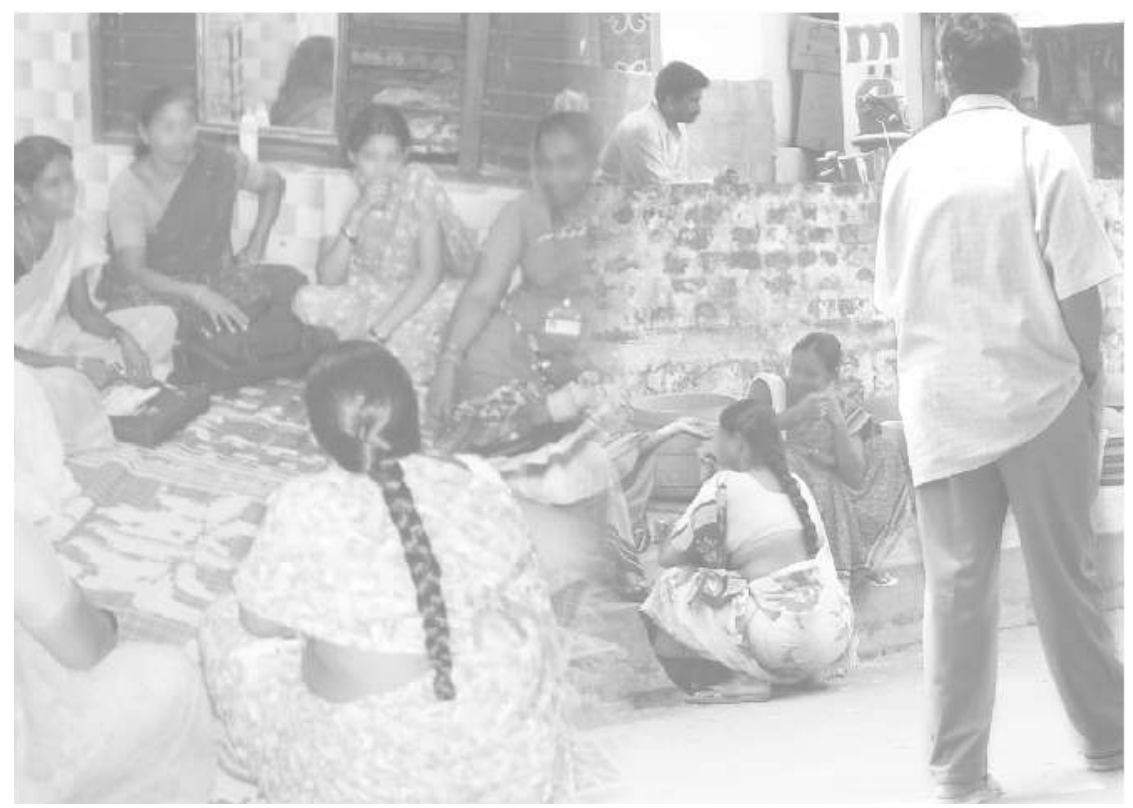


Clearly, the female sex workers of Tamil Nadu are mobile to a large extent. About 58 percent of sex workers have moved across at least one district during the past two years and, on average, across four districts in the past two years. To target such a mobile community, places of solicitation and places where sex is performed may be the best points to obtain the optimum reach with an HIV-prevention intervention. In order to determine if this is the case, background information was collected from the sex workers about the places where they solicit clients and have sex. The anticipated proportion of mobile sex workers who could be covered by an intervention and the number of times each woman would likely interact with the programme were calculated by using the most-commonly-reported five places for solicitation or sex.

\subsection{Locations for sex work}

In Tamil Nadu, sex workers solicit sex commonly at railway stations (71 percent), bus stands (65percent), and marketplaces (32 percent) (see Figure 17). This pattern is consistent across all districts except Chennai. More than half of the sex workers in Chennai reported that they solicit in cinema halls, and around 37 percent solicit in hotels and lodges.

\section{Figure 17 : Percentage distribution of mobile female sex workers, by places where they solicit clients, Tamil Nadu State, India}

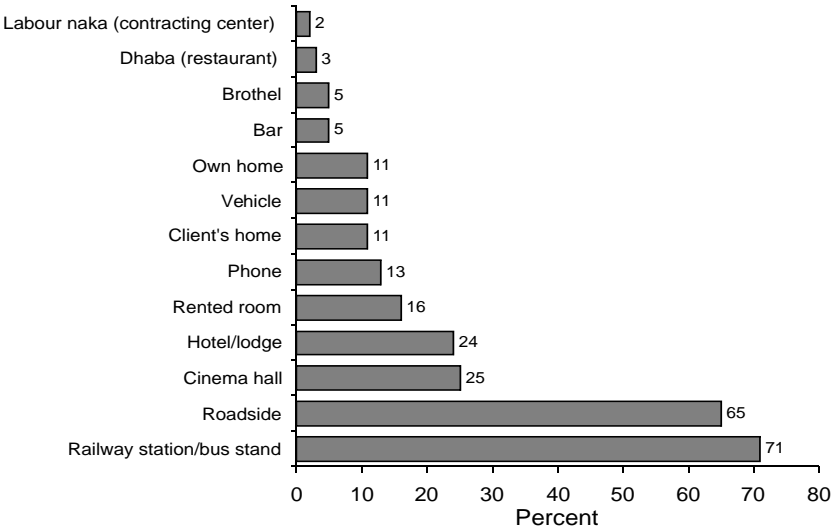




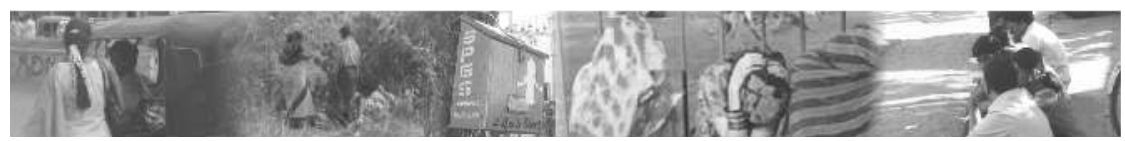

Similarly, sex workers listed numerous sites where they had sex with their customers. The most frequently mentioned were hotel/lodge (69 percent), rented rooms (49 percent), and the woman's own home (34 percent) (see Figure 18). This pattern is consistent across all of the districts studied (see Table 18).

Figure 18 : Percentage distribution of mobile female sex workers surveyed, by places where they have sex with clients, Tamil Nadu State, India

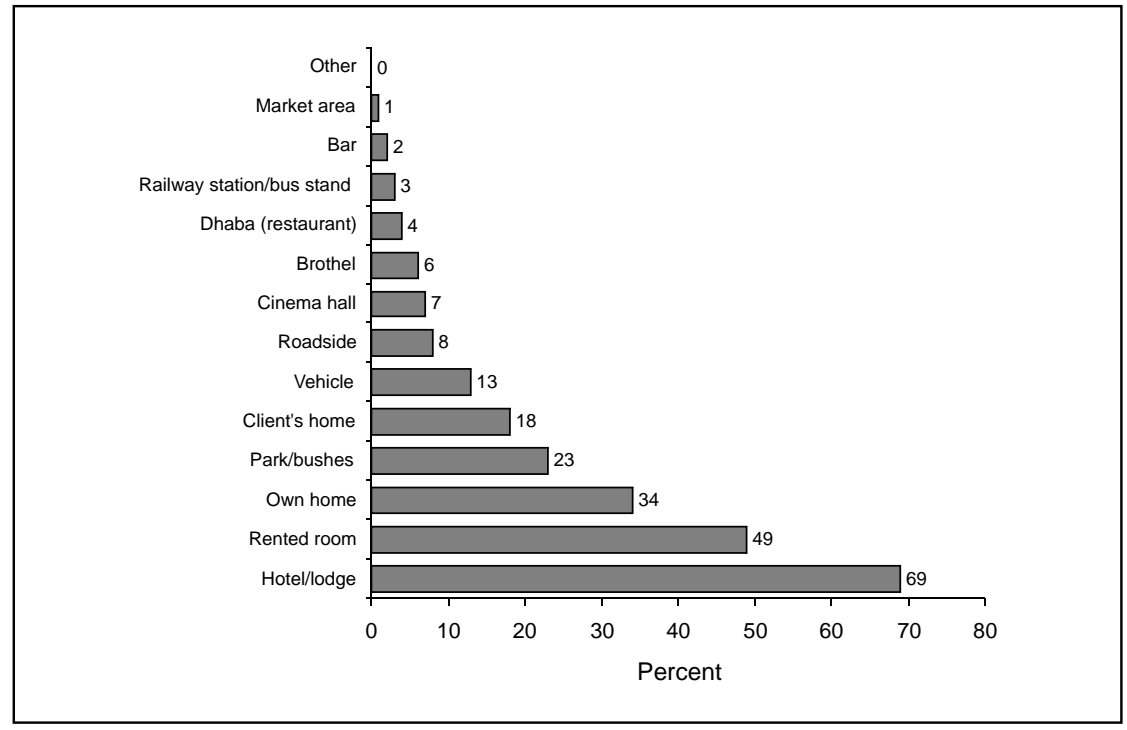

On examining the association between the place of contact and the location where they have sex, most commonly mentioned for all types of sex workers were railway stations and bus stands (71 percent), hotels (71 percent) and roadsides (65 percent) (see Figure 19 and Table 18). Street-based and highwaybased FSWs mentioned railway stations as the most suitable place for solicitation and having sex. 


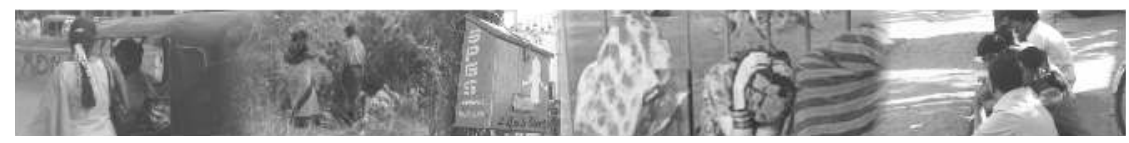

Figure 19 : Percentage of distribution of mobile female sex workers surveyed, by places where they solicit clients or have sex, Tamil Nadu State, India

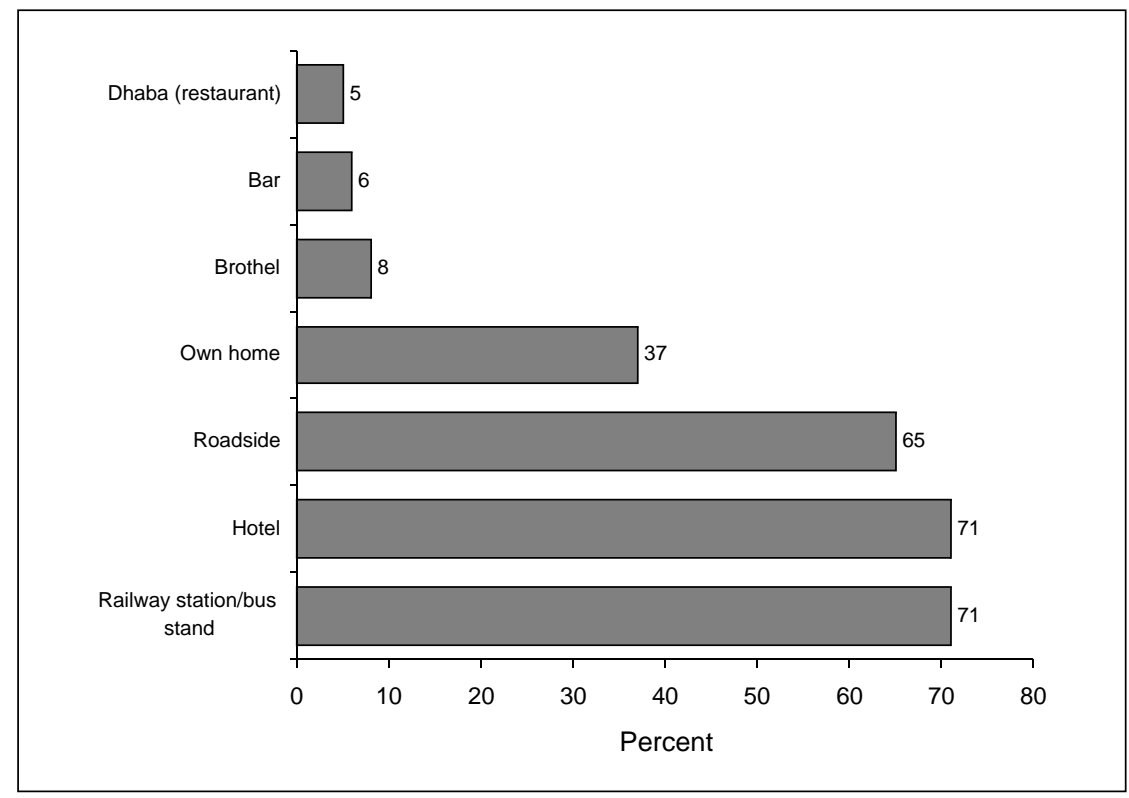

\subsection{HIV-prevention programme coverage of FSWs}

Hotels/lodges, railway stations/bus stands, marketplaces, brothels, and dhabas (popular restaurants) are the main locations where the women solicit clients or have sex, and that also are potential locations for programme intervention points. Other places frequently mentioned are the roadside, open spaces and homes, but these places are difficult to reach with programme interventions. Anticipated programme coverage in each district can be estimated by adding together the proportions of sex workers who report that they solicit/have sex at each place. 


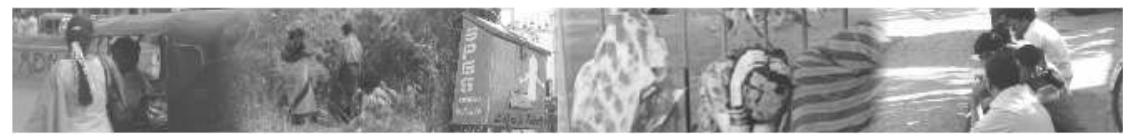

As shown in Table 20, more than 90 percent of the mobile FSWs surveyed can be contacted by simultaneously covering the following five places: brothels, dhabas, railway stations/bus stands, bars, and hotels.

The results also suggest that a large majority of mobile FSWs in Tamil Nadu solicit clients or have sex in railway stations/bus stands, hotels, on the roadside, and in their own homes. Targeting FSWs on the roadside would be difficult, however, because the workers shift their solicitation points. In Tamil Nadu, railway stations and bus stands are already covered by the intervention. Efforts may be stepped up to target interventions in hotels, brothels, and large migrant sites where many of the sex workers' clients live, work, and gather. If these five places are targeted in each district, the FSWs are likely to receive programme information at least twice in a short time.

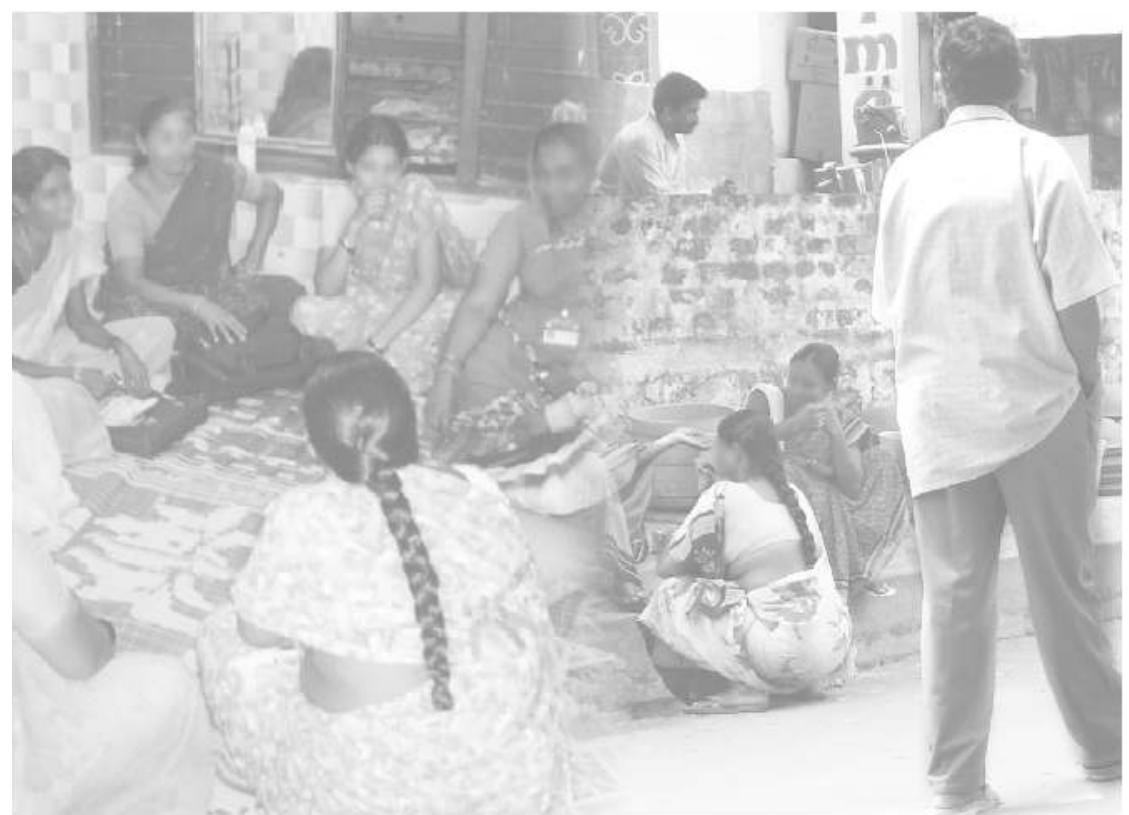




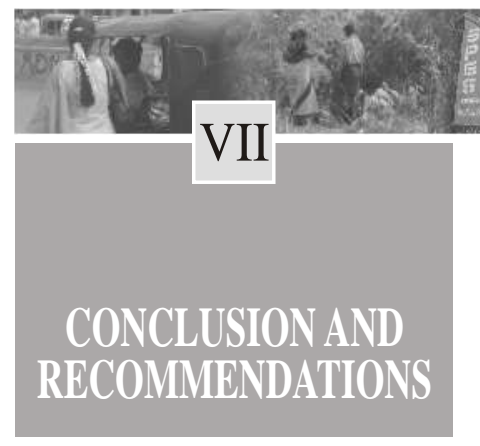

The recommendations from this study are;

brothels, and the vicinity of wine shop.

- The most likely places to contact mobile female sex workers for programme interventions are railway stations, bus stands, hotels, and

- FSWs who move frequently to different locations and who visit other areas for short periods are at greater risk of acquiring HIV infection than their less mobile counterparts; special efforts are required to cover these sex workers with HIV-prevention interventions.

- District-specific interventions are essential and must be scaled up in districts such as Kanyakumari, Madurai and Tiruchirapalli in order for them to have optimum impact, because HIV vulnerability varies substantially from district to district.

- Interventions should also be targeted on clients of FSWs through a multipronged programme approach implementing effective prevention strategies.

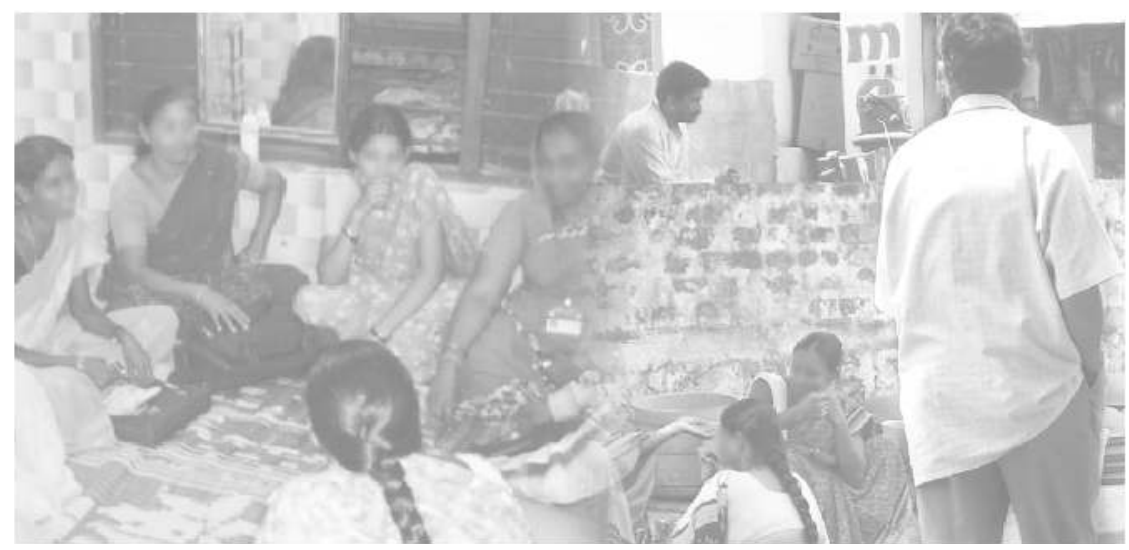




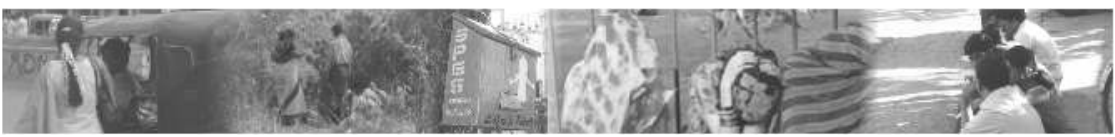

\section{APPENDIX}

Table 1: Percentage of female sex workers surveyed by district, type of location, place of contact, and age group, according to number of times they moved to obtain sex work and number of times they moved across the district, Tamil Nadu State, India

\begin{tabular}{|c|c|c|c|c|c|c|c|c|c|}
\hline \multirow[b]{2}{*}{ Characteristic } & \multicolumn{3}{|c|}{$\begin{array}{c}\text { Number of moves in past two } \\
\text { years }\end{array}$} & \multicolumn{3}{|c|}{$\begin{array}{l}\text { Number of moves across } \\
\text { district in the past two years }\end{array}$} & \multirow{2}{*}{$\begin{array}{l}2+\text { moves and } \\
\text { at least one } \\
\text { across district }\end{array}$} & \multirow{2}{*}{$\begin{array}{l}\text { Moved } \\
\text { across } \\
\text { states }\end{array}$} & \multirow[b]{2}{*}{ (n) } \\
\hline & $1+$ & $2+$ & Average & $1+$ & $2+$ & Average & & & \\
\hline \multicolumn{10}{|l|}{ District } \\
\hline Chennai & 72.4 & 68.5 & 3.7 & 52.5 & 44.7 & 3.3 & 49.9 & 12.0 & (667) \\
\hline Kanyakumari & 88.8 & 88.8 & 6.0 & 78.9 & 78.9 & 3.8 & 78.9 & 42.7 & (403) \\
\hline Madurai & 90.0 & 88.1 & 4.5 & 81.8 & 78.4 & 3.8 & 79.2 & 13.8 & (269) \\
\hline Namakkal & 88.1 & 88.1 & 4.6 & 52.2 & 51.9 & 4.5 & 52.2 & 8.6 & (395) \\
\hline Tiruchirapalli & 75.8 & 75.4 & 4.7 & 49.8 & 44.6 & 4.1 & 48.5 & 7.3 & (641) \\
\hline \multicolumn{10}{|l|}{ Type of location } \\
\hline Urban & 79.9 & 78.3 & 4.7 & 60.9 & 56.3 & 3.8 & 59.5 & 16.8 & $(1,971)$ \\
\hline Rural & 84.4 & 83.9 & 4.6 & 52.2 & 51.5 & 4.3 & 51.7 & 9.7 & $(404)$ \\
\hline \multicolumn{10}{|l|}{ Place of contact } \\
\hline Brothel & 78.6 & 77.4 & 4.7 & 64.3 & 61.9 & 3.8 & 63.1 & 21.4 & (84) \\
\hline Lodge & 85.1 & 85.1 & 5.2 & 70.3 & 66.2 & 4.2 & 67.6 & 25.7 & (74) \\
\hline Street & 81.6 & 79.8 & 4.5 & 59.2 & 55.4 & 3.8 & 57.9 & 16.3 & $(1,369)$ \\
\hline Home & 73.8 & 72.8 & 4.6 & 56.3 & 51.3 & 3.5 & 55.8 & 13.0 & (378) \\
\hline Highway & 83.2 & 82.3 & 4.9 & 60.0 & 56.4 & 4.1 & 58.5 & 13.0 & $(470)$ \\
\hline \multicolumn{10}{|c|}{ Age group (years) } \\
\hline $15-19$ & 88.2 & 86.5 & 4.8 & 20.2 & 19.1 & 2.5 & 1.9 & $1.1^{\mathrm{a}}$ & (178) \\
\hline $20-24$ & 65.5 & 64.1 & 4.6 & 17.1 & 16.1 & 2.8 & 16.1 & 3.7 & (516) \\
\hline $25-29$ & 69.0 & 67.7 & 4.5 & 55.4 & 53.7 & 3.9 & 53.7 & 12.8 & (523) \\
\hline $30-34$ & 88.1 & 86.6 & 4.6 & 78.6 & 77.4 & 4.1 & 77.4 & 21.7 & (411) \\
\hline $35-39$ & 94.8 & 93.8 & 4.6 & 91.8 & 90.8 & 3.9 & 90.8 & 21.1 & (403) \\
\hline $40+$ & 91.9 & 90.1 & 5.0 & 88.4 & 86.9 & 4.0 & 86.7 & 31.4 & (344) \\
\hline Total percent & 80.7 & 79.3 & 4.7 & 59.4 & 55.5 & 3.9 & 58.1 & 15.6 & - \\
\hline$(\mathbf{N})$ & $(2,375)$ & $(2,375)$ & - & $(2,375)$ & $(2,375)$ & - & $(2,375)$ & $(2,375)$ & $(2,375)$ \\
\hline
\end{tabular}

${ }^{\mathrm{a}}$ Fewer than ten cases. $-=$ Not applicable.

Source : Screening questionnaire.

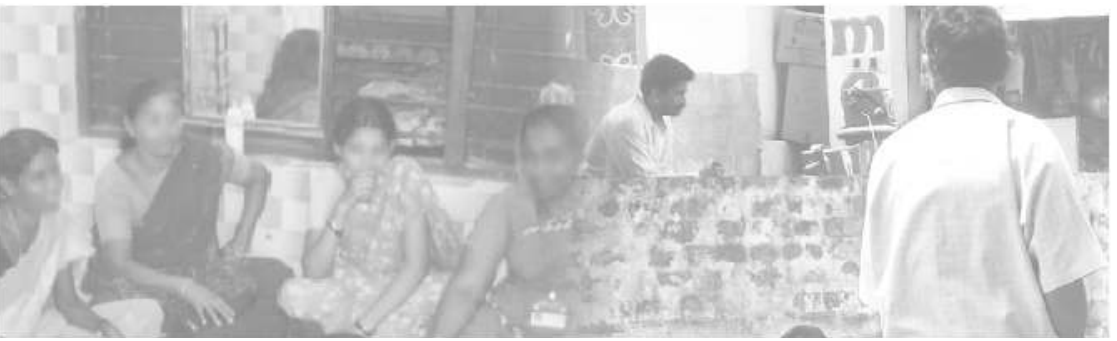


Table 2 : Percentage of female sex workers surveyed, by place of contact and age group, according to district, Tamil Nadu State, India

\begin{tabular}{lccccccc}
\hline \multicolumn{1}{c}{ Characteristic } & Chennai & Kanyakumari & Madurai & Namakkal & Tiruchirapalli & Total & (n) \\
\hline $\begin{array}{l}\text { Age group (years) } \\
\text { 15-19 }\end{array}$ & 24.4 & 40.0 & $70.0^{\mathrm{a}}$ & $1.9^{\mathrm{a}}$ & $10.9^{\mathrm{a}}$ & 19.1 & $(178)$ \\
$20-24$ & 21.3 & 24.1 & 44.7 & $5.7^{\mathrm{a}}$ & 7.9 & 16.1 & $(516)$ \\
$25-29$ & 42.6 & 86.1 & 67.2 & 56.4 & 41.9 & 53.7 & $(523)$ \\
$30-34$ & 61.2 & 94.4 & 95.2 & 80.3 & 76.6 & 77.4 & $(411)$ \\
$35-39$ & 79.2 & 92.8 & 92.6 & 96.4 & 96.9 & 90.8 & $(403)$ \\
40+ & 75.3 & 93.5 & 90.0 & 100.0 & 82.1 & 86.9 & $(344)$ \\
\hline Place of contact & & & & & & \\
Brothel & 73.3 & 83.3 & 88.9 & $40.9^{\mathrm{a}}$ & 57.7 & 63.1 & $(84)$ \\
Lodge & 50.0 & 80.0 & 90.0 & $50.0^{\mathrm{a}}$ & na & 67.6 & $(74)$ \\
Street & 48.4 & 77.2 & 76.8 & 53.3 & 46.7 & 57.9 & $(1,369)$ \\
Home & 47.9 & 86.0 & 82.9 & 54.5 & 46.6 & 55.8 & $(378)$ \\
Highway & 53.0 & 80.0 & 81.6 & 51.7 & 54.5 & 58.5 & $(470)$ \\
\hline Total percent & $\mathbf{4 9 . 9}$ & $\mathbf{7 8 . 9}$ & $\mathbf{7 9 . 2}$ & $\mathbf{5 2 . 2}$ & $\mathbf{4 8 . 5}$ & $\mathbf{5 8 . 1}$ & $\mathbf{1 0 0 . 0}$ \\
\hline (N) & $\mathbf{6 6 6 7 )}$ & $\mathbf{( 4 0 3 )}$ & $\mathbf{( 2 6 9 )}$ & $\mathbf{( 3 9 5 )}$ & $\mathbf{( 6 4 1 )}$ & $\mathbf{( 2 , 3 7 5 )}$ & $\mathbf{( 2 , 3 7 5 )}$ \\
\hline
\end{tabular}

${ }^{\mathrm{a}}$ Based on fewer than ten cases. na $=$ Not available.

Source: Screening questionnaire

Table 3 : Percentage distribution of female sex workers surveyed who visited jataras (festivals) for work, by type of clients, and percentage distribution of those who reported using condoms during visits, Tamil Nadu State, India

\begin{tabular}{|c|c|c|c|c|c|c|}
\hline Variable & Chennai & Kanyakumari & Madurai & Namakkal & Tiruchirapalli & Total \\
\hline \multicolumn{7}{|l|}{$\begin{array}{l}\text { Visited jatara in past } 12 \\
\text { months }\end{array}$} \\
\hline Yes & 17.8 & 2.3 & 10.2 & 22.5 & 11.3 & 12.4 \\
\hline No & 82.2 & 97.7 & 89.8 & 77.5 & 88.7 & 87.6 \\
\hline \multicolumn{7}{|l|}{ Visited in group $^{a}$} \\
\hline Yes & 35.7 & 71.4 & 52.4 & 69.6 & 44.1 & 50.6 \\
\hline Alone & 64.3 & 28.6 & 47.6 & 30.4 & 55.9 & 49.4 \\
\hline \multicolumn{7}{|l|}{ Clients (at last visit) ${ }^{b}$} \\
\hline $\begin{array}{l}\text { Male migrants from different } \\
\text { places }\end{array}$ & 59.6 & 14.3 & 15.8 & 28.3 & 53.1 & 41.1 \\
\hline $\begin{array}{l}\text { Male migrants from the same } \\
\text { district }\end{array}$ & 27.7 & $\mathrm{Na}$ & 15.8 & 71.7 & 25.0 & 37.7 \\
\hline Local nonmigrant men & 12.8 & 85.7 & 68.4 & na & 21.9 & 21.2 \\
\hline \multicolumn{7}{|c|}{$\begin{array}{l}\text { Condom use with clients in last visit to } \\
\text { jatara }{ }^{b}\end{array}$} \\
\hline With all clients & 93.6 & 100 & 89.4 & 100 & 100 & 96.7 \\
\hline With some clients & 6.4 & na & 5.3 & na & na & 2.6 \\
\hline With no clients & na & na & 5.3 & na & na & .7 \\
\hline Total percent & 100.0 & 100.0 & 100.0 & 100.0 & 100.0 & 100.0 \\
\hline
\end{tabular}

\footnotetext{
a Those who visited jatara areas.

b Those who visited jatara area in the past 12 months and had sex. na $=$ Not available.
} 
Table 4 : Percentage distribution of female sex workers surveyed, by selected socioeconomic and demographic characteristics, according to district, Tamil Nadu State, India

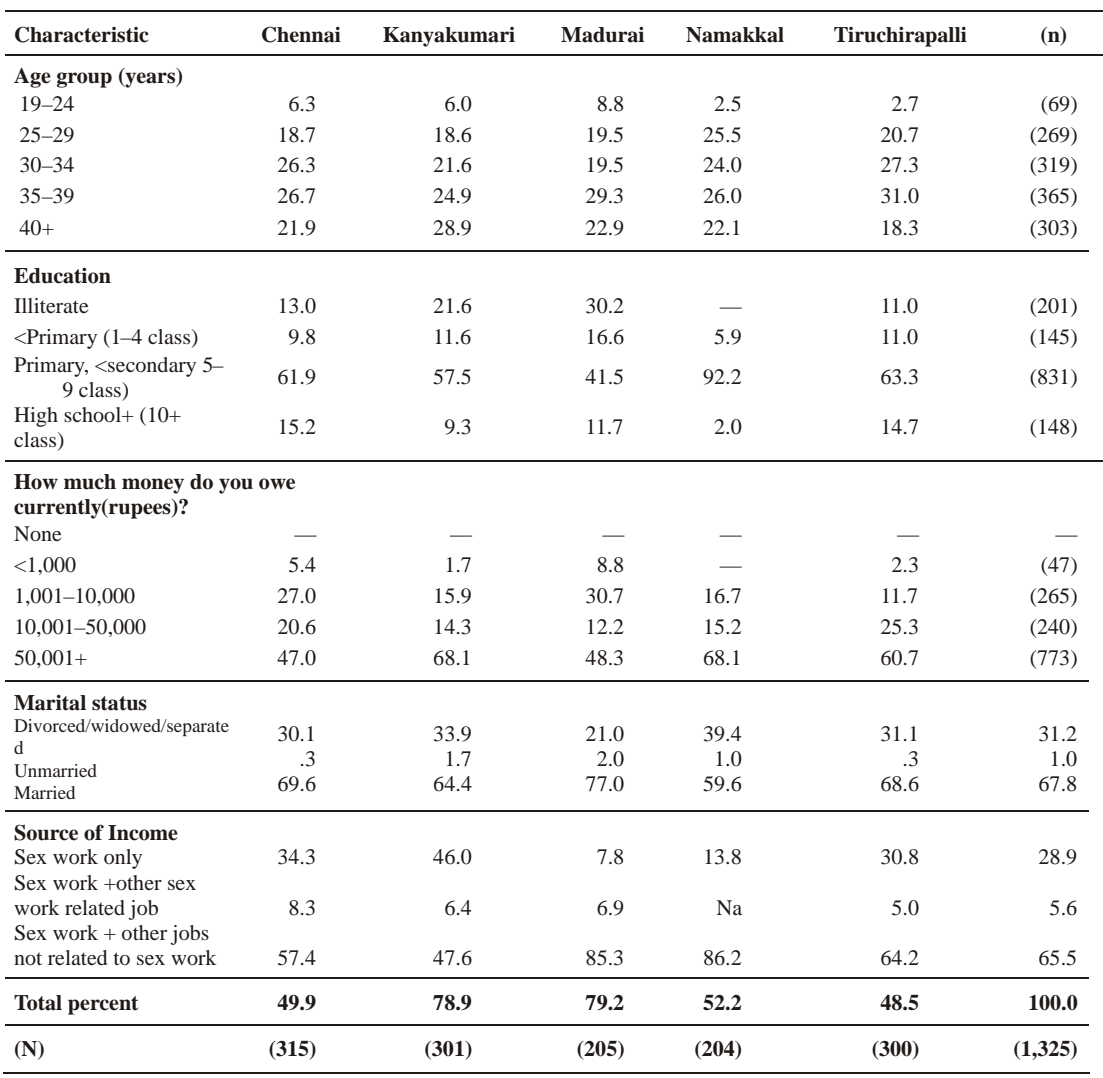

$-=$ None reported.

Note: Survey participants are female sex workers who are at least 18 years old, have moved to at least two locations in the past two years for sex work, and one of the two locations is across the district boarder. 
Table 5 : Percentage of mobile female sex workers surveyed, by their reasons for entering into sex work, according to district, Tamil Nadu State, India

\begin{tabular}{lcccccc}
\hline Reason & Chennai & Kanyakumari & Madurai & Namakkal & Tiruchirapalli & Total \\
\hline Forced & 1.0 & - & 0.5 & 15.8 & 5.4 & 4.0 \\
Economic conditions including & 34.3 & 7.1 & 16.4 & 16.8 & 15.8 & 18.4 \\
debt & 54.0 & 90.6 & 80.1 & 59.9 & 66.8 & 70.2 \\
Economic conditions other than & - & - & 0.5 & - & - & 0.1 \\
debt & 10.7 & 2.4 & 2.5 & 7.4 & 12.1 & 7.3 \\
Family tradition & $\mathbf{( 3 1 5 )}$ & $\mathbf{( 3 0 1 )}$ & $\mathbf{( 2 0 5 )}$ & $\mathbf{( 2 0 4 )}$ & $\mathbf{( 3 0 0 )}$ & $\mathbf{( 1 , 3 2 5 )}$ \\
Own choice/interest & & & & &
\end{tabular}

$-=$ None reported.

Table 6 : Percentage of mobile female sex workers surveyed who reported that they had used tobacco, alcohol, or drugs in the month prior to the survey, by substance, according to district, Tamil Nadu State, India

\begin{tabular}{lcccccc}
\hline Substance use in past month & Chennai & Kanyakumari & Madurai & Namakkal & Tiruchirapalli & Total \\
\hline Tobacco & 57.8 & 23.6 & 25.9 & 53.4 & 50.0 & 42.6 \\
Alcohol & 56.5 & 43.5 & 41.5 & 44.1 & 45.3 & 46.8 \\
Drugs & 1.3 & - & 1.0 & 1.5 & - & 0.7 \\
\hline (N) & $\mathbf{( 3 1 5 )}$ & $\mathbf{( 3 0 1 )}$ & $\mathbf{( 2 0 5 )}$ & $\mathbf{( 2 0 4 )}$ & $\mathbf{( 3 0 0 )}$ & $\mathbf{( 1 , 3 2 5 )}$ \\
\hline
\end{tabular}

$-=$ None reported.

Table 7 : Percentage of mobile female sex workers surveyed who had access to bank accounts, their own money, and cellular phones, by district, Tamil Nadu State, India

\begin{tabular}{lcccccc}
\hline Measure of autonomy & Chennai & Kanyakumari & Madurai & Namakkal & Tiruchirapalli & Total \\
\hline Separate bank/post office & 32.8 & 15.4 & 27.0 & 52.2 & 25.1 & 29.2 \\
$\quad$ accounts & 69.5 & 92.6 & 74.5 & 82.8 & 65.2 & 76.6 \\
Money set aside & 29.9 & 13.8 & 14.2 & 35.5 & 27.1 & 24.0 \\
Cellular phone & $\mathbf{( 3 1 5 )}$ & $\mathbf{( 3 0 1 )}$ & $\mathbf{( 2 0 5 )}$ & $\mathbf{( 2 0 4 )}$ & $\mathbf{( 3 0 0 )}$ & $\mathbf{( 1 , 3 2 5 )}$ \\
\hline $\mathbf{( N )}$ & & & & & &
\end{tabular}


Table 8 : Percentage of distribution of mobile female sex workers surveyed who reported that they had experienced violence in the past year and among those, the perpetrator of the violence, by district, Tamil Nadu State, India

\begin{tabular}{|c|c|c|c|c|c|c|}
\hline Variable & Chennai & Kanyakumari & Madurai & Namakkal & Tiruchirapalli & Total \\
\hline \multicolumn{7}{|c|}{$\begin{array}{l}\text { Experienced violence in past } \\
\text { year }\end{array}$} \\
\hline Often & 7.6 & 3.3 & -- & -- & $1.3^{\mathrm{a}}$ & 2.9 \\
\hline Sometimes & 13.3 & 11.6 & 6.8 & 5.9 & 7.3 & 9.4 \\
\hline Rarely & 5.1 & $1.3^{\mathrm{a}}$ & $2.9^{\mathrm{a}}$ & $4.4^{\mathrm{a}}$ & 4.0 & 3.5 \\
\hline Never & 74.0 & 83.7 & 90.2 & 89.7 & 87.3 & 84.2 \\
\hline Total percent & 100.0 & 100.0 & 100.0 & 100.0 & 100.0 & 100.0 \\
\hline$(\mathbf{N})$ & (315) & (301) & (205) & (204) & (300) & $(1,325)$ \\
\hline \multicolumn{7}{|l|}{ Perpetrator } \\
\hline Police & 51.3 & 91.5 & -- & 84.2 & 86.8 & 65.8 \\
\hline Clients & $7.5^{\mathrm{a}}$ & $6.4^{\mathrm{a}}$ & $50.0^{\mathrm{a}}$ & $5.3^{\mathrm{a}}$ & $2.6^{\mathrm{a}}$ & 9.9 \\
\hline Rowdies & $5.0^{\mathrm{a}}$ & -- & $16.7^{\mathrm{a}}$ & $10.5^{\mathrm{a}}$ & $5.3^{\mathrm{a}}$ & 5.4 \\
\hline Other & 36.3 & 2.1 & $33.3^{\mathrm{a}}$ & -- & $5.3^{\mathrm{a}}$ & 18.8 \\
\hline Total percent & 100.0 & 100.0 & 100.0 & 100.0 & 100.0 & 100.0 \\
\hline (n) & (80) & (47) & (18) & (19) & (38) & (202) \\
\hline
\end{tabular}

${ }^{\mathrm{a}}$ Based on fewer than ten cases.

$--=$ None reported.

Table 9 : Percentage of mobile female sex workers surveyed, by their exposure to the mass media in the month prior to the survey, according to district, Tamil Nadu State, India

\begin{tabular}{lcccccc}
\hline Exposure & Chennai & Kanyakumari & Madurai & Namakkal & Tiruchirapalli & Total \\
\hline Read newspaper/magazine & 36.8 & 34.9 & 29.3 & 40.7 & 39.7 & 36.5 \\
Listened to radio & 70.2 & 30.6 & 62.4 & 71.6 & 63.3 & 58.6 \\
Watched movie/ television & 97.1 & 92.4 & 93.2 & 99.5 & 99.3 & 96.3 \\
\hline $\mathbf{( N )}$ & $\mathbf{( 3 1 5 )}$ & $\mathbf{( 3 0 1 )}$ & $\mathbf{( 2 0 5 )}$ & $\mathbf{( 2 0 4 )}$ & $\mathbf{( 3 0 0 )}$ & $\mathbf{( 1 , 3 2 5 )}$ \\
\hline
\end{tabular}




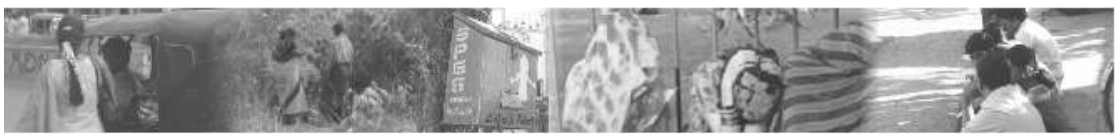

Table 10 : Percentage of mobile female sex workers surveyed who are members of or are exposed to social organizations, and percentage who have received benefits from such exposure, by district, Tamil Nadu State, India

\begin{tabular}{|c|c|c|c|c|c|c|}
\hline Variable & Chennai & Kanyakumari & Madurai & Namakkal & Tiruchirapalli & Total \\
\hline \multicolumn{7}{|l|}{ Member of } \\
\hline Self-help group & 29.2 & 53.8 & 26.3 & 32.8 & 16.0 & 31.9 \\
\hline Community-based organization & 15.2 & 6.0 & 24.9 & 3.9 & 2.0 & 9.9 \\
\hline Nongovernmental organization & 55.2 & 47.5 & 93.2 & 92.6 & 69.7 & 68.4 \\
\hline Collective & 21.0 & 2.3 & 3.4 & 48.0 & 15.7 & 17.0 \\
\hline Any of the above & 67.9 & 66.1 & 95.6 & 93.1 & 71.3 & 76.5 \\
\hline \multicolumn{7}{|l|}{ Benefit received } \\
\hline Condoms & 61.3 & 48.8 & 93.7 & 92.6 & 67.3 & 69.7 \\
\hline Knowledge of STDs & 43.2 & 37.5 & 85.4 & 89.7 & 58.0 & 58.9 \\
\hline Referral to health centers & 34.3 & 13.0 & 43.9 & 88.2 & 33.0 & 38.9 \\
\hline \multicolumn{7}{|l|}{$\begin{array}{l}\text { Contacted by outreach workers } \\
\text { from }\end{array}$} \\
\hline Government & 32.5 & 58.1 & 57.4 & 78.3 & 49.8 & 53.2 \\
\hline NGO & 56.6 & 40.9 & 89.7 & 92.6 & 89.6 & 71.3 \\
\hline Avahan & 45.3 & 31.5 & 91.7 & 70.9 & 10.7 & 45.5 \\
\hline \multicolumn{7}{|l|}{ Used any of the following } \\
\hline Public health system & 63.3 & 59.1 & 36.8 & 49.8 & 73.9 & 58.6 \\
\hline Private doctor & 59.2 & 47.7 & 45.8 & 91.6 & 65.6 & 61.0 \\
\hline STI clinic from NGO & 55.9 & 29.5 & 80.3 & 88.2 & 64.6 & 61.2 \\
\hline$(\mathbf{N})$ & (315) & (301) & (205) & (204) & (300) & $(1,325)$ \\
\hline
\end{tabular}

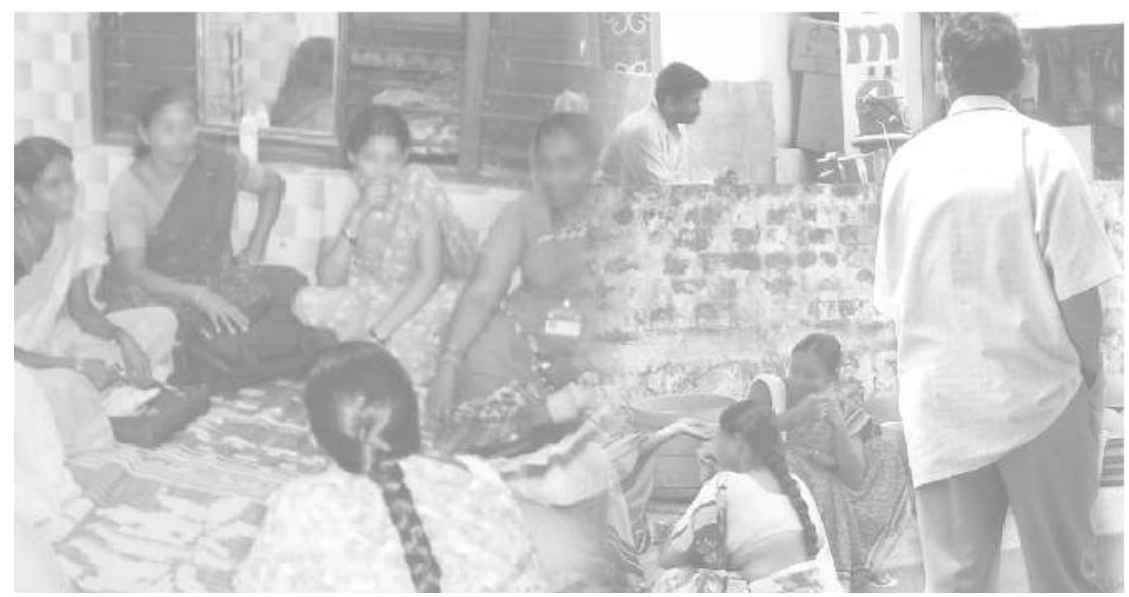


Table 11 : Percentage of mobile female sex workers surveyed, by selected characteristics of their vulnerability to HIV infection, according to district, Tamil Nadu State, India

\begin{tabular}{|c|c|c|c|c|c|c|}
\hline Characteristic & Chennai & Kanyakumari & Madurai & Namakkal & Tiruchirapalli & Total \\
\hline \multicolumn{7}{|l|}{ Consistent condom use with } \\
\hline Occasional clients & 93.5 & 84.6 & 83.7 & 98.0 & 98.3 & 92.1 \\
\hline Regular clients & 92.4 & 83.0 & 76.1 & 98.0 & 98.6 & 90.1 \\
\hline Nonpaying partners & 90.3 & 50.0 & 41.9 & 96.9 & 97.3 & 90.4 \\
\hline Any client $\mathrm{a}^{\mathrm{a}}$ & 90.7 & 82.4 & 67.3 & 95.5 & 96.3 & 87.4 \\
\hline Had STI symptoms & 59.0 & 51.8 & 39.5 & 82.4 & 61.3 & 58.5 \\
\hline $\begin{array}{l}\text { Have STI symptoms and } \\
\text { continued to have sex }\end{array}$ & 4.8 & 2.7 & 9.8 & na & 4.0 & 4.2 \\
\hline $\begin{array}{l}\text { Did not use condom during } \\
\text { experience of sexual violence }\end{array}$ & 5.1 & 2.0 & 6.3 & 2.5 & 1.7 & 3.4 \\
\hline \multicolumn{7}{|l|}{$\begin{array}{l}\text { Respondent's risk perception of } \\
\text { her vulnerability to HIV }\end{array}$} \\
\hline High & 3.2 & 1.7 & 1.0 & 1.5 & 0.3 & 1.6 \\
\hline Moderate & 24.8 & 46.1 & 16.2 & 48.8 & 19.4 & 30.8 \\
\hline Low & 71.0 & 51.5 & 81.4 & 48.8 & 79.9 & 66.8 \\
\hline Tested for HIV & 91.3 & 93.6 & 97.1 & 94.1 & 95.7 & 94.1 \\
\hline Voluntarily tested for HIV & 69.2 & 91.8 & 70.1 & 99.0 & 89.9 & 83.8 \\
\hline$(\mathbf{N})$ & (315) & (301) & (205) & (204) & (300) & $(1,325)$ \\
\hline
\end{tabular}

na $=$ None reported.

${ }^{\text {a }}$ Consistent condom use is computed using the weighted average number of clients with whom the respondents had sex.

${ }^{\mathrm{b}}$ Experienced any of the following symptoms in the past six months: excessive vaginal discharge, foulsmelling discharge, ulcers /sores in genital area, swelling in groin area, pain during intercourse, itching in genital area, pain in lower abdomen, frequent/sometimes painful urination.

${ }^{\mathrm{c}}$ Includes only those who had at least one of the STI symptoms and continued to have sex.

${ }^{\mathrm{d}}$ Includes only those who were physically forced to have sex or beaten, and who did not use a condom during that experience.

Table 12 : Percentage of mobile female sex workers surveyed, by availability of and their ability to use condoms, according to district, Tamil Nadu State, India

\begin{tabular}{lcccccc}
\hline Survey question & Chennai & Kanyakumari & Madurai & Namakkal & Tiruchirapalli & Total \\
\hline $\begin{array}{l}\text { Have there been times when a } \\
\quad \begin{array}{c}\text { condom was not available and } \\
\text { hence not used? }\end{array}\end{array}$ & 21.6 & 31.2 & 24.0 & 42.9 & 19.1 & 26.9 \\
$\begin{array}{c}\text { Have there been times when the } \\
\text { client refused to use a condom } \\
\text { and you agreed? }\end{array}$ & 21.3 & 14.1 & 13.2 & 42.9 & 17.4 & 20.9 \\
$\begin{array}{l}\text { Have there been times when the } \\
\text { client refused to use a condom } \\
\text { but you convinced him to use } \\
\text { one? }\end{array}$ & 56.8 & 23.5 & 20.1 & 77.8 & 48.2 & 44.8 \\
\hline (N) & $\mathbf{( 3 1 5 )}$ & $\mathbf{( 3 0 1 )}$ & $\mathbf{( 2 0 5 )}$ & $\mathbf{( 2 0 4 )}$ & $\mathbf{( 3 0 0 )}$ & $\mathbf{( 1 , 3 2 5 )}$ \\
\hline
\end{tabular}



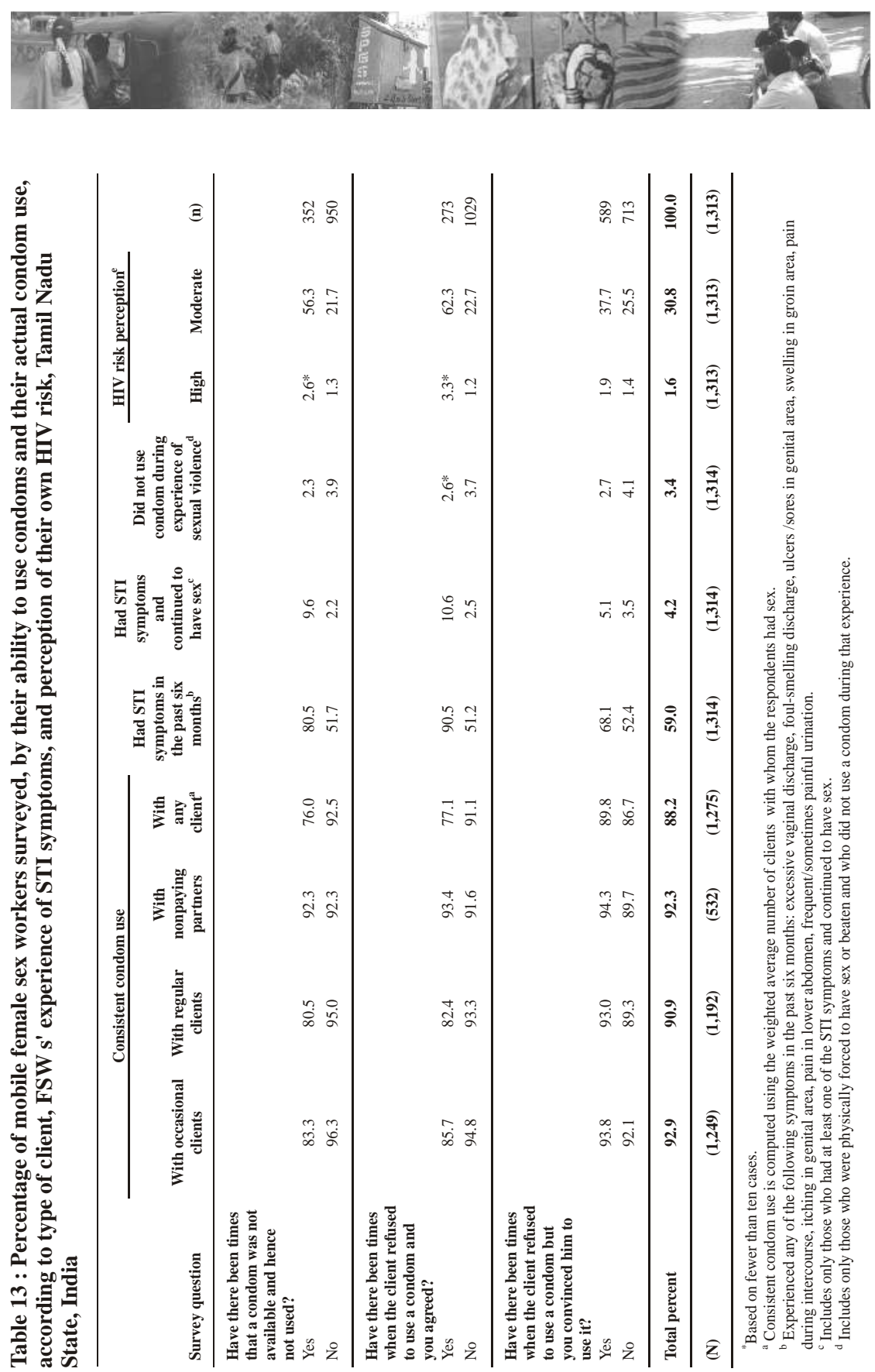

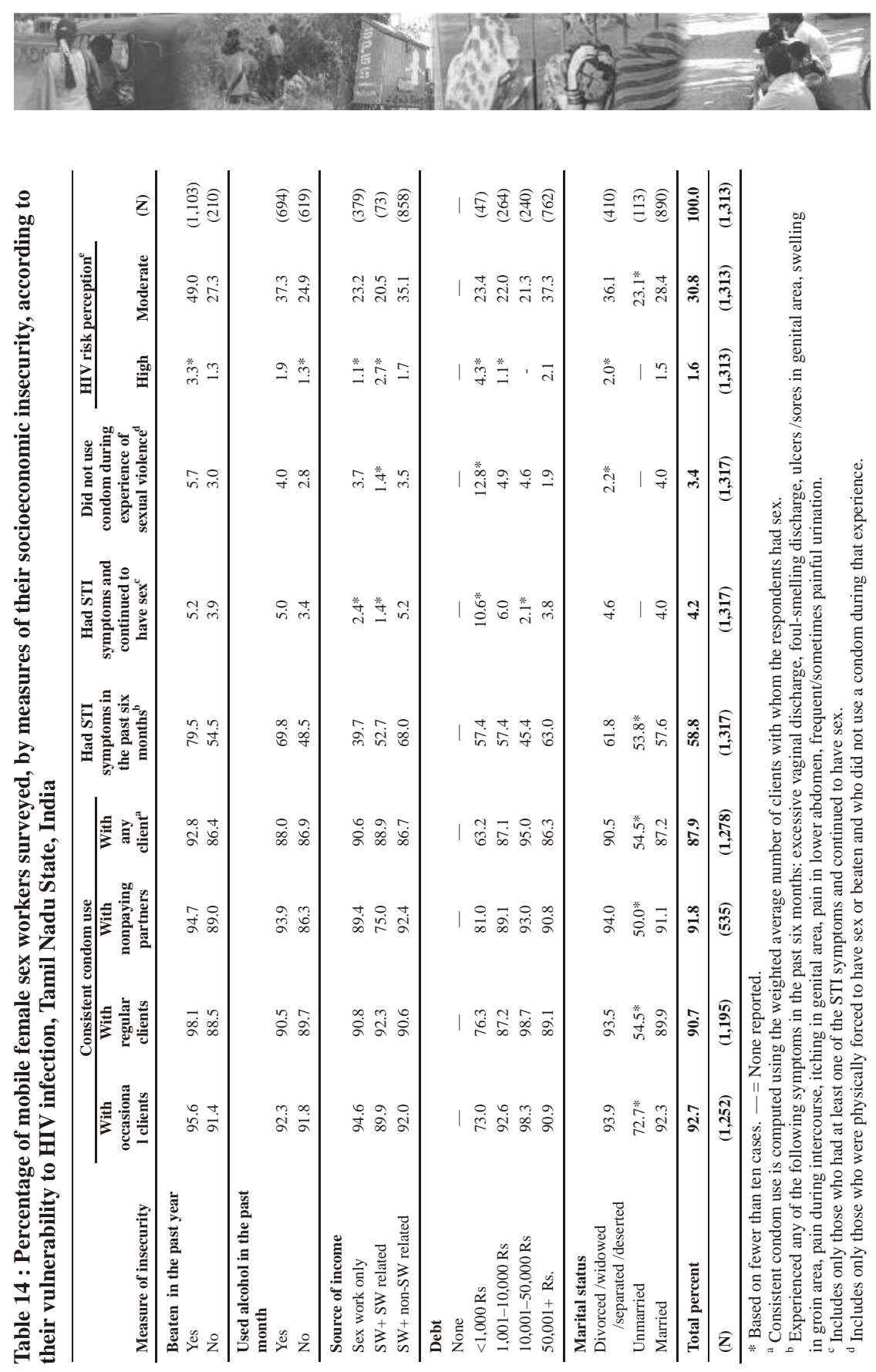

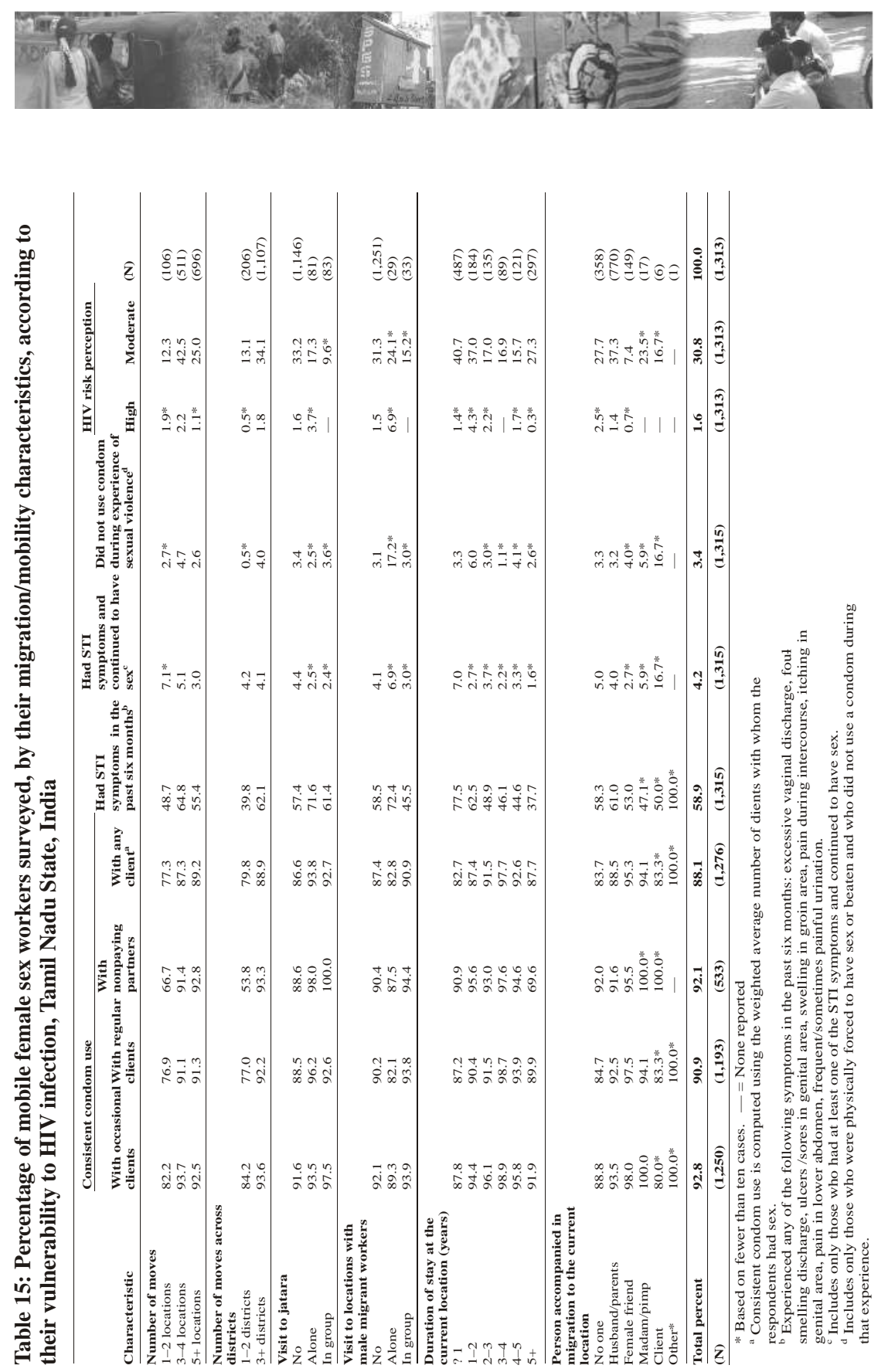

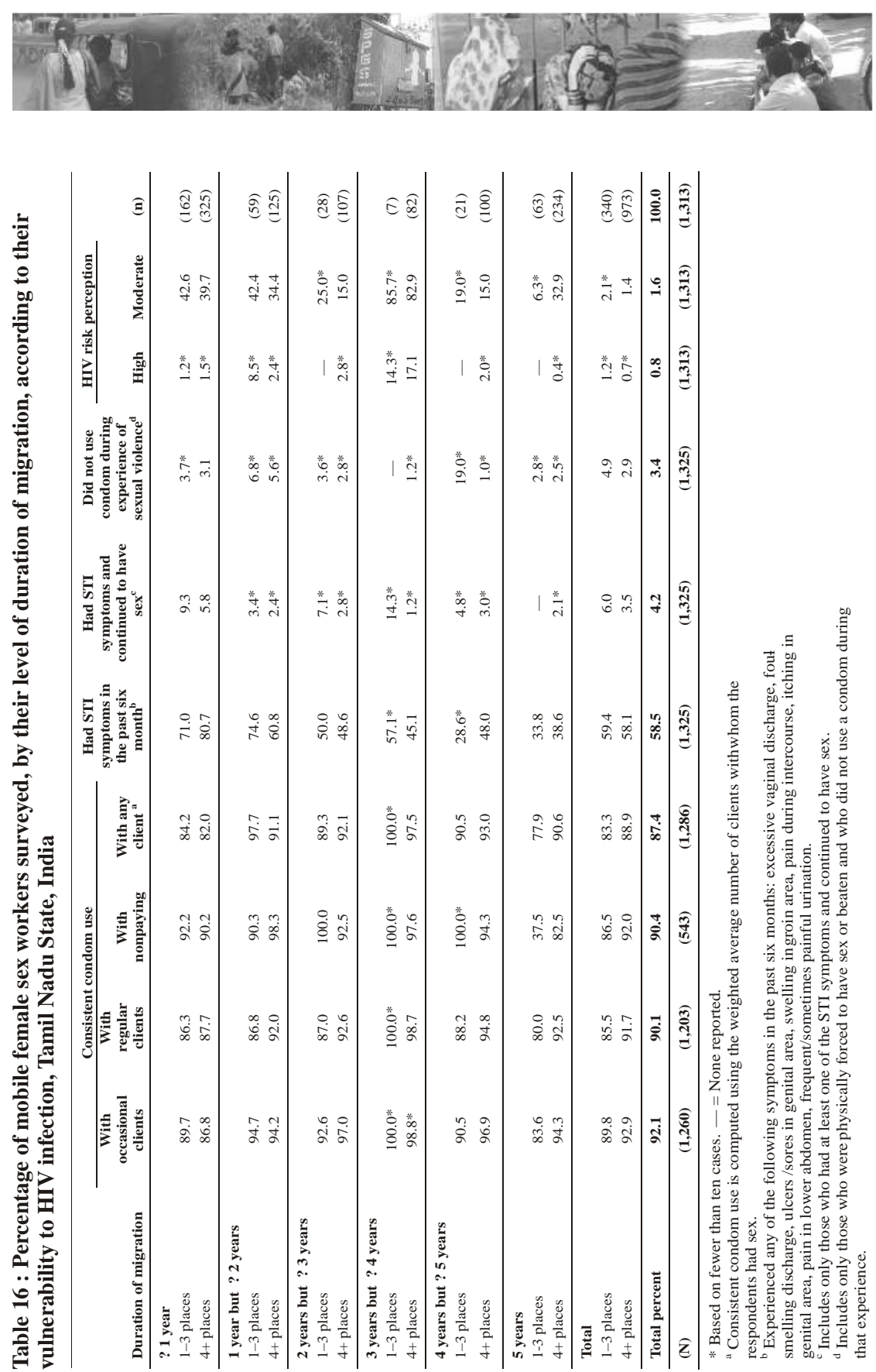
Table 17 : Percentage of mobile female sex workers surveyed who reported that they use condoms consistently, continue to have sex even while having STI symptoms, and perceive themselves to be at risk for HIV, by their place of contact with clients and number of locations they visited, Tamil Nadu State, India

\begin{tabular}{|c|c|c|c|c|c|c|}
\hline $\begin{array}{l}\text { Place of } \\
\text { contact/number } \\
\text { of locations }\end{array}$ & $\begin{array}{l}\text { Consistent } \\
\text { condom use with } \\
\text { any client }\end{array}$ & $\begin{array}{l}\text { Had STI } \\
\text { symptoms in the } \\
\text { past six months }\end{array}$ & $\begin{array}{c}\text { Had STI } \\
\text { symptoms and } \\
\text { continued to have } \\
\operatorname{sex}^{\mathrm{c}}\end{array}$ & $\begin{array}{c}\text { Did not use } \\
\text { condom during } \\
\text { experience of } \\
\text { sexual violence }\end{array}$ & $\begin{array}{c}\text { HIV risk } \\
\text { perception } \\
\text { (high/moderate) }\end{array}$ & $(\mathbf{N})$ \\
\hline \multicolumn{7}{|l|}{ Brothel } \\
\hline $1-2$ & $100.0^{*}$ & $50.0^{*}$ & na & na & $36.4 *$ & (2) \\
\hline $3-4$ & 95.5 & 63.6 & na & $9.1^{*}$ & $14.3^{*}$ & (22) \\
\hline $5+$ & 92.3 & 53.6 & na & $7.1^{*}$ & 23.1 & (28) \\
\hline \multicolumn{7}{|l|}{ Street } \\
\hline $1-2$ & 70.8 & 46.3 & $90.0^{*}$ & $3.0^{*}$ & $14.3^{*}$ & (63) \\
\hline $3-4$ & 84.3 & 64.6 & 6.6 & 5.6 & 43.7 & (304) \\
\hline $5+$ & 89.1 & 59.0 & 4.7 & 2.9 & 27.6 & (384) \\
\hline \multicolumn{7}{|l|}{ Home } \\
\hline $1-2$ & 87.5 & 62.5 & $4.2^{*}$ & $4.2^{*}$ & $9.0^{*}$ & (22) \\
\hline $3-4$ & 88.1 & 61.2 & $2.4^{*}$ & na & 42.2 & (83) \\
\hline $5+$ & 85.4 & 55.0 & $2.0^{*}$ & $2.0^{*}$ & 29.3 & (99) \\
\hline \multicolumn{7}{|l|}{ Highway } \\
\hline $1-2$ & 82.4 & $38.9^{*}$ & $5.6^{*}$ & na & $23.5^{*}$ & (17) \\
\hline $3-4$ & 94.4 & 69.1 & $3.2^{*}$ & $3.2^{*}$ & 52.1 & (94) \\
\hline $5+$ & 89.6 & 49.0 & $0.7^{*}$ & $0.7^{*}$ & 20.6 & (151) \\
\hline \multicolumn{7}{|l|}{ (Total) } \\
\hline $1-2$ & 77.3 & 48.7 & $7.1^{*}$ & $2.7^{*}$ & 14.2 & (106) \\
\hline $3-4$ & 87.3 & 64.8 & 5.1 & $4.7^{*}$ & 44.7 & (511) \\
\hline $5+p$ & 89.2 & 55.4 & 3.0 & 2.6 & 26.1 & (696) \\
\hline Total percent & 87.4 & 58.5 & 4.2 & 3.4 & 32.4 & 100.0 \\
\hline$(\mathrm{N})$ & $(1,286)$ & $(1,325)$ & $(1,325)$ & $(1,325)$ & $(1,313)$ & $(\mathbf{1 , 3 1 3})$ \\
\hline
\end{tabular}

$*$ Based on fewer than ten cases. na $=$ Not available.

${ }^{\text {a }}$ Consistent condom use is computed using the weighted averagenumber of clients with whom the respondents had sex.

${ }^{\mathrm{b}}$ Experienced any of the following symptoms in the past six months: excessive vaginal discharge, foukmelling discharge, ulcers /sores in genital area, swelling in groin area, pain during intercourse, itching in genital area, pain in lower abdomen, frequent/sometimes painful urination.

${ }^{\mathrm{c}}$ Includes only those who had at least one of the STI symptoms and continued to have sex.

${ }^{\mathrm{d}}$ Includes only those who were physically forced to have sex or beaten and who did not use a condom during that experience.






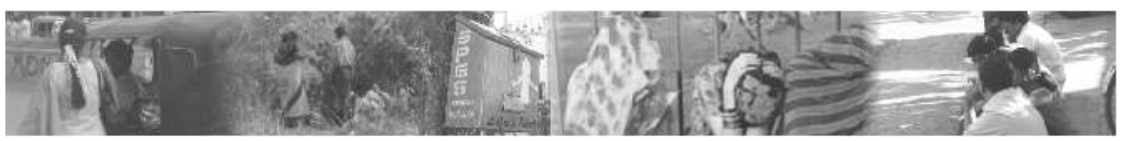

Table 18 : Percentage of mobile female sex workers surveyed, by locations they reported where they solicit clients and where they have sex, by district, Tamil Nadu State, India

\begin{tabular}{|c|c|c|c|c|c|c|}
\hline Location & Chennai & Kanyakumari & Madurai & Namakkal & Tiruchirapalli & Total \\
\hline \multicolumn{7}{|l|}{ For solicitation of clients } \\
\hline Roadside & 58.7 & 36.9 & 51.7 & 90.2 & 89.7 & 64.5 \\
\hline Railway station/bus stand & 61.9 & 75.1 & 46.3 & 78.4 & 86.3 & 70.6 \\
\hline Marketplaces & 39.7 & 22.6 & 30.2 & 30.4 & 36.7 & 32.2 \\
\hline Hotel/lodge & 37.8 & 7.0 & $2.9^{*}$ & $3.9 *$ & 53.0 & 23.6 \\
\hline Own home & 14.3 & 12.0 & 13.2 & $2.5^{*}$ & 8.7 & 10.5 \\
\hline Cinema hall & 51.4 & 5.6 & 19.0 & 10.3 & 28.7 & 24.5 \\
\hline Telephone & 16.8 & 9.0 & 10.7 & $1.5^{*}$ & 22.7 & 13.1 \\
\hline Brothel & 7.0 & 3.7 & 5.4 & $3.9 *$ & 4.7 & 5.0 \\
\hline Rented room & 25.1 & $2.0^{*}$ & 9.3 & $0.5^{*}$ & 37.3 & 16.4 \\
\hline Dhaba (restaurant) & 6.7 & na & na & $3.9 *$ & 4.0 & 3.1 \\
\hline Client's home & 16.8 & $2.3^{*}$ & 7.8 & 7.8 & 19.3 & 11.3 \\
\hline Bar & 6.3 & $2.0^{*}$ & 15.1 & 0.5 & 4.0 & 5.3 \\
\hline Vehicle & 22.9 & $2.7 *$ & $3.4^{*}$ & na & 19.7 & 11.0 \\
\hline $\begin{array}{l}\text { Labor naka (contracting } \\
\text { center) }\end{array}$ & $1.3^{*}$ & $2.7^{*}$ & $1.5^{*}$ & na & 3.3 & 1.9 \\
\hline \multicolumn{7}{|l|}{ For having sex } \\
\hline Rented room & 41.9 & 29.9 & 43.4 & 70.1 & 66.0 & 49.2 \\
\hline Hotel/lodge & 62.2 & 77.7 & 50.7 & 70.1 & 79.0 & 69.0 \\
\hline Own home & 28.6 & 41.2 & 44.4 & 39.7 & 22.0 & 34.1 \\
\hline Roadside & 10.5 & 8.0 & 20.5 & na & na & 7.5 \\
\hline Client's home & 29.5 & 14.0 & 14.1 & $3.9 *$ & 20.0 & 17.5 \\
\hline Brothel & 9.2 & 4.0 & 12.7 & $2.9 *$ & 3.7 & 6.3 \\
\hline Dhaba (restaurant) & 6.7 & $0.3^{*}$ & $0.5^{*}$ & $2.0 *$ & 6.7 & 3.5 \\
\hline Park/bushes & 30.2 & $2.7 *$ & $3.9^{*}$ & 19.1 & 51.3 & 22.9 \\
\hline Cinema hall & 10.2 & 7.3 & 14.1 & $3.4 *$ & $0.7^{*}$ & 6.9 \\
\hline Marketplace & $2.9 *$ & $0.3^{*}$ & $1.0^{*}$ & $0.5^{*}$ & na & 1.0 \\
\hline Railway station/ bus stand & 8.6 & $1.3^{*}$ & $2.0^{*}$ & $0.5^{*}$ & $0.3^{*}$ & 2.8 \\
\hline Vehicle & 13.3 & 10.3 & $4.4^{*}$ & 14.2 & 20.0 & 12.9 \\
\hline Bar & 5.1 & na & $3.9 *$ & na & $0.3 *$ & 1.9 \\
\hline Other & $0.3^{*}$ & na & $0.5^{*}$ & na & na & $0.2^{*}$ \\
\hline (N) & (315) & (301) & (205) & (204) & $(300)$ & $(\mathbf{1}, \mathbf{3 2 5})$ \\
\hline
\end{tabular}

* Based on fewer than ten cases. na $=$ Not available.

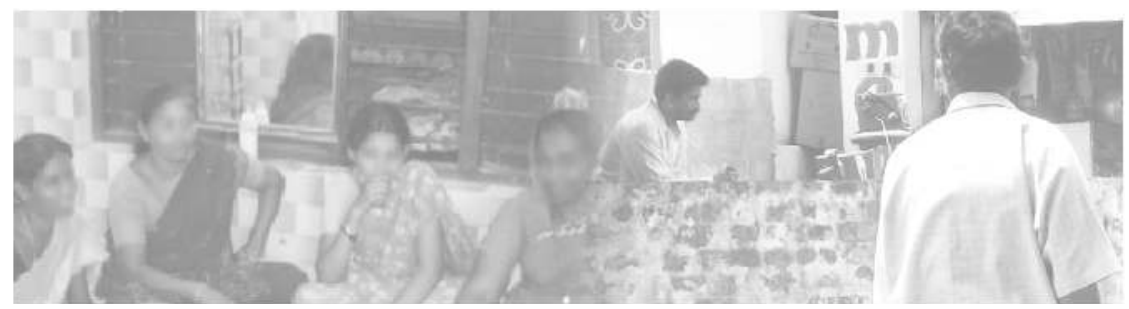


Table 19 : Percentage of mobile female sex workers surveyed, by location where they were interviewed, according to place where they solicit clients or have sex, Tamil Nadu State, India

\begin{tabular}{lcccccc}
\hline \multirow{2}{*}{$\begin{array}{l}\text { Location where } \\
\text { interviewer met sex } \\
\text { worker }\end{array}$} & Hotel & $\begin{array}{c}\text { Railway } \\
\text { station }\end{array}$ & $\begin{array}{c}\text { Phaba } \\
\text { (restaurant) }\end{array}$ & Bar & Brothel & $\begin{array}{c}\text { Any of } \\
\text { these }\end{array}$ \\
\cline { 2 - 7 } Brothel & 23.1 & 28.8 & na & na & 75.0 & 94.2 \\
Lodge & 93.2 & 29.5 & na & $4.5^{*}$ & na & 97.7 \\
Street & 80.6 & 82.0 & 1.3 & 7.1 & 4.1 & 94.3 \\
Home & 53.6 & 54.1 & $0.5^{*}$ & 5.7 & 12.0 & 72.2 \\
Highway & 63.5 & 68.8 & 21.3 & 4.6 & $2.7^{*}$ & 91.3 \\
\hline
\end{tabular}

* Based on fewer than ten cases. na = not available.

Table 20 : Percentage mobile female sex workers surveyed, by locations where they solicit clients or have sex and estimated HIV-prevention programme coverage at these locations, by district, Tamil Nadu State, India

\begin{tabular}{|c|c|c|c|c|c|c|}
\hline Variable & Chennai & Kanyakumari & Madurai & Namakkal & Tiruchirapalli & $\begin{array}{c}\text { Total } \\
\text { percent }\end{array}$ \\
\hline \multicolumn{7}{|l|}{ Location for solicitation/sex } \\
\hline Brothel & 11.4 & 4.3 & 15.1 & 3.9 & 4.7 & 7.7 \\
\hline Dhaba (restaurant) & 10.5 & 0.3 & 0.5 & 5.9 & 6.7 & 5.1 \\
\hline Railway station/bus stand & 63.8 & 75.1 & 46.8 & 78.9 & 86.3 & 71.2 \\
\hline Bar & 8.6 & 2.0 & 16.1 & 0.5 & 4.3 & 6.0 \\
\hline Hotel & 69.8 & 78.7 & 50.7 & 70.1 & 79.3 & 71.1 \\
\hline Own home & 33.0 & 42.2 & 46.3 & 39.7 & 25.7 & 36.5 \\
\hline Roadside & 59.7 & 37.2 & 52.7 & 90.2 & 89.7 & 65.0 \\
\hline \multicolumn{7}{|l|}{$\begin{array}{l}\text { Estimated programme coverage } \\
\text { by location }\end{array}$} \\
\hline Brothel & 11.4 & 4.3 & 15.1 & 3.9 & 4.7 & 7.7 \\
\hline Brothel + dhaba & 21.6 & 4.7 & 15.6 & 9.8 & 11.0 & 12.6 \\
\hline $\begin{array}{l}\text { Brothel+ dhaba + railway } \\
\text { station/bus stand }\end{array}$ & 75.6 & 78.7 & 54.1 & 84.3 & 88.3 & 77.2 \\
\hline $\begin{array}{l}\text { Brothel + dhaba + railway } \\
\text { station/bus stand + bar }\end{array}$ & 77.8 & 79.7 & 66.3 & 84.8 & 89.7 & 80.2 \\
\hline $\begin{array}{l}\text { Brothel + dhaba + railway } \\
\text { station/bus stand + bar + hotel }\end{array}$ & 90.8 & 90.4 & 78.5 & 95.6 & 94.3 & 90.3 \\
\hline \multicolumn{7}{|l|}{$\begin{array}{l}\text { Estimated number of times } \\
\text { programme would reach sex } \\
\text { workers if all five locations } \\
\text { were covered }\end{array}$} \\
\hline 0 & 9.2 & 9.6 & 21.5 & 4.4 & 5.7 & 9.7 \\
\hline 1 & 28.6 & 21.6 & 35.1 & 34.3 & 19.3 & 26.8 \\
\hline 2 & 51.1 & 67.4 & 36.6 & 58.8 & 65.0 & 56.9 \\
\hline 3 & 11.1 & 1.3 & 6.3 & 2.5 & 8.0 & 6.1 \\
\hline 4 & - & - & 0.5 & - & 2.0 & 0.5 \\
\hline 5 & - & - & - & - & - & - \\
\hline Average number of times & 1.6 & 1.6 & 1.3 & 1.6 & 1.8 & 1.6 \\
\hline$(\mathbf{N})$ & (315) & (301) & (205) & (204) & (300) & $(1,325)$ \\
\hline
\end{tabular}

- $=$ None reported. 


\section{$(1$ Population Council}

www.popcouncil.org 